INSTITUTO DE PESQUISAS ENERGÉTICAS E NUCLEARES

AUTARQUIA ASSOCIADA À UNIVERSIDADE DE SÃO PAULO

AVALIAÇÃO ECOTOXICOLÓGICA DE SEDIMENTOS DO RIO TIETÊ, ENTRE OS MUNICÍPIOS DE SALESÓPOLIS E SUZANO, SP

GABRIEL FONSECA ALEGRE

Dissertação apresentada como parte dos requisitos para obtenção do Grau de Mestre em Ciências na Área de Tecnologia Nuclear Aplicações.

Orientadora:

Dra. Sueli Ivone Borrely

São Paulo

2009 
INSTITUTO DE PESQUISAS ENERGÉTICAS E NUCLEARES

AUTARQUIA ASSOCIADA À UNIVERSIDADE DE SÃO PAULO

AVALIAÇÃO ECOTOXICOLÓGICA DE SEDIMENTOS DO RIO TIETÊ, ENTRE OS MUNICÍPIOS DE SALESÓPOLIS E SUZANO, SP

GABRIEL FONSECA ALEGRE

Dissertação apresentada como parte dos requisitos para obtenção do Grau de Mestre em Ciências na Área de Tecnologia Nuclear Aplicações.

Orientadora:

Dra. Sueli Ivone Borrely

São Paulo

2009 
Dedico este trabalho aos meus portos seguros: minha família, meus amigos e à minha namorada, Maria Fernanda. 
“E o Tietê deu a São Paulo tudo quanto possuía: o ouro das areias, a força das águas, a fertilidade das terras, a madeira das matas, os mitos do sertão. Despiu-se de todo encanto e de todo mistério; despoetizou-se e empobreceu por São Paulo e pelo Brasil."

Alcântara Machado 
Agradecimentos

Ao Instituto de Pesquisas Energéticas e Nucleares - IPEN, por possibilitar a realização deste trabalho.

À Dra. Sueli Ivone Borrely, minha orientadora, por tudo o que aprendi profissional e pessoalmente e, principalmente por idealizar este trabalho.

À Dra. Déborah Fávaro do Centro do Reator de Pesquisas do IPEN pela valiosa contribuição nas análises químicas.

Ao Dr. Bauer Rachid e à Fundespa por toda ajuda e disponibilidade na escolha dos pontos de amostragem, além de realização das coletas. Sem esquecer o Élder (Dom).

Aos companheiros do LEBA: Alessandro, Neto, Natalia, Marcela, Dymes, Letícia, Vanessa, Renata, Rebeca e Reginaldo.

A todos os bolsistas do CTR: Michel, Renato, Camilo, Priscila e Gustavo.

Ao Instituto Butantã: Lenita e Dra. Eliana Nakano, pelo apoio.

Ao Dr. Afonso de Aquino e à Dra. Marta Vieira pela amizade e apoio no PAE.

Ao Dr. Augusto Cesar pela colaboração com as análises multivariadas.

Ao Centro Tecnológico da Marinha, em especial à Sandra e Thabiani por todo apoio e amizade.

Aos meus amigos André, Marcos, Jeferson, Gabriel, Bruno e Pedro, Thiago, Mauro e Fabrício pelo apoio, amizade e companheirismo.

À Maria Fernanda, não só por toda paciência, ajuda, preocupação e dicas super importantes neste trabalho, mas principalmente por todo amor e carinho doados.

À minha tia Marielza que foi como uma mãe para mim durante minha estadia em São Paulo e claro, à minhas primas e priminhas pelo carinho.

Finalmente agradeço à minha família, pelo apoio incondicional em todos os sentidos, e por todo amor e carinho, não só durante a realização deste trabalho, como durante toda minha vida. 


\title{
AVALIAÇÃO ECOTOXICOLÓGICA DE SEDIMENTOS DO RIO TIETÊ, ENTRE OS MUNICÍPIOS DE SALESÓPOLIS E SUZANO, SP
}

\author{
Gabriel Fonseca Alegre
}

\begin{abstract}
RESUMO
Uma vez introduzidos no ambiente aquático os resíduos podem ser adsorvidos por partículas orgânicas em suspensão. Dependendo da morfologia do rio e das condições hidrológicas, essas partículas são depositadas ao longo de seu curso, tornando-se parte dos sedimentos de fundo, tornando-os, muitas vezes, fonte de contaminação para a coluna d'água e para os organismos bentônicos. $\mathrm{Na}$ avaliação de recursos hídricos, os sedimentos têm sido um dos mais importantes indicadores do nível de contaminação de ecossistemas aquáticos, representando a deposição de contaminantes no ambiente ocorrida durante décadas. O rio Tietê corta o estado de São Paulo, porém é na região metropolitana que este sofre piores impactos. Na região de Salesópolis as águas do rio Tietê são utilizadas para abastecimento público, porém, ao atravessar a cidade de Mogi das Cruzes, a qualidade de suas águas diminui de maneira expressiva. Dada a importância do rio Tietê e dos sedimentos à biota aquática, este trabalho teve por objetivo avaliar a toxicidade do sedimento em cinco pontos ao longo do rio Tietê, entre os municípios de Salesópolis e Suzano, São Paulo. Foram realizadas quatro coletas: duas no verão e duas no inverno. O sedimento integral foi avaliado por ensaios de toxicidade aguda e crônica com Hyalella azteca e Ceriodaphnia dubia respectivamente; o elutriato por ensaios de toxicidade crônica com C. dubia; e a água intersticial foi submetida à Vibrio fischeri. Amostras de água do rio também foram avaliadas para efeitos crônicos com C. dubia.

As amostras de sedimento também foram caracterizadas quanto a presença de metais e hidrocarbonetos, buscando correlacionar os efeitos biológicos à contaminação química. Os resultados obtidos nos ensaios com sedimento integral apontam os pontos localizados nas cidades de Mogi das Cruzes (P3) e Suzano (P4) como os mais tóxicos, além de apresentarem concentrações mais elevadas de metais pesados. Os ensaios em fases aquosas do sedimento (elutriato e água intersticial) apontaram Biritiba-Mirim (P1) como um local com elevada freqüência de efeitos tóxicos e importante presença de hidrocarbonetos. $\mathrm{O}$ ponto $\mathrm{P} 2$, em Biritiba-Mirim também apresentou hidrocarbonetos. No reservatório Ponte Nova (P0) a toxicidade foi o segundo local menos freqüente. Os resultados evidenciaram um gradiente de toxicidade e contaminação que aumenta de acordo com o distanciamento do reservatório da Ponte Nova (P0) e aproximação da metrópole.
\end{abstract}




\title{
ECOTOXICOLOGICAL ASSESSMENT OF SEDIMENTS FROM TIETÊ RIVER BETWEEN SALESÓPOLIS AND SUZANO, SP
}

\author{
Gabriel Fonseca Alegre
}

\begin{abstract}
Once introduced into the aquatic environment, many substances can bind or be adsorbed by organic particles in suspension. Depending on the river morphology and hydrological conditions, these particles in suspension containing the contaminants can be deposited along its course, becoming part of the bottom sediments, making them actual sinks and often a source of contamination for the water column and benthic organisms. In the assessment of water, sediment has been one of the most important indicators of the contamination levels in aquatic ecosystems, representing the deposition of contaminants in the environment that occurred over the years and even decades. The Tietê River cross the São Paulo state, however, in the metropolitan region of São Paulo, the river shows the most severe degradation. In the region of Salesópolis, the waters of the Tietê River are used for public supply, but across the city of Mogi das Cruzes the water quality decreases significantly. Considering the importance of the Tietê river and the sediment for the aquatic biota, this study aimed to evaluate the toxicity of the sediment at five points along the Tietê river, between the cities of Salesópolis and Suzano, São Paulo. Four sampling were carried out: two in the summer (rainy season) and two in winter (dry season). The whole sediment was assessed by acute and chronic toxicity tests with Hyalella azteca and Ceriodaphnia dubia, respectively, the elutriate was assessed by chronic toxicity test using C. dubia, while the porewater was evaluated by acute toxicity test with Vibrio fischeri. Samples of river water were also evaluated for chronic toxicity tests with C. dubia. The quantification of metals and hydrocarbons in sediment samples was also carried out in order to correlate the biological effects with the chemical contamination. The obtained results with the whole sediment test indicate Mogi das Cruzes (P3) and Suzano (P4) cities as the most toxic sites and also as the sites with the highest concentrations of heavy metals. The tests with aqueous phases (elutriate and porewater) indicated the site located in Biritiba-Mirim (P1) as the most problematic. High concentrations of hydrocarbons were also found in this site, as well as in another site located in Biritiba-Mirim (P2). The Ponte Nova reservoir site (P0) showed toxicity in a few occasions, and it is the only site where high concentrations of contaminants was observed. The results showed a gradient of toxicity and contamination that increases according to the distance from the reservoir (P0) and with the proximity of populated and industrialized cities (P3 and P4).
\end{abstract}




\section{SUMÁRIO}

1. INTRODUÇÃO

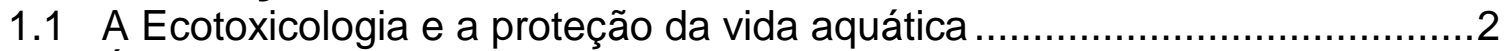

1.2 Área de Abrangência do Projeto ………….........................................

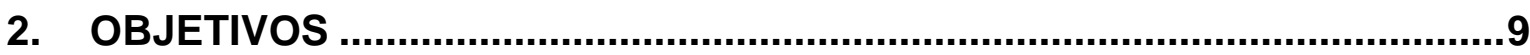

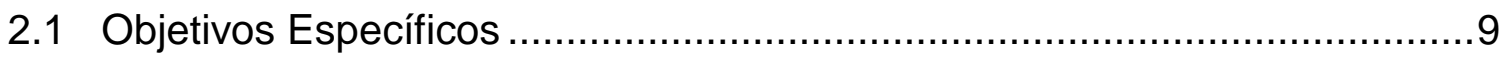

3. CONSIDERAÇÕES TEÓRICAS E REVISÃO BIBLIOGRÁFICA .....................10

3.1 Ensaios de toxicidade e organismos-teste ..........................................10

3.2 Ensaios de toxicidade em sedimentos ..............................................12

3.2.1 Toxicidade em sedimentos e suas frações (integral, interface sedimento-água e elutriato) .........................................................13

3.3 A Ecotoxicologia de sedimentos no Brasil............................................15

3.4 Qualidade dos sedimentos ........................................................... 17

3.5 Metais e compostos aromáticos (HPA's) no ambiente aquático .................21

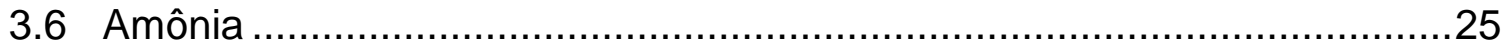

3.7 Integração dos dados de toxicidade e contaminação ambiental ..................26

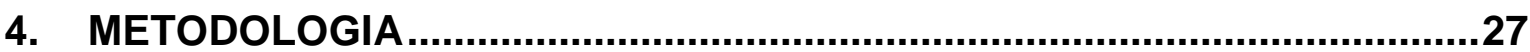

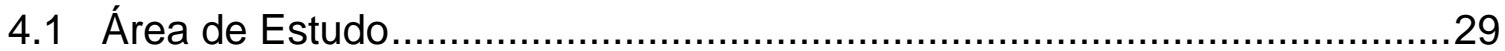

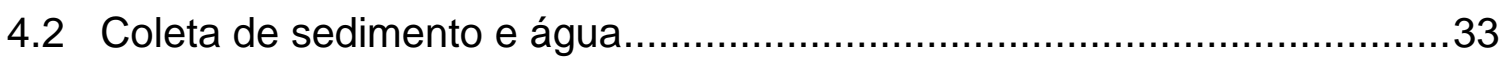

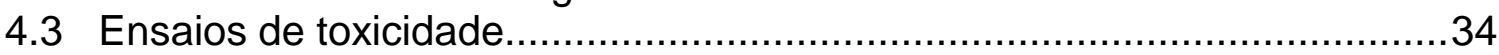

4.3.1 Ensaios de toxicidade com sedimento integral - Hyalella azteca...........35

4.3.2 Ensaios de toxicidade com sedimento integral - Ceriodaphnia dubia...38

4.3.3 Ensaios de toxicidade com elutriato - Ceriodaphnia dubia...................39

4.3.4 Ensaios de toxicidade com amostras de água do Rio Tietê Ceriodaphnia dubia ..................................................................40

4.3.5 Análise estatística: Teste de Hipóteses por Bioequivalência .................41

4.3.6 Ensaios de toxicidade em água intersticial dos sedimentos - Vibrio fischeri.......................................................................... 42

4.4 Quantificação de contaminantes orgânicos e inorgânicos em amostras de

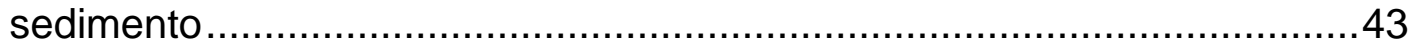

4.5 Determinação da amônia não ionizada ..................................................4

4.6 Análises Multivariadas................................................................. 4

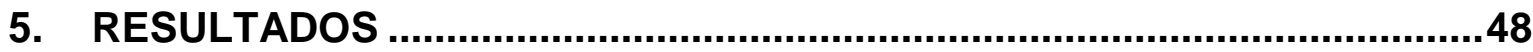

5.1 Resultados dos Ensaios de Toxicidade .............................................. 48

5.2 Resultados obtidos na quantificação dos contaminantes orgânicos e

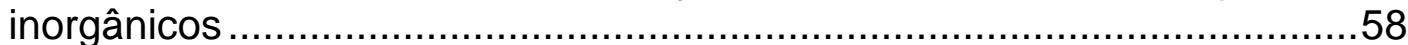

5.3 Quantificação de amônia não ionizada...................................................62

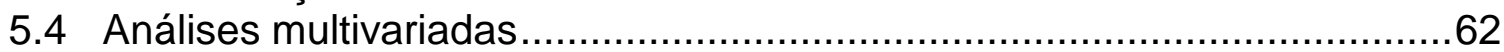

6. DISCUSSÃO

6.1 A Presença de metais no ambiente e riscos associados..........................67

6.2 Hidrocarbonetos policíclicos aromáticos (HPA'S) ....................................69

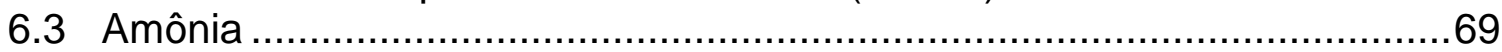

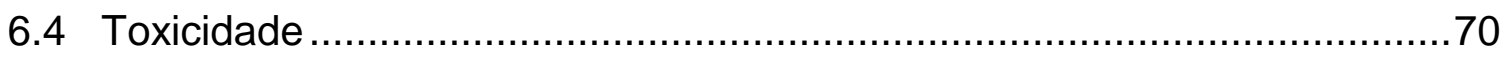

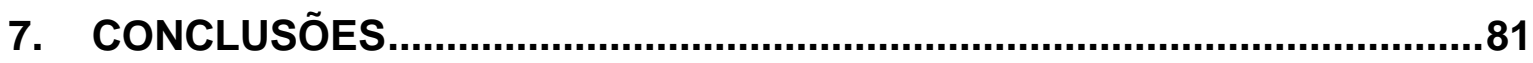

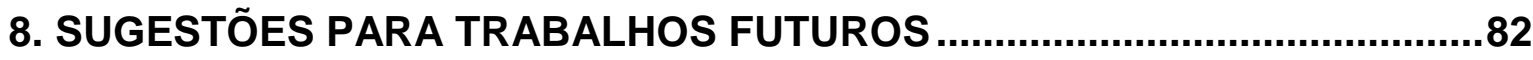




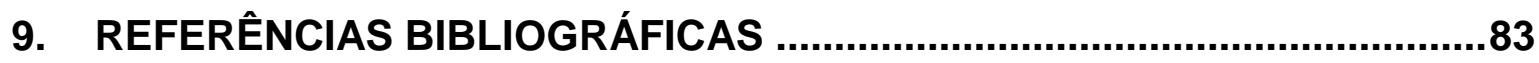

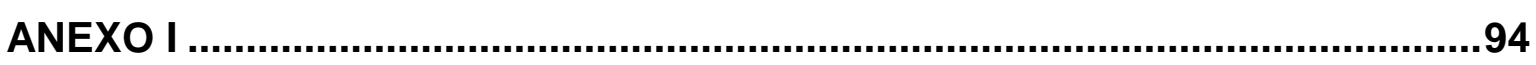

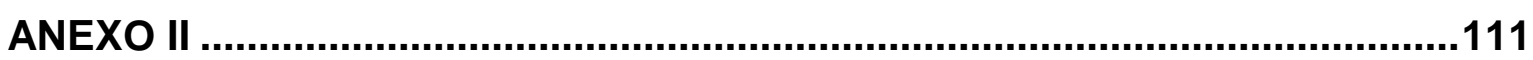




\section{INTRODUÇÃO}

A água é o recurso natural mais precioso deste planeta. Dela surgiram as primeiras formas de vida, das quais se originaram todas as outras que conhecemos hoje. A água participa do balanço térmico do planeta, provê habitat para muitos animais, é o elemento mais importante para a manutenção da vida, sendo constituinte de todos os seres vivos.

Desde sua aparição na terra o homem sempre se estabeleceu próximo a corpos d'água, principalmente rios, pois essa proximidade the garantia água, alimentos e até mesmo defesa natural. Grandes civilizações se desenvolveram por meio de uma estreita ligação com os rios, como é o caso dos egípcios e fenícios.

Com o crescimento populacional houve um substancial aumento da demanda por recursos naturais, entre eles a água. Os recursos hídricos têm grande importância na economia, uma vez que muitas atividades (agrícolas, pecuárias, industriais, de geração de energia, saneamento, entre outras) necessitam de água. $\mathrm{O}$ aumento das atividades industriais gerou uma elevada demanda por este precioso recurso e, consequentemente, fez crescer os lançamentos de um grande número de resíduos e substâncias químicas nos corpos d'água.

Com vistas à preservação dos recursos naturais e das espécies que habitam ambientes terrestres e aquáticos, há séculos o homem busca conhecer o impacto ambiental de suas atividades. Como é possível imaginar, praticamente toda atividade humana na face deste planeta constitui uma fonte potencial de contaminantes para os ecossistemas aquáticos e terrestres (Mozeto \& Zagatto, 2006). Dentre os recursos naturais, a água é o mais importante para os seres vivos e também mais suscetível a alterações decorrentes destas atividades.

A necessidade em conhecer os efeitos dos compostos de origem antropogênica sobre os ecossistemas aquáticos tem levado ao desenvolvimento de diversos métodos de avaliação dos efeitos biológicos dessas substâncias, que em conjunto com as análises químicas, complementam a informação. Segundo Zagatto (2006) a partir da Toxicologia humana, surgiu a analise de risco ambiental (potencialidade de contaminantes e produtos em causar efeitos aos organismos, 
estabelecimento da relação dose/efeito, etc) de novas substâncias químicas, principalmente agrotóxicos, para diferentes ambientes e em diversos níveis tróficos, utilizando para tal o conhecimento das características físico-químicas e ecotoxicológicas e, sua disposição e destino final no ambiente.

Segundo a Sociedade Americana de Química existe cerca de 10 milhões de substâncias químicas, destas, aproximadamente 100 mil são de uso cotidiano. A cada ano entre mil a duas mil novas substâncias são adicionadas a essa lista (Mozeto \& Zagatto, 2006). Desta extensa lista, apenas cerca de 2 mil substâncias têm seus efeitos tóxicos conhecidos, dificultando a tomada de decisões em caso de acidentes ambientais. Nos últimos trinta anos a CETESB registrou mais de 7500 acidentes dessa natureza somente no estado de São Paulo (Cadeq Cadastro de Emergências Químicas da CETESB).

Dentre as principais fontes de poluição dos ecossistemas aquáticos no país encontram-se efluentes domésticos e industriais, que muitas vezes contêm metais pesados e diferentes moléculas orgânicas sintéticas (Prósperi, 2002). Os despejos radioativos hoje encontram-se em evidência, bem como a presença de fármacos nas águas, ambos pelo uso crescente na área da saúde (Rand, 1995); a lixiviação de solos agrícolas também representa importante contribuição para os poluentes introduzidos nas águas Hoje, além dessas fontes de contaminação, os hormônios, drogas e produtos de cuidado pessoal (PCP's) que chegam aos corpos hídricos através de efluentes de ETE's e lançamentos de esgoto in natura vêm chamando a atenção da comunidade científica que busca determinar seus efeitos aos organismos aquáticos (Péry et al., 2008; Pomati et al., 2008; Quinn et al., 2009).

\subsection{A Ecotoxicologia e a proteção da vida aquática}

A necessidade de estudos ambientais com ênfase nas respostas dos organismos em conjunto com as análises químicas, levou ao desenvolvimento de uma ciência denominada Ecotoxicologia. Segundo Newman \& Unger (2002), a Ecotoxicologia é uma ciência que estuda os contaminantes e seus efeitos nos constituintes da biosfera, avaliando a capacidade de substâncias químicas (isoladas ou em combinação) e amostras ambientais de causar efeitos deletérios aos organismos expostos (Pereira et al., 2004). A ecotoxicologia é uma ciência 
multidisciplinar, que combina a Química, a Toxicologia, a Farmacologia e a Ecologia (Connell, 1999).

A busca por organismos que representam adequadamente o ambiente a ser estudado, além da necessidade de cultivo de organimos-teste e trabalhos com qualidade resultou em conhecimentos específicos da biologia e necessidade de profissionais da área para atuar nessa nova ciência (Knie \& Lopes, 2004; Zagatto \& Bertoletti, 2008; Flynn, 2009). Com a mesma intenção, os estudos ecológicos, de teratogenia, bioacumulação e biomarcadores também se desenvolvem amplamente nos dias de hoje (Pereira, 2008; Nowiersky et al., 2005; Namiesnik et al., 2008).

Desse modo os ensaios de toxicidade têm sido empregados para fins diversos, dentre eles: avaliação da qualidade de águas e sedimentos bem como em programas de monitoramento ambiental (Relatório de Qualidade de Águas Interiores, Subterrâneas e Litorâneas - CETESB). Na definição de limites máximos permissíveis para o lançamento de efluentes e substâncias químicas (CONAMA 357, 2005; CONAMA 344, 2004), na avaliação da eficiência de tratamento de efluentes e determinação de seu potencial tóxico (Borrely, 2001, Hamada, 2008; Neto, 2009) entre outros.

Uma vez introduzidas no ambiente aquático, muitas substâncias podem se ligar ou serem adsorvidas por partículas orgânicas em suspensão. Dependendo da morfologia do rio e das condições hidrológicas, essas partículas em suspensão com seus contaminantes podem se depositar ao longo de seu curso, tornando-se parte dos sedimentos de fundo (Viganò et al, 2003), podendo funcionar assim como depósitos de substâncias químicas orgânicas e inorgânicas (Waltraud \& Wolfgang, 1996).

Os sedimentos constituem também substrato para uma variedade de organismos, no seu interior ou na interface sedimento-água (Portela et al., 2006). Desse modo o sedimento pode ser fonte de contaminação para organismos bentônicos, por exposição direta, e também para os organismos pelágicos, pela ressuspensão dos contaminantes, provocada por atividades biológicas, tempestades, dragagens; via alimentar, ou ainda pela troca que existe entre a água intersticial e a água sobrejacente aos sedimentos (Zamboni, 1993). 
Assim, a manutenção da qualidade dos sedimentos é reconhecidamente necessária para a proteção da vida aquática (Adams et al., 1992), pois estes em geral apresentam contaminantes em concentrações mais elevadas em relação à coluna d'água, podendo alterar a qualidade da mesma.

\section{2 Área de Abrangência do Projeto}

O Rio Tietê (que em Tupi, significa "caudal volumoso"), tem suas nascentes a leste da cidade de São Paulo, no Parque Nascentes do Rio Tietê, em Salesópolis. Nasce na Serra do Mar, a 840 metros de altitude e, ao contrário da maioria dos rios que correm para o mar, este rio segue para o interior, atravessando a Região Metropolitana de São Paulo (RMSP). O rio banha 62 municípios no estado, percorrendo 1.136 quilômetros até desaguar no Rio Paraná (Plano da Bacia do Alto Tietê, 2008; www.tietecabeceiras.com.br).

A importância do Rio Tietê remonta a fundação da Vila Piratininga, há mais de 450 anos, quando o rio foi considerado pelos Jesuítas como o principal motivo para a instalação do povoado que deu origem à Grande São Paulo de hoje. Palco das bandeiras e monções, servindo de caminho para exploradores, tropeiros, missionários, comerciantes e militares (Medaglia \& Cunha, 2009).

O Rio Tietê é utilizado atualmente para abastecimento de água, geração de energia elétrica (Usina Hidrelétrica de Barra Bonita, SP), lazer, navegação (Hidrovia Tietê-Paraná) e, também, para o despejo de toneladas de efluentes domésticos e industriais (Medaglia \& Cunha, 2009).

A bacia é composta por 6 sub-bacias hidrográficas, sendo elas: Alto Tietê, Sorocaba-Médio Tietê, Piracicaba-Capivari-Jundiaí, Tietê-Batalha, Tietê-Jacaré e Baixo Tietê, como destacado na Figura 1. 


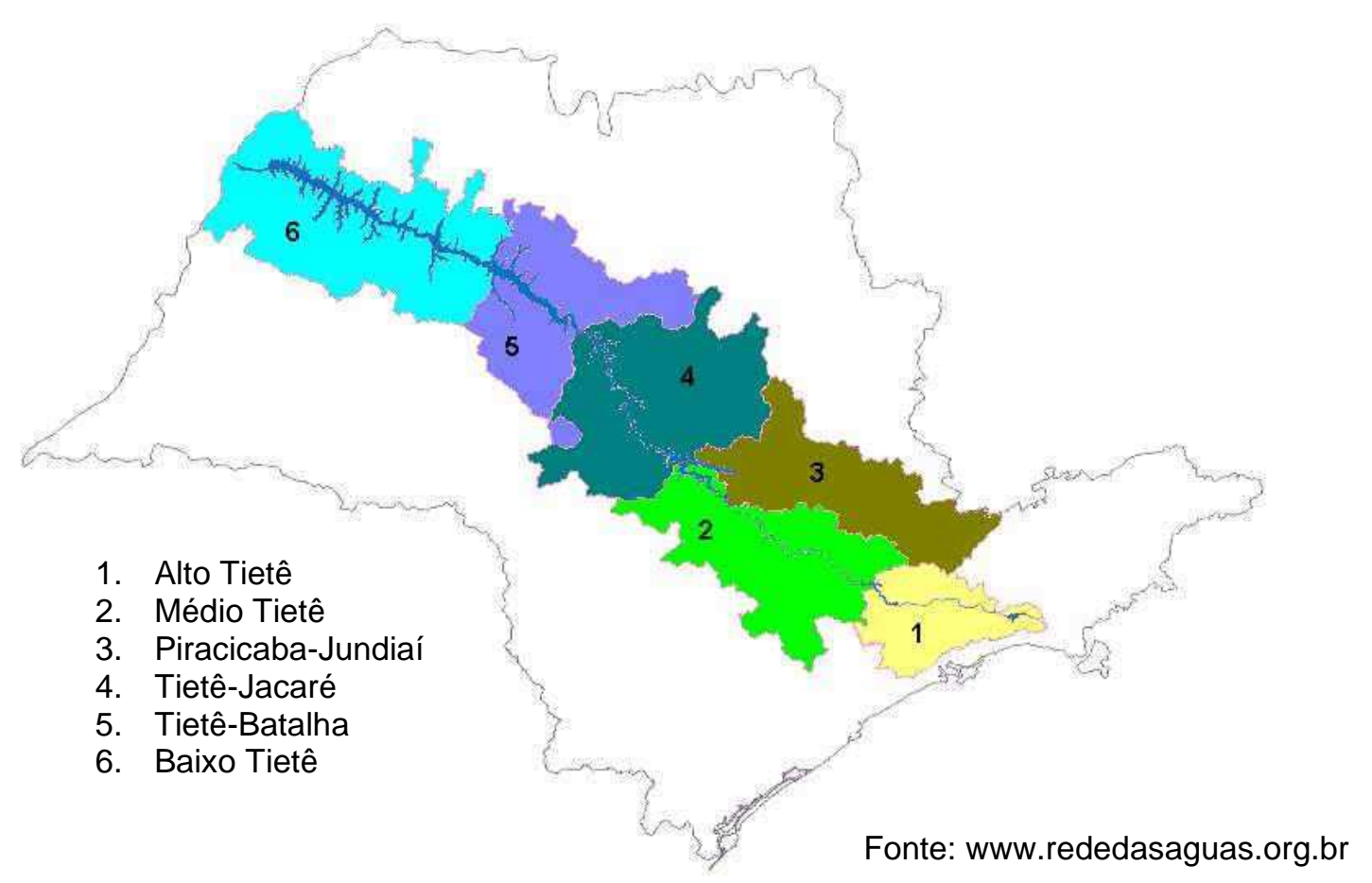

Figura 1. Divisões da Bacia Hidrográfica do Rio Tietê

A Bacia Hidrográfica do Alto Tietê corresponde à área total drenada pelo Rio Tietê, desde sua nascente em Salesópolis, até a barragem do Rasgão (próxima a cidade de Pirapora do Bom Jesus), sendo uma área de aproximadamente 5.775 $\mathrm{km}^{2}$. É considerada altamente complexa devido à grande quantidade de obras hidráulicas existentes para regularização de vazões, controle de cheias e outros fins que alteram o regime natural dos seus cursos d'água, além de atravessar muitos trechos com elevada densidade demográfica e ocupação intensa e desordenada do solo (Plano da Bacia do Alto Tietê, 2008).

Esta Bacia está inserida no bioma da Mata Atlântica, riquíssimo em biodiversidade de plantas e animais, com formações que variam desde densas florestas nas regiões de maior altitude a brejos e várzeas ao longo dos cursos d'água nas terras mais baixas de planalto.

A ocupação desordenada, lançamentos de esgotos in natura e a presença de diversos parques industriais na RMSP comprometeram grande parte dos recursos hídricos da Bacia do Alto Tietê, dificultando sua utilização para o abastecimento público, que atualmente depende em mais de $50 \%$, da utilização de outras bacias hidrográficas, como o Sistema Cantareira, que capta as águas da Bacia do Piracicaba (EMPLASA, 1992). 
Em seu curso superior (Tietê Cabeceiras) a ocupação da bacia é predominantemente agrícola, embora existam neste trecho, centros urbanos de importância, tais como Mogi das Cruzes e Suzano, com diversificado parque industrial, como ilustra a Figura 2.

Este estudo englobou o Rio Tietê em sua passagem pelos municípios de Salesópolis, Biritiba-Mirim, Mogi das Cruzes e Suzano, SP.

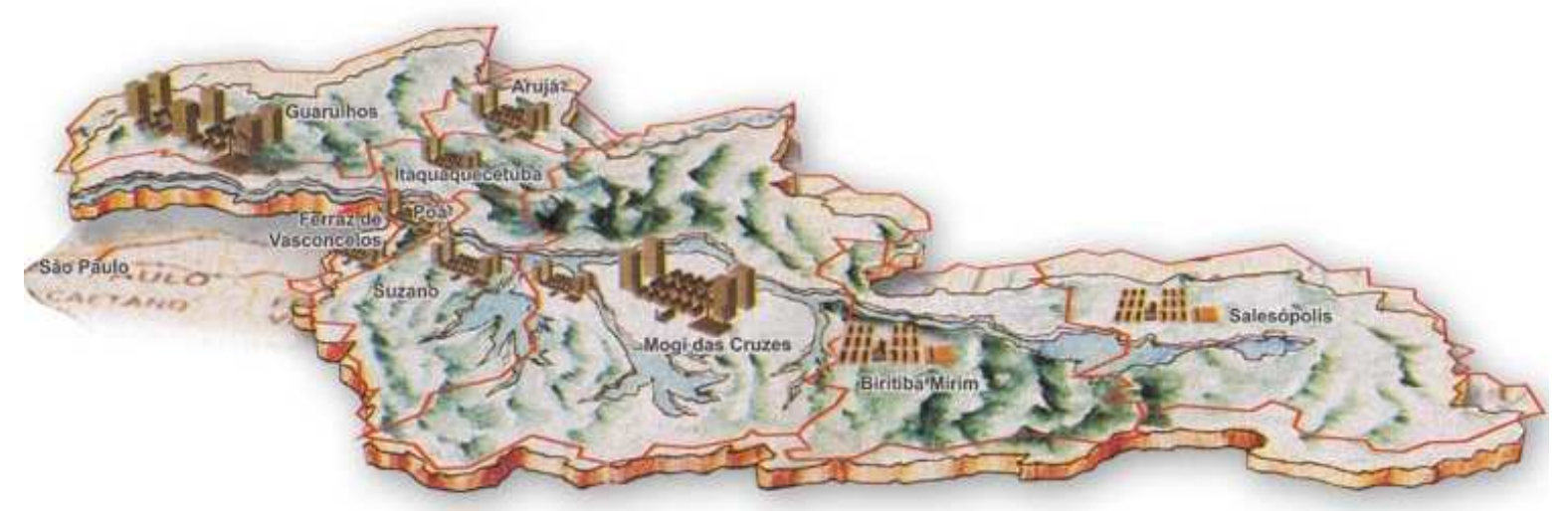

Fonte: www.tietecabeceiras.com.br

Figura 2. Municípios inseridos na região Tietê-Cabeceiras, SP.

$\mathrm{Na}$ área de estudo, encontra-se também a Área de Proteção Ambiental da Várzea do Rio Tietê: com 6.795,22 hectares, que tem por objetivo a proteção de parte da várzea do Rio Tietê, ocupada por áreas rurais e urbanas dos municípios de Salesópolis, Biritiba-Mirim, Mogi das Cruzes, Suzano, Poá, Itaquaquecetuba, Guarulhos, Osasco, Barueri, Carapuicuíba, Santana do Parnaíba e São Paulo (Plano da Bacia do Alto Tietê, 2008).

A cidade de Salesópolis, com aproximadamente 15 mil habitantes, não só abriga a nascente do Rio Tietê, como também o reservatório de Ponte Nova. $\mathrm{O}$ reservatório foi construído em 1972 pelo DAEE (Departamento de Águas e Energia Elétrica) e possui uma área inundada de $28,07 \mathrm{~km}^{2}, 320 \mathrm{~km}^{2}$ de área de drenagem e volume útil de $296 \times 10^{6}$ metros cúbicos, fornecendo 3,4 mil litros de água por segundo para abastecimento público da região metropolitana de São Paulo. A barragem também auxilia na contenção de enchentes e no controle da poluição do Rio Tietê, ao regular o fluxo de água na região da nascente (www.daee.sp.gov.br). A região de Salesópolis, que já foi uma fazenda de gado de vegetação rala e rasteira, devastada pela erosão, foi reflorestada e 
transformada no Parque da Nascente do Tietê. O ecoturismo é uma das principais atividades econômicas do município (Medaglia \& Cunha, 2009).

Muito próximo a esse importante reservatório, encontra-se o município de Biritiba-Mirim, que possui uma população de aproximadamente 30 mil habitantes e tem grande importância na região, pois faz parte do "cinturão verde", que abastece a grande São Paulo com legumes, frutas e hortaliças, utilizando as águas do Rio Tietê para irrigação (Plano da Bacia do Alto Tietê, 2008; www.tietecabeceiras.com.br). É importante mencionar que o município trata 100\% do esgoto que coleta (95\% do total produzido) antes de lançá-lo no Rio Tietê (CETESB, 2009). Cabe mencionar que a região apresenta importante atividade agrícola com possível introdução de defensivos agrícolas nas águas do rio por meio da lixiviação do solo.

A cidade de Mogi das Cruzes possui a maior produção de hortifrutigranjeiros do Estado de São Paulo e um parque industrial bastante desenvolvido. Conta com uma população de mais de 350 mil habitantes e não possui uma estação de tratamento de esgotos em funcionamento. Embora colete cerca de $90 \%$ de seu esgoto, apenas 43\% é tratado na ETE Suzano, sendo o restante descartado in natura no Rio Tietê e seus afluentes (Plano da Bacia do Alto Tietê, 2008; CETESB, 2009). Nesse município, o aporte de contaminantes altera a qualidade do rio de forma bastante expressiva.

A cidade de Suzano possui cerca de 280 mil habitantes, coleta cerca de $80 \%$ do esgoto que produz e conta com uma estação de tratamento de esgotos, a ETE Suzano, onde são tratados apenas 70\% desse total (CETESB, 2009). Essa ETE também trata parte dos esgotos de Mogi das Cruzes e muitos efluentes industriais (Hamada, 2008).

O corpo receptor dos efluentes da ETE Suzano é o Rio Tietê. Além do efluente da ETE, o rio também recebe efluentes, provenientes de indústrias de cerâmica, têxtil, metalúrgica, tratamento de peles, tinturaria e estamparia, corantes, produção de papel, farmacêutica e química-farmacêutica, entre outras (Plano da Bacia do Alto Tietê, 2008; CETESB, 2009).

A Companhia Ambiental do Estado de São Paulo (CETESB) monitora 395 pontos em rios e represas no estado de São Paulo com o intuito de obter um 
panorama da qualidade das águas para abastecimento, bem como dos sedimentos dos principais reservatórios do estado de São Paulo. Os resultados deste monitoramento são compilados no Relatório de Qualidade de Águas Interiores no Estado de São Paulo. Destes, 82 encontram-se na região da Bacia do Alto Tietê, de onde provém águas superficiais para vários usos, (abastecimento público, industrial, irrigação, geração de energia, lazer, transporte e diluição de poluentes) (SABESP, 2006), evidenciando a importância desta região.

A ocupação desordenada de áreas ao redor do Rio Tietê resultou na proliferação de indústrias, residências e loteamentos (muitas vezes clandestinos). As conseqüências desse processo foram dramáticas para o meio ambiente local, em especial pela ocorrência de desmatamentos, depósitos de lixo e favelização, levando à degradação da qualidade das águas. 


\section{OBJETIVOS}

O objetivo deste trabalho foi avaliar a toxicidade dos sedimentos do Rio Tietê além da determinação de contaminantes químicos entre os municípios de Salesópolis e Suzano, buscando compreender a relação causa-efeito.

\subsection{Objetivos Específicos}

Avaliar a toxicidade aguda de amostras do sedimento integral utilizando como organismo-teste o anfípodo Hyalella azteca

Avaliar a toxicidade crônica da interface sedimento-água utilizando o microcrustáceo Ceriodaphnia dubia.

Avaliar a toxicidade do elutriato das amostras de sedimento utilizando 0 microcrustáceo Ceriodaphnia dubia.

Avaliar a toxicidade aguda da água intersticial dos sedimentos utilizando a bactéria bioluminescente Vibrio fischeri.

Quantificar os contaminantes orgânicos e inorgânicos presentes nas amostras de sedimentos.

Correlacionar os resultados obtidos nos ensaios ecotoxicológicos com a contaminação química encontrada. 


\section{CONSIDERAÇÕES TEÓRICAS E REVISÃO BIBLIOGRÁFICA}

Mesmo com o avanço da legislação, com leis específicas para preservação ambiental e do alerta da comunidade científica, as múltiplas atividades humanas continuam causando a degradação dos ecossistemas aquáticos, sobretudo nas áreas mais desenvolvidas e urbanizadas do globo (Nascimento, 2003).

Não somente visando a preservação da biota, como também a busca pela melhoria da qualidade das águas, a Resolução do Conselho Nacional do Meio Ambiente, CONAMA 357/05 (que substituiu a CONAMA 20), incluiu os ensaios de toxicidade na avaliação de lançamentos de efluentes e do ambiente aquático, bem como a Resolução CONAMA 344/04, que incluiu a avaliação ecotoxicológica dos sedimentos a serem dragados.

Desde 2003 começaram a serem editadas pela Associação Brasileira de Normas Técnicas (ABNT) metodologias padronizadas para ensaios de toxicidade com diversos organismos-teste, que contemplam os ambientes aquáticos dulcícolas e marinhos, além de sedimentos. Atualmente o grupo de especialistas está organizando normas destinadas também estudos de contaminação em solos.

\subsection{Ensaios de toxicidade e organismos-teste}

Os organismos-teste utilizados nos ensaios de toxicidade são escolhidos e padronizados de acordo com algumas características, entre elas a ampla distribuição geográfica, a alta sensibilidade a diversas classes de contaminantes, a baixa variabilidade genética, a sua disponibilidade em abundância e, de preferência, ser autóctone e representativo do ambiente em estudo (Rand et al., 1995).

Entre os organismos mais utilizados no mundo para avaliação de toxicidade, podemos destacar as espécies de peixe Danio rerio (Brasil e Alemanha), Ariopsis assimilis (México) e Poecilia reticulata (Brasil); os anfípodos Hyalella azteca (Brasil, Alemanha e Estados Unidos), Melita plumulosa (Austrália) e Tiburunella viscabana (Brasil); os cládoceros Ceriodaphnia dubia (Brasil e Itália), Daphnia similis (Brasil) e Daphnia magna (México, Estados Unidos, Espanha e sul do Brasil); a bactéria luminescente Vibrio fischeri (Brasil, França e Itália); os ouriços 
do mar Lytechinus variegatus e Echinometera lucunter (Brasil) (Rand,1995; Cesar, 2003; Araújo et al., 2006a).

O tempo de exposição, a concentração utilizada no ensaio e o efeito observado classificam um ensaio de toxicidade. Em geral são considerados ensaios de toxicidade para efeito agudo aqueles que avaliam doses elevadas de contaminantes por um curto período de exposição. Normalmente a duração desses ensaios varia de 24 a 96 horas, sendo o efeito observado a morte dos organismos-teste expostos. Os resultados dos ensaios de toxicidade aguda são expressos através da CE50, que representa a concentração da amostra que causa efeito agudo a $50 \%$ dos organismos expostos, nas condições de ensaio.

Por outro lado, podem ser classificados como ensaios para efeito crônico aqueles que avaliam os efeitos de concentrações inferiores de contaminantes por um período de exposição mais longo. Esses ensaios abrangem parte significativa do ciclo de vida do organismo, resultando em mudanças na taxa de crescimento e reprodução (Romanelli, 2004). Em ensaios de toxicidade para estudo de efeitos crônicos, os resultados podem ser expressos em CENO (concentração de efeito não observado) cuja definição segundo a Norma NBR13373 (2005) é a "maior concentração testada da amostra que não causa efeito deletério estatisticamente significativo na sobrevivência e reprodução nas condições de ensaio" e CEO (concentração de efeito observado), que representa menor a concentração onde se observa tal efeito.

Outra maneira de expressão de resultados em ensaios de toxicidade que não apresentam diluição e avaliam qualitativamente amostras ambientais é caracterizar a amostra como "Tóxica", quando sua mortalidade ou reprodução for significativamente diferente daquela obtida no controle, ou "Não tóxica", quando a amostra não apresentar essa diferença.

Avaliações periódicas de sensibilidade dos organismos-teste, bem como os procedimentos de execução dos ensaios, são realizados com substâncias de referência (fenol, cloreto de sódio, dicromato de potássio, cloreto de potássio, etc.). Os resultados obtidos com a substância de referência são utilizados, ainda, para compor a carta controle de sensibilidade de um organismo-teste. Um ensaio de toxicidade é considerado aceitável se a sensibilidade à substância de 
referência estiver dentro dos limites estabelecidos pela média da $\mathrm{CL}_{50}$ ou $\mathrm{CE}_{50}$ de um determinado número de ensaios \pm 2 desvios-padrão (ABNT, 2006).

\subsection{Ensaios de toxicidade em sedimentos}

Segundo Araújo et al. (2006a) uma variedade de métodos têm sido propostos na avaliação da qualidade dos sedimentos. Entre os procedimentos já estabelecidos, podemos citar a aplicação dos diferentes organismos-teste: bactérias, protozoários, oligoquetas, poliquetas, insetos, anfípodas, cladóceros, peixes, entre outros.

Para uma avaliação completa da toxicidade dos sedimentos, deve-se levar em consideração a complexidade deste compartimento bem como suas diversas fases passíveis de avaliação, entre elas o sedimento integral, o elutriato e a água intersticial.

O sedimento integral é a porção da amostra que mantém suas características físicas originais, sem nenhum tipo de tratamento prévio. A importância desse ensaio é a proximidade com as condições de uma exposição realizadas in situ, por esse motivo, apenas adiciona-se água de diluição à amostra de sedimento, sem que haja ressuspensão do mesmo.

O anfípodo Hyalella azteca tem se mostrado um bom organismo-teste para avaliação da toxicidade de sedimentos de corpos de água doce no Brasil e no exterior. É um animal de água doce, epibentônico detritívoro-herbívoro, que ocasionalmente cava os sedimentos em busca de alimento (Burton et al., 2002). No estado de São Paulo, esse organismo tem sido adotado em estudos de qualidade de sedimentos em ambientes dulcícolas, sendo utilizado pela CETESB para avaliar a qualidade dos sedimentos dos principais reservatórios do estado, desde 2000.

O ensaio com Hyalella azteca já está bastante difundido no país. Entre os trabalhos que utilizaram esse organismo na avaliação da toxicidade de sedimentos podemos citar Araújo (2005), que não só avaliou diferentes metodologias de cultivo e ensaio para o organismo Hyalella azteca, como também a qualidade dos rios e reservatórios do estado de São Paulo, abordando análises químicas, de comunidade bentônica e ensaios de toxicidade. 
Portela et al. (2006) utilizaram $H$. azteca na avaliação ecotoxicológica dos sedimentos do Arroio Sapucaia, RS. Silvério (2003) utilizou dados de toxicidade para $H$. azteca para compor valores-guia de qualidade de sedimentos para metais em cinco reservatórios do Rio Tietê (Billings, Rasgão, Barra Bonita, Bariri e Promissão).

\subsubsection{Toxicidade em sedimentos e suas frações (integral, interface sedimento-água e elutriato)}

Enquanto que no ensaio com sedimento integral ocorre somente adição de água ao sedimento sem ressuspensão do mesmo, o ensaio com elutriato utiliza a solução aquosa obtida após adição de um líquido extrator à amostra de sedimento, agitação da mistura e por fim, decantação do sistema ou centrifugação quando necessário. Essa metodologia tem por objetivo simular a ressuspensão de sedimentos contaminados, como em uma situação de dragagem, tempestade ou aporte de grandes volumes de água pluvial (água de drenagem) no corpo receptor que possam causar algum distúrbio nos sedimentos de fundo e estudar a biodisponibilização dos contaminantes desse sedimento, sendo uma forma complementar de avaliação da toxicidade.

A espécie padronizada e recomendada por Burton et al. (2002) para estudos que incluam efeitos crônicos, tanto em amostras de sedimento e suas fases (interface, elutriato, água intersticial) como em amostras de água (coluna d'água), são as espécies de cladóceros Ceriodaphnia dubia e Ceriodaphnia silvestrii.

Em comparação com ensaios utilizando Daphnia sp, os ensaios com Ceriodaphnia sp apresentam vantagens, entre elas: o pequeno tamanho da espécie que exige menores volumes de água nos cultivos, produção de muitas crias e poucos efípios (ovos de resistência), tem uma distribuição mais cosmopolita do que a Daphnia magna e no ensaio, além da reprodução, pode-se avaliar também a mortalidade, uma vez que este organismo é bastante sensível (Burton et al. 2002).

Os microcrustáceos, apesar de serem organismos tipicamente planctônicos, habitam as camadas mais profundas do ambiente aquático, alimentando-se sobre a superfície do sedimento (Esteves, 1988). Além disso, a maioria das espécies é 
filtradora não seletiva, ingerindo tanto partículas suspensas como depositadas no sedimento (Burton, 1992).

Portela (2002) analisou a toxicidade de amostras de água e sedimentos do Arroio Sapucaia, no Rio Grande do Sul, obtendo boa correlação entre resultados com C. dubia e aqueles obtidos com H. azteca. Rodgher et al. (2005) utilizaram os organismos Ceriodaphnia dubia, Daphnia similis e Danio rerio na análise da água e dos sedimentos dos reservatórios em cascata do Rio Tietê.

A água intersticial é a água que ocupa os espaços entre as partículas do sedimento (U.S. EPA, 2003). De acordo com Chapman et al. (2002), a água intersticial é a rota chave de exposição para muitos organismos, em particular a infauna (organismos que vivem abaixo da superfície dos sedimentos), sendo importante a avaliação de sua toxicidade. Uma das principais razões para a utilização de ensaios de toxicidade com água intersticial por agências reguladoras é que estes fornecem informações adicionais não obtidas em um ensaio utilizando a fase sólida ou elutriato de sedimentos, além de serem geralmente mais baratos e rápidos do que ensaios que utilizam a fase sólida dos sedimentos (CARR et al., 2001).

Um ensaio amplamente utilizado para determinar a toxicidade de amostras de água, efluentes e extratos de sedimentos (elutriato e água intersticial) de água doce e marinhos é aquele que utiliza como organismo-teste a bactéria marinha bioluminescente Vibrio fischeri.

Esse ensaio se baseia na diferença entre a emissão de luz da bactéria antes e depois de sua exposição a uma amostra por um período de 15 minutos. A intensidade de luz emitida é comparada a um controle. A luminescência produzida pela bactéria Vibrio fischeri é decorrente do processo enzimático de seu metabolismo. Este processo enzimático pode ser modificado ou sofrer danos por exposição a substâncias tóxicas, culminando na diminuição da bioluminescência. Esse decréscimo da quantidade de luz emitida é proporcional à toxicidade da amostra (Romanelli, 2004; ABNT 2006; Hsu et al., 2007).

O ensaio com a bactéria bioluminescente apresenta diversas vantagens como rapidez na obtenção dos resultados, alta sensibilidade a diferentes grupos de contaminantes, pois detecta substâncias tóxicas em baixas concentrações, 
boa reprodutibilidade, simplicidade e custo relativamente baixo além de não exigir grandes quantidades de amostra (Sanchez \& Sato, 2002; Romanelli, 2004; Coz et al., 2008). Este ensaio é bastante difundido no Brasil e no exterior em ensaios com amostras marinhas e dulcícolas. Entre os trabalhos que utilizaram amostras de água doce no exterior podemos citar Viganò et al. (2003) que utilizaram V. fischeri na avaliação de extratos de sedimentos do Rio Pó, Itália. Delistraty \& Yokel (2007) utilizaram a bactéria na avaliação da água intersticial do Rio Columbia, nos Estados Unidos.

Borrely (2001) avaliou a remoção da toxicidade de efluentes da ETE Suzano através da aplicação de radiação ionizante utilizando para tal os organismos Daphnia similis, Vibrio fischeri e o peixe Poecilia reticulata. Romanelli (2004) estudou amostras de surfactantes utilizando os organismos $V$. fischeri e $D$. similis (de água doce), conseguindo uma boa correlação entre a toxicidade encontrada para estes dois organismos.

\subsection{A Ecotoxicologia de sedimentos no Brasil}

No Brasil, os primeiros trabalhos que avaliaram toxicidade de sedimentos foram realizados na década de 1980, com material proveniente da represa Billings e do Rio Cubatão, como parte de projetos mais amplos para controle da poluição e recuperação ambiental desenvolvido pela CETESB (CETESB, 1983 a, b apud Araújo et al, 2006a). A realização de testes de toxicidade nesses estudos teve por finalidade contribuir para o conhecimento da possibilidade de liberação de nutrientes e substâncias tóxicas do sedimento para a coluna d'água e verificar se esse processo resultava em concentrações suficientes para causar efeito agudo às comunidades aquáticas desses locais.

Outros estudos envolvendo toxicidade de sedimentos foram reiniciados pela CETESB a partir da década de 1990. Os procedimentos propostos foram os ensaios de toxicidade com água intersticial, utilizando-se o microcrustáceo Ceriodaphnia dubia e a bactéria marinha Vibrio fischeri (sistema Microtox®). No estado do Rio Grande do Sul, Rosado (1998) utilizou Ceriodaphnia dubia e Hyalella azteca para avaliar a qualidade do sedimento da Baía de Ipanema (Araújo et al., 2006a). Na Bacia do Médio Tiête Superior, Peláez-Rodriguez et al. (2002) utilizaram os organismos Ceriodaphnia dubia e silvestrii para avaliação 
ecotoxicológica da água e sedimento e para a aplicação do Índice de Proteção a Vida Aquática (IVA), respectivamente.

Cada vez mais os estudos com sedimentos vêm ganhando importância no país, pois são imprescindíveis para uma avaliação abrangente do ecossistema aquático, sendo incluídos na aplicação do Índice de Proteção da Vida Aquática. A CETESB também tem incluído dados de toxicidade do sedimento dentro de sua rede de monitoramento nos principais reservatórios do estado em seu Relatório Anual de Águas Interiores.

No estado de São Paulo, já foram realizados diversos estudos sobre a toxicidade de sedimentos. Próximo à região do presente estudo, Costa \& Espíndola (2002) estudaram a qualidade da água e do sedimento em tributários do reservatório de Barra Bonita (Bacia do Médio Tietê Superior) encontrando no Rio Tietê baixas concentrações de oxigênio dissolvido, elevadas concentrações de zinco, cádmio e cobre biodisponíveis no sedimento, demonstrando séria degradação ambiental no sistema.

Silvério (2003) caracterizou os metais nos sedimentos dos reservatórios Billings, Barra Bonita, Bariri, Promissão e Rasgão do Rio Tietê, SP (Projeto Qualised) associando à toxicidade para Hyalella azteca e Tubifex tubifex às elevadas concentrações de cobre, níquel, chumbo e zinco. Em um estudo semelhante, a toxicidade obtida para Daphnia similis e Chironomus xanthus no reservatório de Barra Bonita foi associada a elevadas concentrações de manganês, chumbo, cádmio e níquel (Bramorsky, 2004).

Rodgher et al. (2005) avaliaram a água e o sedimento dos reservatórios em cascata do Rio Tietê utilizando análises químicas que revelaram que o maior aporte de nutrientes e metais no reservatório de Barra Bonita ocorre através dos rios Tietê e Piracicaba. Os ensaios de toxicidade aguda com Daphnia similis revelaram toxicidade apenas nos reservatórios à jusante de Barra Bonita, e os ensaios de toxicidade crônica com Ceriodaphnia dubia e Danio rerio demonstraram toxicidade decrescente de Barra Bonita à Três Irmãos.

Em projetos do final da década de 90 e atuais (Hamada, 2008; Tallarico, 2009) a qualidade da água do rio nesse trecho tem sido avaliada e grande esforço tem sido dedicado para melhorar a carga tóxica de afluentes que chegam à ETE 
Suzano (Borrely et al., 2002; Zagatto et al., 1992), incluindo pesquisas com tecnologia avançada para alguns efluentes de origem industrial bastante críticos (Duarte, 1999 e Borrely, 2001). Mais recentemente Tallarico (2009) avaliou o potencial mutagênico e tóxico de amostras de água do Rio Tietê na Região de Suzano.

Em suma, avaliar apenas a coluna d'água pode levar a uma interpretação equivocada da verdadeira situação de um ecossistema aquático, o que torna importante a inclusão da avaliação dos sedimentos em estudos de corpos d'água. Segundo César (2003), para uma avaliação abrangente, deve-se utilizar o maior número possível de rotas de exposição oriundas do sedimento (sedimento integral, água intersticial, elutriato e interface sedimento-água).

\subsection{Qualidade dos sedimentos}

$\mathrm{Na}$ avaliação de recursos hídricos, os sedimentos têm sido um dos mais importantes indicadores do nível de contaminação de ecossistemas aquáticos, pois representam um compartimento potencial para o acúmulo de elementos-traço metálicos e outros contaminantes (geoacumulação), que pode resultar em efeitos ecológicos adversos (Nascimento, 2003).

O Conselho Canadense de Ministros do Meio Ambiente (CCME) foi o pioneiro na determinação de limites para substâncias químicas nos sedimentos, com a publicação de seu Protocolo de Derivação da Qualidade dos Sedimentos para a proteção da vida aquática, em 1995. Os valores estabelecidos pelo CCME foram baseados em dados químicos (concentrações totais) e biológicos (ensaios de toxicidade e parâmetros da comunidade bentônica), sendo estes valores utilizados pela CETESB desde 2002 para monitorar a qualidade dos sedimentos (Araújo, 2005).

No Brasil, o Conselho Nacional do Meio Ambiente publicou em 2004 a resolução CONAMA 344, e a Secretaria do Meio Ambiente, a Resolução SMA 39 as quais dispõe sobre a classificação e disposição do material a ser dragado no país, bem como critérios de qualidade dos sedimentos. Os valores-guia desta resolução foram importados do protocolo do CCME, já com seus valores atualizados em 2002. 
Os valores estabelecidos pelo CCME, bem como pela resolução CONAMA 344 são baseados em concentrações totais e na probabilidade de ocorrência de efeito sobre a biota. O menor limite - TEL "Threshold Effect Level" ou Nível 1 representa a concentração abaixo da qual raramente são esperados efeitos adversos para os organismos. O maior limite - PEL "Probable Effect Level" ou Nível 2 - representa a concentração acima da qual são freqüentemente esperados efeitos adversos para os organismos. Na faixa entre TEL (Nível 1) e PEL (Nível 2) situam-se os valores onde ocasionalmente esperam-se esses efeitos (CCME, 2002, CONAMA 344, 2004).

Atualmente muitos autores têm estudado a contaminação química dos sedimentos buscando determinar o grau de comprometimento dos corpos d'água. Zhang et al., (2009) avaliaram a contaminação por metais pesados nos sedimentos da zona de alagamento do Rio Yangtze na China, enquanto que Yan, (2009), estudou a distribuição espacial e temporal de hidrocarbonetos policíclicos aromáticos na baía de Daya, na China.

No âmbito nacional, Pederzolli (2006) avaliou duas áreas impactadas por diferentes refinarias de petróleo (REFAP e Ipiranga) estado do Rio Grande do Sul, quantificando hidrocarbonetos policíclicos aromáticos (HPA's), matéria orgânica, além de ânions e cátions de interesse. Fronza (2006) determinou a capacidade de liberação de HPA's na Lagoa dos Patos, RS.

Próximo à área deste estudo, Nascimento (2003) determinou a qualidade de sedimentos límnicos e fluviais da Bacia do Tietê, desde sua nascente até sua foz com uma extensão de aproximadamente $800 \mathrm{~km}$, com pontos de coleta em 29 municípios e Silvério (2003) estudou a qualidade dos sedimentos de cinco reservatórios do Rio Tietê (Promissão, Barra Bonita, Bariri, Billings e Rasgão). Estes dois estudos tiveram como objetivo a proposição de valores-referência para metais e metalóides, para esta região. Padial, (2008), estudou a qualidade heteroespacial e a biodisponibilidade de metais na represa de Guarapiranga.

Porém, segundo Baudo et al. (1999) uma avaliação ambiental deve ser realizada com análises químicas e dados ecotoxicológicos, a fim de estabelecer qual poluente é verdadeiramente biodisponível e capaz de interagir e causar efeitos aos organismos vivos. Com isso, entende-se que as análises químicas devem ser combinadas com ensaios de toxicidade, visando determinar os 
possíveis efeitos dos contaminantes à biota local, bem como entender a dinâmica desses contaminantes no ambiente.

Neste sentido, muitos autores quantificaram contaminantes (orgânicos e inorgânicos) nos sedimentos buscando uma correlação entre as concentrações encontradas com a toxicidade apresentada pelos sedimentos. Algumas citações foram organizadas na Tabela 1. 
Tabela 1. Estudos que avaliaram o potencial tóxico e contaminação química em amostras de sedimento, no exterior.

\begin{tabular}{|c|c|c|c|}
\hline Local do estudo & Organismo-teste & Fase estudada & Referência Bibliográfica \\
\hline Rio Po, Itália. & $\begin{array}{c}\text { Ceriodaphnia dubia e Vibrio } \\
\text { fischeri }\end{array}$ & $\begin{array}{l}\text { Sedimento integral e } \\
\text { extratos. Metais, HPA's e } \\
\text { PCB's. }\end{array}$ & VIGANÒ et al., 2003. \\
\hline $\begin{array}{l}\text { Baía de Santander, } \\
\text { Espanha. }\end{array}$ & Vibrio fischeri & $\begin{array}{l}\text { Sedimento integral e água } \\
\text { intersticial. Metais e HPA's. }\end{array}$ & COZ et al., 2007. \\
\hline $\begin{array}{l}\text { Rios da região de Ozark, } \\
\text { Estados Unidos }\end{array}$ & $\begin{array}{c}\text { Hyalella azteca e } \\
\text { Ceriodaphnia dubia. }\end{array}$ & $\begin{array}{l}\text { Sedimento e água } \\
\text { intersticial. Metais. }\end{array}$ & BESSER et al., 2009. \\
\hline
\end{tabular}




\subsection{Metais e compostos aromáticos (HPA's) no ambiente aquático}

Dentre os poluentes, os metais potencialmente tóxicos representam um grupo especial, pois não são degradados química ou biologicamente, de forma natural. A presença de metais potencialmente tóxicos no ambiente aquático e em concentrações elevadas pode causar a morte de animais e organismos fotossintetizantes (Rocha et al., 2009).

De acordo com Silvério et al. (2005) e Mozeto \& Zagatto (2006) são muitos os fatores que influenciam a biodisponibilidade de metais, entre eles: a concentração de oxigênio, pois em ambientes anóxicos, o sulfeto resultante da decomposição de matéria orgânica pode controlar a disponibilidade de íons metálicos livres, reagindo com eles e formando sais insolúveis, potencialmente não biodisponíveis; $\mathrm{pH}$, pois valores acima de 6 favorecem a adsorção de cátions metálicos.

Segundo Mariani (2006), a granulometria também é importante, pois partículas finas (argila e silte) têm maior capacidade de adsorção e remoção de metais. Assim, qualquer fator que cause uma mudança nas condições do ambiente sedimentar, pode também influenciar na disponibilidade dos metais.

Altas concentrações de metais afetam organismos bentônicos, podendo bioconcentrar esses contaminantes, causando efeito direto na cadeia alimentar aquática, mesmo não havendo remobilização dos metais presentes no sedimento por mudanças nas condições ambientais (Mozeto \& Zagatto, 2006).

Os metais também encontram-se na lista de contaminantes considerados como poluentes prioritários nos sedimentos de ecossistemas de água doce e que têm concentrações máximas estabelecidas na Resolução CONAMA 344 de 2004, que se refere às atividades de dragagem.

Segundo muitos autores o maior aporte de metais ao ambiente aquático é proveniente de atividades humanas, mineração, lançamento de efluentes domésticos e industriais (metalurgia, papel e celulose, farmacêutica, entre outras), atividades de galvanoplastia e descarte inapropriado de produtos que utilizam metais em sua manufatura (Lamparelli, 2001; Manahan, 2001; Weiner et al., 2002; Nascimento, 2003; Campagna, 2005). 
A seguir são apresentadas informações sobre os principais metais encontrados em sedimentos de ecossistemas aquáticos.

Os metais podem ser classificados como "essenciais" quando participam do metabolismo dos seres vivos e como "não essenciais" quando não fazem parte dele. Embora os metais cobre, zinco, cromo e níquel sejam considerados essenciais e façam parte do metabolismo da maior parte dos seres vivos, em altas concentrações podem causar efeitos negativos.

Os elementos cádmio, chumbo, mercúrio e arsênio são considerados não essenciais, tendo efeito tóxico quando ingeridos ou absorvidos. Entre os metais considerados não essenciais, o mercúrio $(\mathrm{Hg})$ possui elevada toxicidade, gerando grande preocupação como poluente. Esse elemento é encontrado como traço em muitos minerais (rochas continentais contêm em média cerca de 80 ppb).

Lodos residuais do tratamento de esgotos são importantes fontes de contaminação por mercúrio e muitas vezes chegam a conter até 10 vezes a concentração desse metal encontrada em águas naturais. No ambiente aquático, os sais de $\mathrm{Hg}$ são rapidamente metilados pela ação de microrganismos, originando metil-mercúrio ( $\mathrm{MeHg}$ ), que é potencialmente mais tóxico, além de assimilado mais rapidamente pela biota, podendo ser acumulado nos sedimentos e transferido desse compartimento para os organismos bentônicos e para os peixes (Abessa, 2002).

Outro metal não-essencial encontrado em ambientes aquáticos é o cádmio (Cd). É considerado um mineral raro, ocorrendo na crosta terrestre em uma concentração média de $0,2 \mathrm{mg} / \mathrm{kg}^{-1}$ (Nascimento, 2003).

O cádmio consta na lista de poluentes tóxicos persistentes bioacumulativos, da Agência de Proteção Ambiental dos Estados Unidos (USEPA), que criou regulamentações para diminuição e controle do seu uso. Este metal possui potencial carcinogênico para humanos. No sedimento de ecossistemas aquáticos, o metal adsorvido à superfícies minerais como argila ou materiais orgânicos é mais facilmente liberado quando há distúrbios ambientais, do que quando esta associado a compostos insolúveis (Padial, 2008).

O chumbo $(\mathrm{Pb})$ é outro metal não-essencial, altamente tóxico, cujos efeitos biológicos conhecidos são sempre deletérios (Pattee \& Pain, 2002). Segundo os 
mesmos autores, a absorção de chumbo por organismos aquáticos pode ocorrer através da pele, brânquias, além da via alimentar (intestinos). Os fatores que influenciam a taxa de absorção desse metal são a forma química e sua concentração na água e nos sedimentos, sendo que a forma orgânica é a mais tóxica.

O cromo ( $\mathrm{Cr}$ ) é também considerado um metal essencial quando em pequenas concentrações. Em altas concentrações pode apresentar efeitos tóxicos a organismos aquáticos. Pode ser encontrado em diversas formas no ambiente aquático, sendo as duas principais o cromo hexavalente $(+6)$, mais solúvel em água doce e 100 vezes mais tóxico à biota que o cromo trivalente $(+3)$, que apresenta maior capacidade de complexação (Gusmão, 2004).

Segundo Nascimento (2003), o arsênio (As) é um metalóide de ocorrência natural, com ampla distribuição na superfície terrestre, ocorrendo na maioria das rochas em concentrações que variam de 2 a $5 \mu \mathrm{g} / \mathrm{g}$. No ambiente aquático, ocorre principalmente em sedimentos argilosos podendo atingir $13 \mu \mathrm{g} / \mathrm{g}$. Possui potencial carcinogênico para seres humanos, além apresentar efeitos agudos e crônicos nos sistemas respiratório, cardiovascular, gastrintestinal e nervoso quando ingerido ou absorvido por animais.

O níquel $(\mathrm{Ni})$ é um metal relativamente abundante, presente na crosta terrestre com um valor médio de $56 \mu \mathrm{g} / \mathrm{g}$. Cerca de metade da produção de níquel é utilizada em ligas de ferro (Lamparelli, 2001).

O cobre $(\mathrm{Cu})$ é considerado um metal essencial em baixas concentrações, pois está presente em praticamente todos os organismos vivos. Em ambientes aquáticos o cobre ocorre na forma solúvel e mais frequentemente nas formas particulada e coloidal. A fração solúvel pode conter tanto o íon livre, como o cobre complexado a ligantes orgânicos e inorgânicos (Gusmão, 2004).

O zinco $(\mathrm{Zn})$ é um metal amplamente distribuído na natureza, ocorrendo nos solos e, como nutriente essencial, nas plantas em geral. Nos solos, os valores de zinco em áreas não poluídas variam de 10 a $30 \mu \mathrm{g} / \mathrm{g}$. O uso do zinco em sua forma metálica ou em sais do metal é comum nos mais diversos ramos industriais (Lamparelli, 2001). 


\section{Hidrocarbonetos Policíclicos Aromáticos (HPA's)}

Outros tipos de contaminantes normalmente acumulados em sedimentos de água doce são os Hidrocarbonetos Policíclicos Aromáticos, ou HPA's, que são considerados poluentes orgânicos prioritários em estudos ambientais, pois algumas dessas substâncias apresentam elevada toxicidade e são precursoras de efeitos mutagênicos (Meire et al, 2007).

Os HPA's são compostos orgânicos que contêm apenas carbono e hidrogênio, de dois ou mais anéis benzênicos fundidos, produzidos naturalmente ou por processos industriais (Abessa, 2002). Fontes naturais de HPA's incluem incêndios florestais, escoamento de petróleo e vulcões. Entretanto, as fontes antropogênicas dominam a entrada de HPA's na natureza (Wright \& Welbourn, 2002), sendo as maiores emissões de HPA's provindas de processos industriais ligados à produção de aço e alumínio, da exaustão de incineradores de rejeito e por resíduos sólidos industriais e principalmente pela queima de combustíveis fósseis (Wright \& Welbourn, 2002; Meire et al., 2007). Assim, as maiores concentrações de HPA's são observadas em grandes centros urbanos.

Devido a sua toxicidade à biota, alguns HPA's são classificados como contaminantes prioritários pela USEPA (EPA, 1986) em estudos de contaminação de ambientes aquáticos. Segundo Chapman (1995), os hidrocarbonetos podem ser rapidamente metabolizados por alguns organismos, resultando muitas vezes em efeitos tóxicos, outros organismos porém, não conseguem metabolizar esses compostos, bioacumulando-os.

Os HPA's de baixo peso molecular (dois ou três anéis) apresentam maior solubilidade, sendo mais facilmente transportados pela água pois possuem baixa adsorção nas partículas do solo (CETESB, 2008) e toxicidade aguda significativa, enquanto que os HPA's de maior peso molecular possuem maior probalidade de adsorção (CETESB 2008) e normalmente apresentam efeitos carcinogênicos. Entre os HPA's que apresentam elevada toxicidade aguda estão: naftaleno, antraceno, fluoreno, acenafteno, fenantreno, fluoranteno, pireno e criseno.

Segundo Wright \& Welbourn (2002) e Meire et al., (2007), os HPA's são compostos relativamente hidrofóbicos e lipofílicos (característica que facilita sua passagem pela membrana celular, ocasionando bioacumulação). Devido a sua 
hidrofobicidade, uma vez no ambiente aquático, os HPA's são rapidamente adsorvidos no material particulado orgânico e inorgânico e acabam por depositarse nos sedimentos (Mozeto \& Zagatto, 2006; Cullen et al., 1994).

Segundo Ignácio (2007) e Reible et al. (1996), embora os HPA's possuam uma boa estabilidade, devido a sua persistência nos sedimentos, estes podem ser redisponibilizados para a coluna d'água e para a biota por meio de processos naturais como difusão, bioturbação, tempestades, ação de correntes, bem como por atividades antrópicas como dragagens.

A granulometria e o teor de carbono dos sedimentos são fatores muito importantes para a acumulação e persistência dos hidrocarbonetos. Os sedimentos mais ricos em frações finas (silte e argila) são geralmente mais ricos em HPA's, pois apresentam maior capacidade de retenção de matéria orgânica e, conseqüentemente, dos contaminantes (Ignácio, 2007).

\subsection{Amônia}

Amônia é um termo geral para designar as espécies amônia e amônio. A espécie amônia $\left(\mathrm{NH}_{3}\right)$ também é denominada amônia não-ionizada ou amônia molecular. Já o íon amônio $\left(\mathrm{NH}_{4}{ }^{+}\right)$, por sua vez, recebe também a denominação de amônia ionizada (Silva \& Jardim, 2007).

Segundo Ankley et al., (1990) e Chapman \& Wang (2001), a amônia pode ocorrer naturalmente porém, em alguns casos, pode ser diretamente introduzida no ambiente ou ter sua concentração aumentada como resultado de atividades antrópicas e, por apresentar elevada toxicidade, pode interferir na interpretação do efeito tóxico causado por contaminantes antropogênicos. Por esse motivo, é importante realizar o monitoramento dos níveis de amônia em ensaios de toxicidade.

A amônia não-ionizada é aproximadamente cem vezes mais tóxica às espécies aquáticas que a forma ionizada. Essa maior toxicidade certamente se deve a capacidade de difusão da amônia não-ionizada pela membrana epitelial das espécies aquáticas, dificultando, por exemplo, mecanismos naturais de eliminação dessa substância desses organismos (USEPA, 1999). 


\subsection{Integração dos dados de toxicidade e contaminação ambiental}

Nos últimos anos, a utilização das análises multivariadas tem se tornado cada vez mais frequentes, principalmente em estudos que envolvem o ambiente marinho e estuarino (Cesar et al., 2009; Riba et al., 2003, DelValls et al. 2002; DelValls et al., 1998, DelValls \& Chapman, 1998). Elas têm como objetivo estabelecer uma relação entre a contaminação ambiental, alterações na comunidade bentônica e efeitos ecotoxicológicos, além de estabelecer intervalos de concentrações de contaminantes que estejam associados a efeitos biológicos.

Segundo Riba et al., (2002), a utilização desta ferramenta permite associar a contaminação química com os efeitos biológicos observados na região de estudo. No Brasil, Almeida \& Rocha (2006) utilizaram análises multivariadas para correlacionar os dados de toxicidade, comunidade bentônica e contaminação dos reservatórios de Billings, Rasgão, Barra Bonita, Bariri e Promissão, obtidos no projeto Qualised.

Neste trabalho, foram analisadas amostras de sedimento integral, elutriato e água intersticial provenientes de cinco pontos da região do Alto Tietê utilizando-se Hyalella azteca, Ceriodaphnia dubia e a bactéria Vibrio fischeri. A seleção de três organismos-teste para este estudo deveu-se a dois fatores importantes: avaliação com classes de organismos diferenciadas e a utilização de organismos cujo significado para os sedimentos seja abrangente e que estejam contemplados em outros estudos de ambiente aquático brasileiro. 


\section{METODOLOGIA}

Este trabalho estimou o potencial tóxico de sedimentos coletados no Rio Tietê, na região que compreende os municípios de Salesópolis até Suzano, Estado de São Paulo, no período de setembro de 2007 a fevereiro de 2009.

Foram realizadas análises de toxicidade em três diferentes compartimentos do sedimento: sedimento integral, elutriato e água intersticial dos sedimentos, além de amostras de água. Foram realizadas ainda, quantificação de contaminantes inorgânicos (metais), orgânicos (HPA's) e amônia, presentes nas amostras de sedimentos, conforme apresentado pela Figura 3.

A Figura 3 apresenta o fluxograma da metodologia utilizada, partindo da coleta dos sedimentos, separação em alíquotas, análises realizadas até o tratamento dos resultados. 


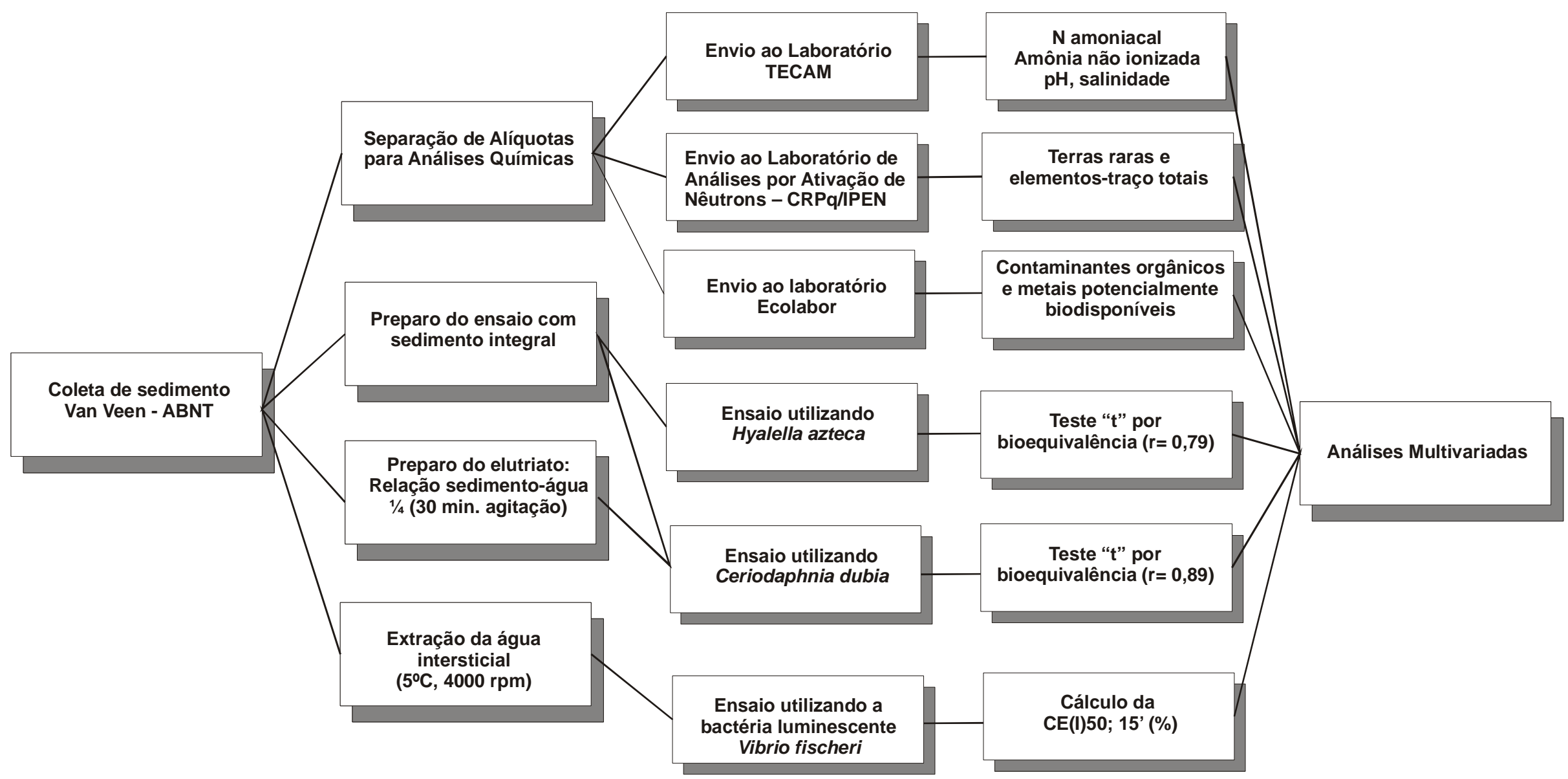

Figura 3. Fluxograma da metodologia utilizada na avaliação da qualidade dos sedimento 


\section{1 Área de Estudo}

A área de estudo compreendeu os municípios de Salesópolis, Biritiba-Mirim, Mogi das Cruzes e Suzano, no estado de São Paulo, conforme a Figura 4. Foram selecionados cinco pontos de amostragem, previamente definidos e referenciados com auxílio do sistema Global Positioning System (GPS), utilizando aparelho de marca GARMIN ${ }^{\circledR}$. As coordenadas geográficas estão apresentadas na Tabela 2, incluindo uma referência que serviu de apoio à localização dos pontos de coleta.

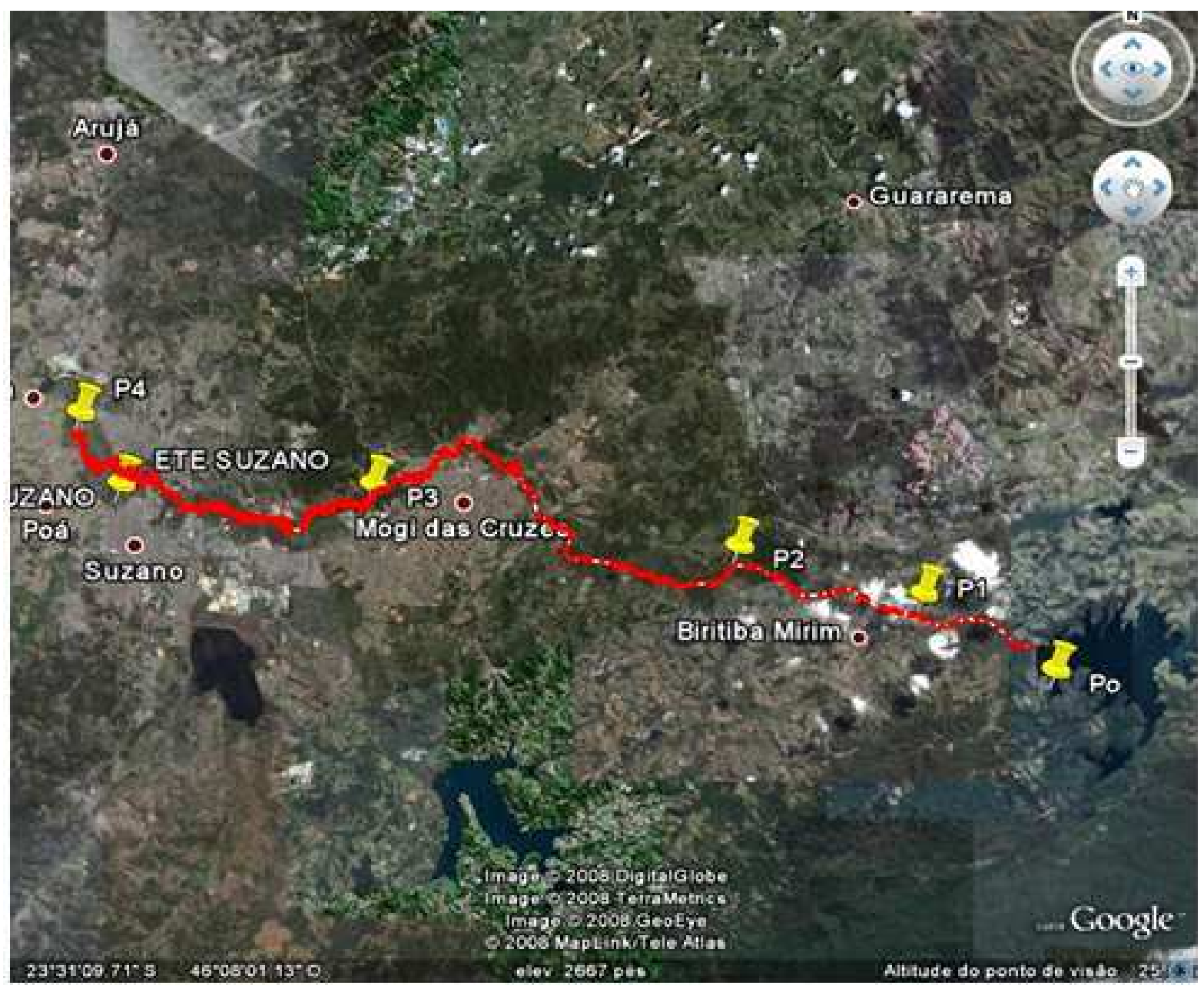

Figura 4. Localização dos pontos de amostragem no reservatório e na calha do Rio Tietê. 
Tabela 2 - Identificação dos pontos de amostragem, suas referências e coordenadas geográficas.

\begin{tabular}{ccc}
\hline & Pontos de amostragem e referência & Coordenadas \\
\hline \multirow{2}{*}{ P0 } & Portinho - Reservatório da Ponte Nova, & $23^{\circ} 35^{\prime} 36^{\prime \prime}$ \\
& aprox. 80m do vestiário & $45^{\circ} 58^{\prime} 04^{\prime \prime}$ \\
\hline \multirow{2}{*}{ P1 } & Estrada Mogi-Salesópolis, km 75 Biritiba & $23^{\circ} 33^{\prime} 54^{\prime \prime}$ \\
& Mirim, prox. A VCN Mineradora & $46^{\circ} 01^{\prime} 00^{\prime \prime}$ \\
\hline \multirow{2}{*}{ P2 } & Estrada do Rio Acima, B. Mirim. Deck na & $23^{\circ} 32^{\prime} 51^{\prime \prime}$ \\
& margem esquerda ao lado da ponte. & $46^{\circ} 05^{\prime} 10^{\prime \prime}$ \\
\hline \multirow{2}{*}{ P3 } & Ponte no sentido Mogi - Suzano, próx. ac & $23^{\circ} 31^{\prime} 32^{\prime \prime}$ \\
& Parque Leon Feffer & $46^{\circ} 13^{\prime} 25^{\prime \prime}$ \\
\hline \multirow{2}{*}{ P4 } & Suzano, primeiro acesso ao rio depois da & $23^{\circ} 29^{\prime} 58^{\prime \prime}$ \\
& ETE - Suzano & $46^{\circ} 20^{\prime} 01^{\prime \prime}$ \\
\hline
\end{tabular}

$\mathrm{Na}$ sequência, são apresentadas as fotografias dos locais onde foram realizadas as coletas de sedimento e água, partindo do Reservatório de Ponte Nova até a cidade de Suzano (Figuras 5 até 9).

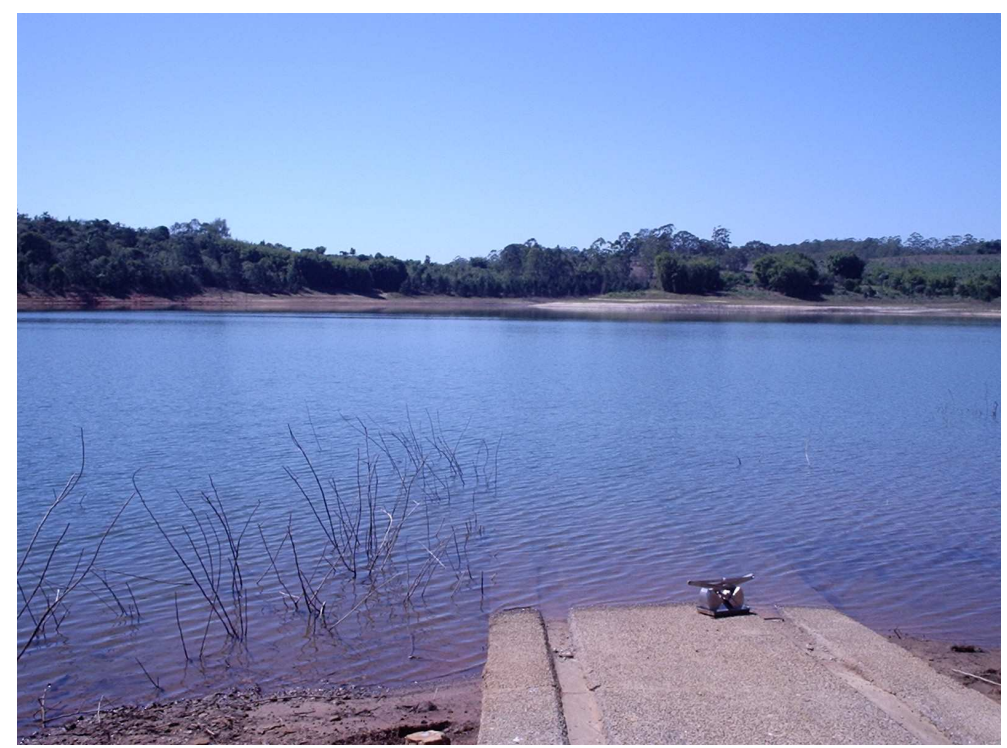

Figura 5 - Fotografia do Portinho, Reservatório de Ponte Nova, Salesópolis (P0). 


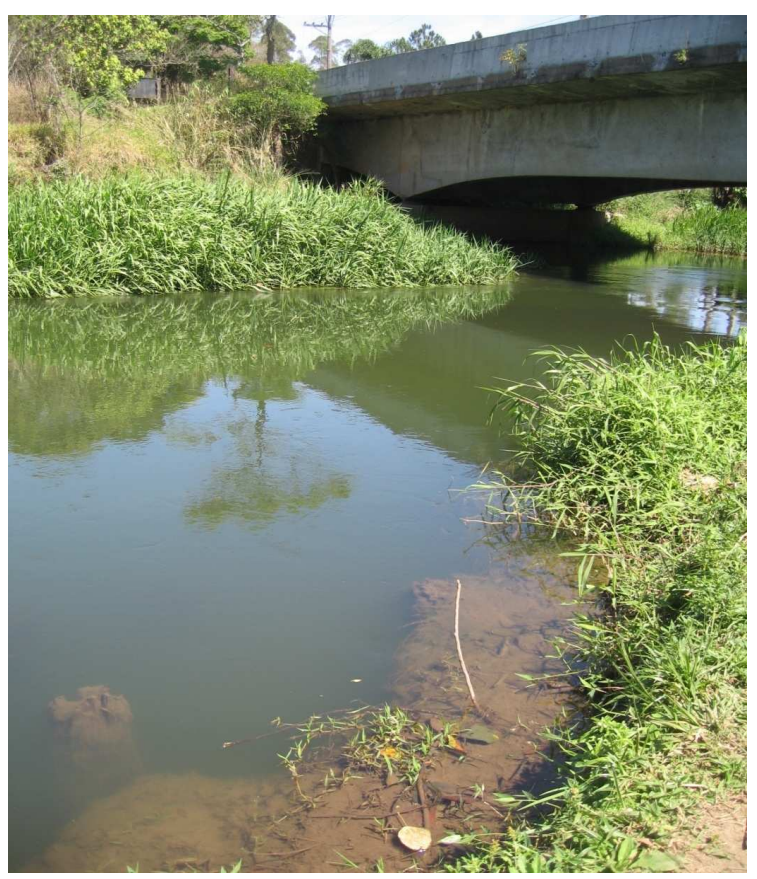

Figura 6. Fotografia do Rio Tietê, próximo à cidade de Biritiba-Mirim (P1).

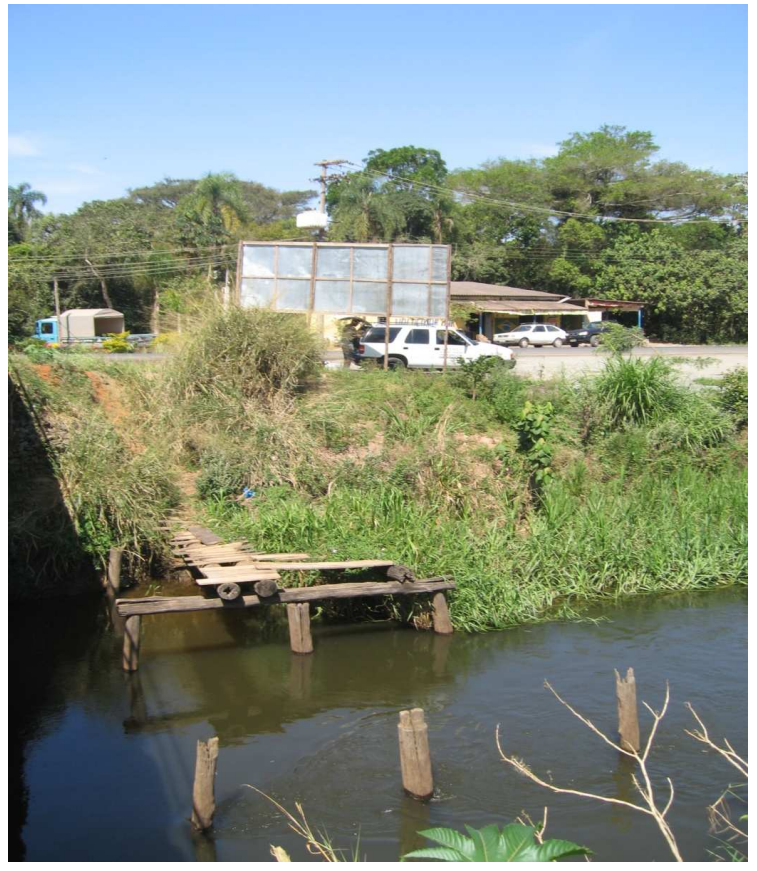

Figura 7. Fotografia do Rio Tietê, estrada do Rio Acima, Biritiba-Mirim (P2). 


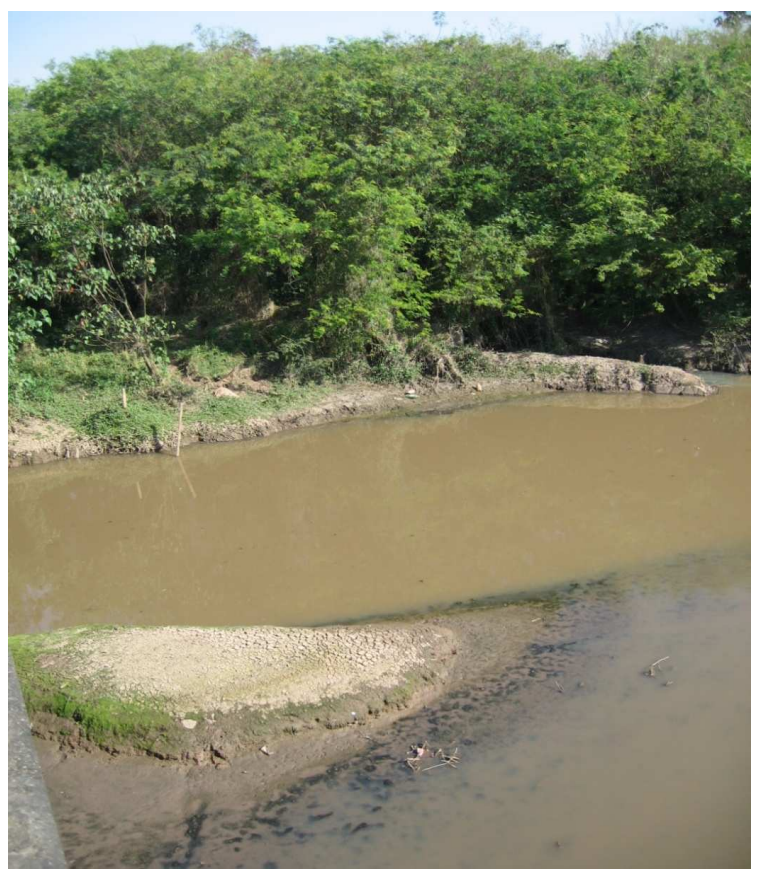

Figura 8. Fotografia do Rio Tietê, Parque Leon Feffer, Mogi das Cruzes (P3).

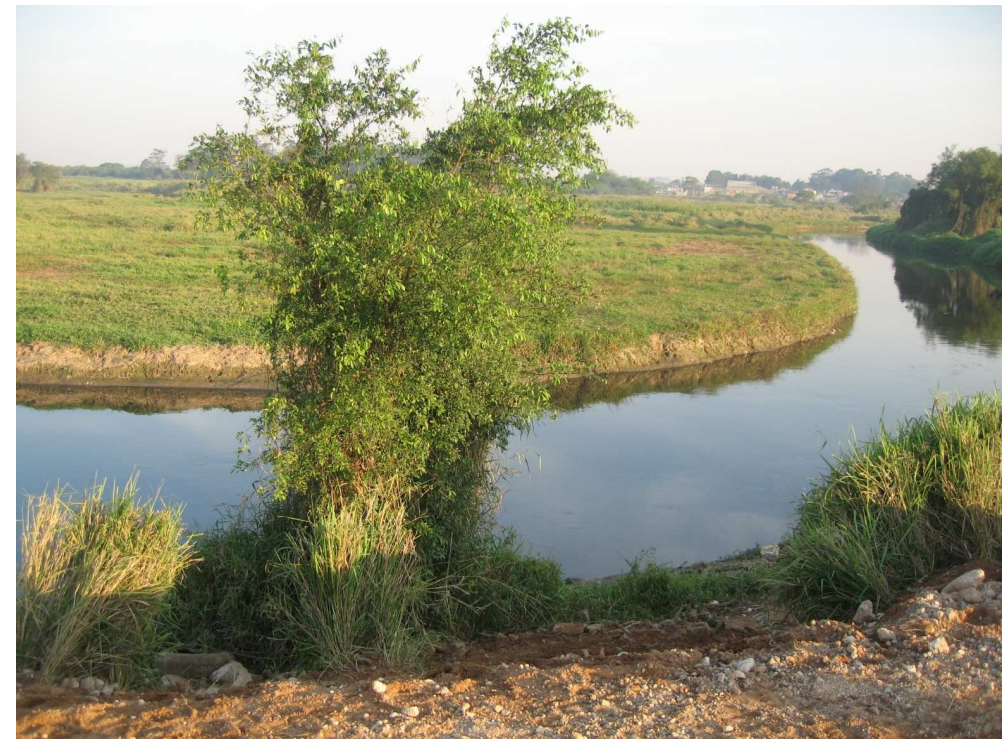

Figura 9. Fotografia do Rio Tietê após passagem pela ETE Suzano (P4). 


\subsection{Coleta de sedimento e água}

Os procedimentos de coleta e preservação das amostras de sedimento e água foram realizados de acordo com a norma de preparo e preservação de amostras ABNT-NBR15469 (2007). Foi utilizado um coletor van Veen na amostragem dos sedimentos (Figura 10) e, um balde de aço inoxidável para tomada de água do Rio Tietê.

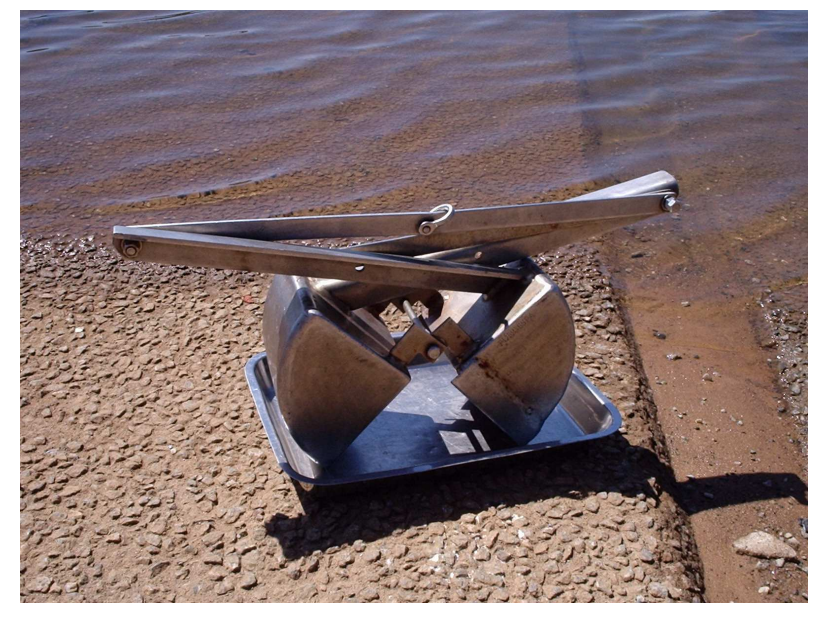

Figura 10. Draga van Veen.

O planejamento de amostragens deste estudo visou abranger dois períodos de seca (coletas 1 e 3 ) e dois períodos chuvosos (coletas 2 e 4), conforme apresentado na Tabela 3.

Tabela 3. Período de realização das coletas dos sedimentos.

\begin{tabular}{cccc}
\hline Coleta 1 & Coleta 2 & Coleta 3 & Coleta 4 \\
\hline Setembro de 2007 & Março de 2008 & Setembro de 2008 & Fevereiro de 2009
\end{tabular}

Nas coletas 3 e 4, foram incluídas também amostras de água do Rio Tietê para realização de ensaios de toxicidade crônica com Ceriodaphnia dubia, a fim de verificar a toxicidade crônica deste compartimento. 
Assim que foram coletadas e durante o transporte, as amostras de sedimento e água foram mantidas refrigeradas em caixas de isopor com gelo. Em laboratório, as amostras de sedimento foram fracionadas em 3 alíquotas.

Uma das alíquotas de sedimento foi destinada aos ensaios de toxicidade e foi mantida em refrigerador (temperatura inferior a 10ํ $\mathrm{C}$ ). Posteriormente, foi realizada a extração das fases aquosas do sedimento bem como o preparo da amostra para os ensaios com sedimento integral e interface sedimento-água.

Uma segunda alíquota foi armazenada em frascos de vidro âmbar e, posteriormente, enviada ao laboratório ECOLABOR Comércio e Consultoria Ltda. para a quantificação dos contaminantes orgânicos. A terceira alíquota foi congelada para posterior tratamento e envio ao Laboratório de Análise por Ativação Neutrônica, do Centro do Reator de Pesquisas no IPEN (CRPq - IPEN /CNEN-SP) para quantificação de elementos-traço, terras-raras e mercúrio total. Nas coletas 1 e 4 não foram realizadas as análises químicas, dispensando o fracionamento das amostras.

Assim que chegaram ao laboratório, as amostras de água foram congeladas até a realização dos ensaios de toxicidade.

\subsection{Ensaios de toxicidade}

Os ensaios de toxicidade foram realizados em amostras de sedimento integral, no elutriato do sedimento, na água intersticial e também nas amostras de água do rio coletadas em setembro de 2008 e fevereiro de 2009. Todos os ensaios foram realizados no Laboratório de Ensaios Biológicos Ambientais do Centro de Tecnologia das Radiações, CTR/IPEN.

Os organismos-teste utilizados neste trabalho foram a Hyalella azteca (Figura 11a), para os ensaios com sedimento integral, e Ceriodaphnia dubia (Figura 11b) para os ensaios com elutriato, sedimento integral e amostras de água do rio. A bactéria luminescente Vibrio fischeri (Figura 11c) foi empregada apenas na avaliação da água intersticial extraída dos sedimentos.

Os organismos $C$. dubia e $H$. azteca utilizados neste trabalho foram cultivados no Laboratório de Ensaios Biológicos Ambientais do Centro de Tecnologia das Radiações, CTR/IPEN de acordo com as Normas técnicas ABNT NBR 13373 (2005) e 
ABNT NBR 15470 (2007), respectivamente. Os cultivos foram mantidos em água natural com dureza corrigida para $45 \pm 2 \mathrm{mg} / \mathrm{L} \mathrm{CaCO}_{3}$.

O alimento fornecido para o organismo $C$. dubia tanto nos cultivos, quanto nos ensaios, foi a alga Pseudokirchneriella subcaptata (na concentração de $2,0 \times 10^{6}$ células por organismos, aproximadamente), complementado com fermentado de ração de truta e leveduras $(\mathrm{RL})$. No caso do organismo $H$. azteca o alimento utilizado foi a ração de peixes em flocos Basic da Alcon ${ }^{\circledR}$, complementada com RL.

Durante a execução dos ensaios de toxicidade, os parâmetros pH e oxigênio dissolvido foram mensurados a cada troca e ao fim do ensaio.

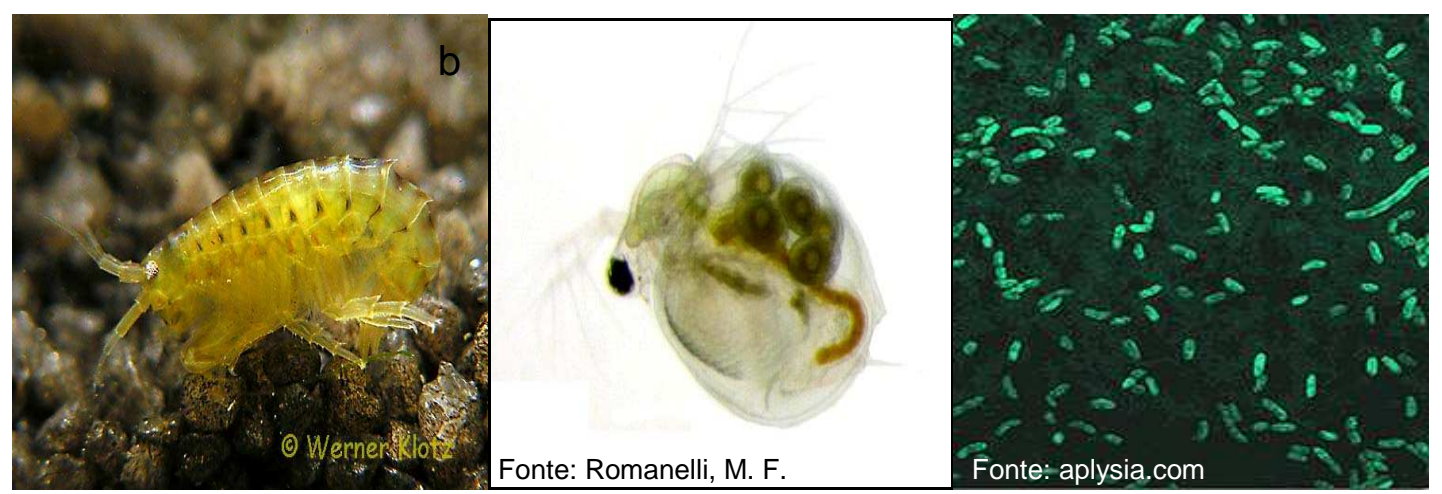

Figura 11. Organismos utilizados nos ensaios de toxicidade (a. H. azteca, b. C. dubia; c. V. fischeri)

\subsubsection{Ensaios de toxicidade com sedimento integral - Hyalella azteca}

A realização dos ensaios com sedimento integral utilizando Hyalella azteca seguiu os procedimentos descritos na Norma ABNT NBR 15470 (2007), com pequenas modificações onde, a proporção utilizada foi de uma parte de sedimento para 4 partes de água. Optou-se por esta proporção por ser a mesma utilizada nos ensaios com sedimento integral (C. dubia) e no preparo do elutriato.

Foram transferidos $100 \mathrm{~mL}$ de sedimento bruto para o recipiente teste (béqueres de $500 \mathrm{~mL}$ ), seguido da adição cuidadosa de $400 \mathrm{~mL}$ de água de diluição (a mesma água utilizada no cultivo dos organismos), evitando-se a ressuspensão do sedimento. Esse sistema foi mantido em repouso por $12 \mathrm{~h}$. Posteriormente, 10 organismos jovens, com idade entre 7 e 14 dias, foram adicionados a cada uma das 
4 réplicas, totalizando 40 organismos para cada ponto (Figura 12 a e b e Figura 13 a e b). Em paralelo, foi realizado um controle com 4 réplicas apenas com água de diluição e 10 organismos em cada uma, com adição de uma malha de "nylon" com aproximadamente $3,0 \mathrm{~cm}^{2}$ como substrato artificial.
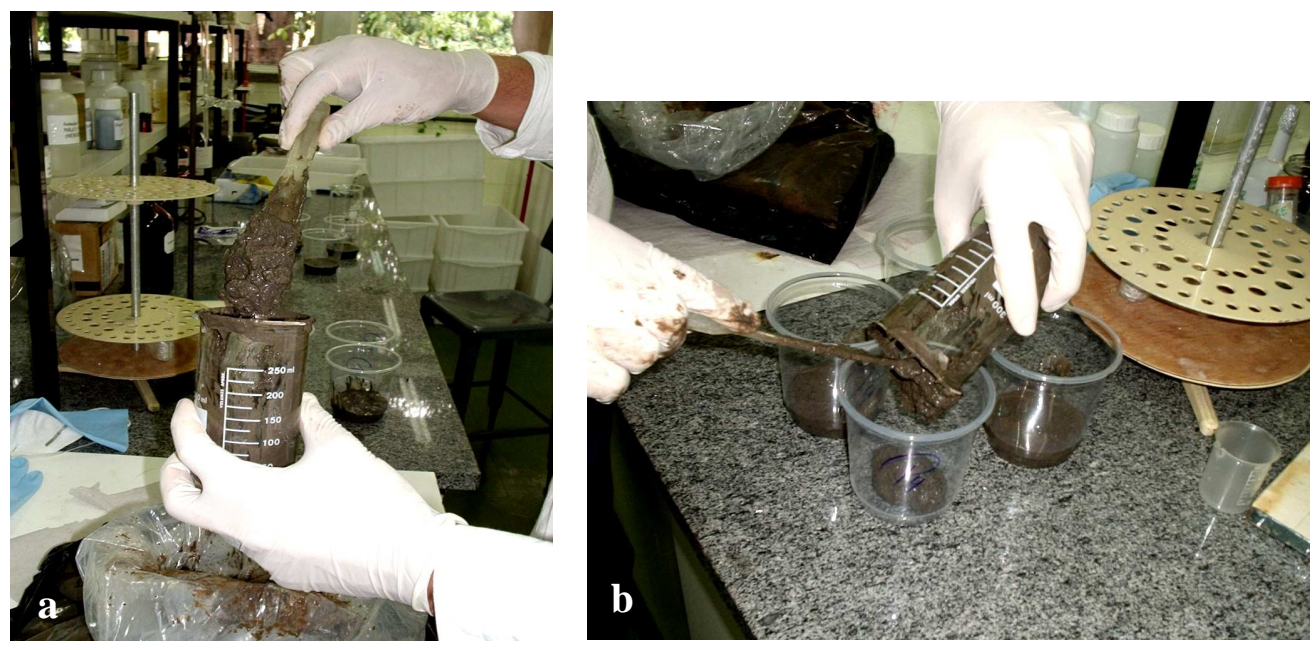

Figura 12 a e b. Preparo do sedimento para ensaios com Hyalella azteca.

Durante os ensaios, a alimentação foi fornecida diariamente. A água sobrejacente foi trocada a cada dois dias, sendo retirada por sifonamento, utilizando uma mangueira de silicone com malha de "nylon" na ponta a fim de evitar a perda dos organismos (Figura 14 a e b).
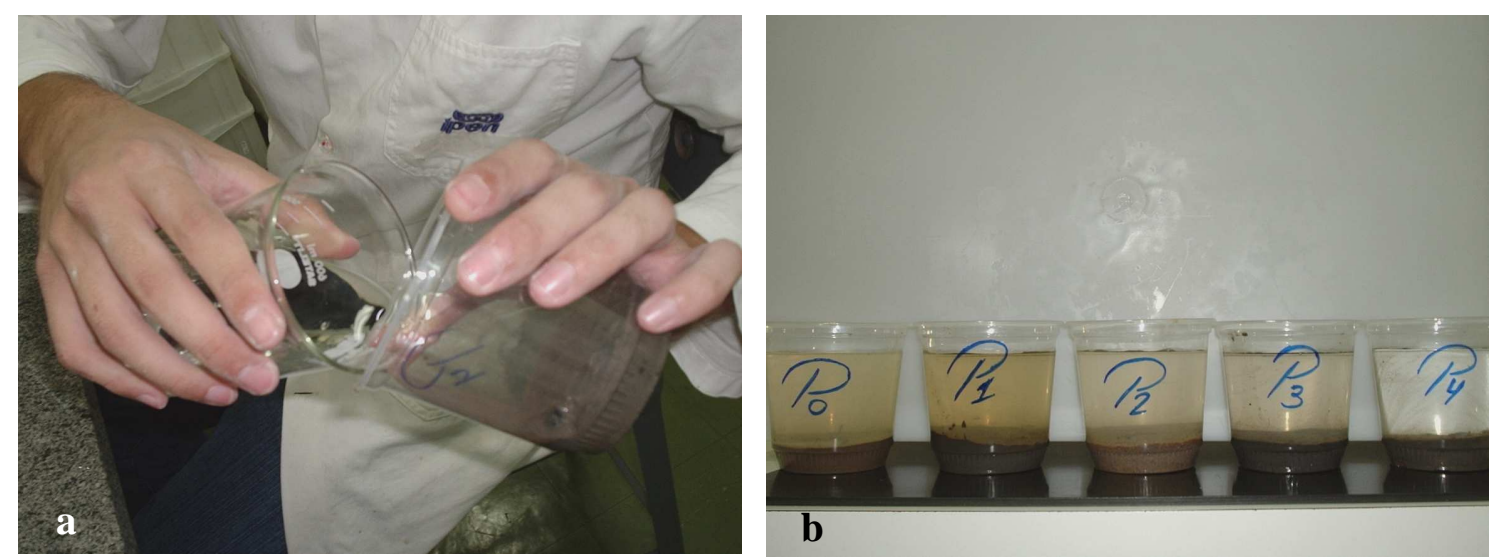

Figura 13 a e b. Adição da água de diluição e réplicas em decantação. 

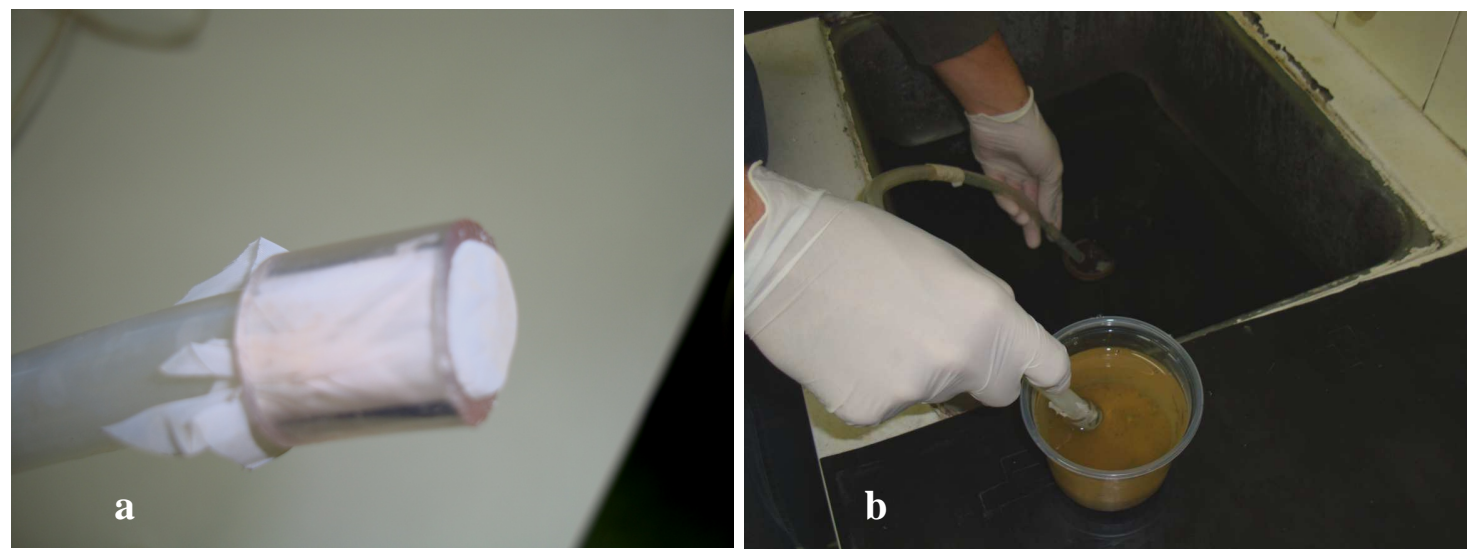

Figura 14. Detalhe da proteção da mangueira de silicone e sua utilização na sifonagem realizada nas trocas de água durante o ensaio.

O período de exposição da $H$. azteca foi 10 dias. Ao final foi realizada a contagem dos organismos vivos em cada réplica (Figura 15 a e b).
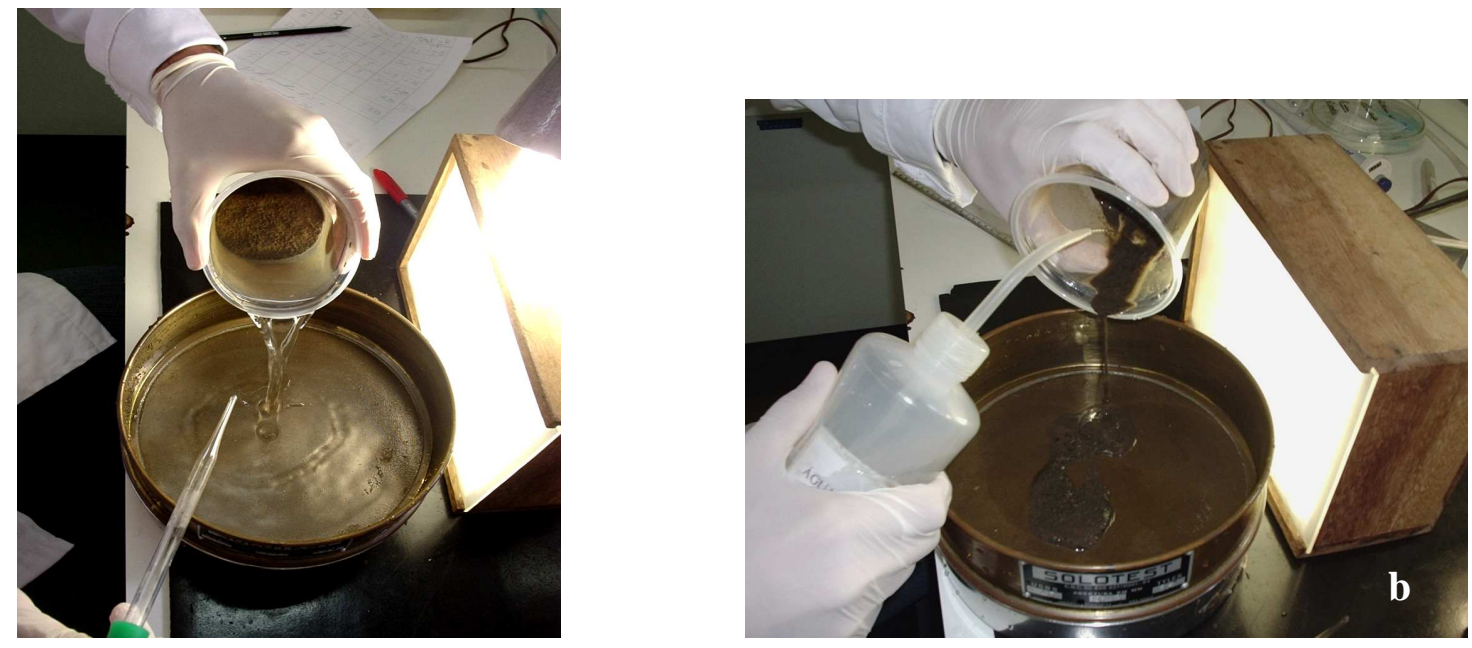

Figura 15. Contagem dos organismos sobreviventes da exposição.

Os organismos desaparecidos foram considerados mortos. A sobrevivência dos organismos de cada ponto foi depois comparada à dos organismos do controle.

A sensibilidade dos organismos-teste foi avaliada mensalmente, utilizando-se como substância-referência o cloreto de potássio $(\mathrm{KCl})$ nas concentrações de 0, 140, 175, 220, 270 e $340 \mathrm{mg} / \mathrm{L}$. Os ensaios de sensibilidade foram também realizados seguindo a metodologia descrita na Norma ABNT 15470 (2007).

Para cada concentração de $\mathrm{KCl}$, foram preparados 10 recipientes com $20 \mathrm{~mL}$ de solução-teste, sendo adicionado um substrato artificial (malha de "nylon" 
com aproximadamente $1,0 \mathrm{~cm}^{2}$ ). $O$ mesmo procedimento foi realizado no preparo do controle, somente com água de cultivo. Após a adição do substrato artificial, os recipientes-teste foram colocados na câmara de incubação por 30 minutos para estabilização da temperatura, a $25^{\circ} \mathrm{C}$. Posteriormente foi adicionado um organismo em cada recipiente-teste, sendo fornecido alimento $(R L)$ no início do ensaio e após 48 horas. Ao fim de 96 horas o ensaio foi finalizado e foram contados os organismos sobreviventes. As concentrações de efeito foram calculadas com programa Trimmed Spearman Karber (ABNT,2007) e os valores obtidos foram utilizados para compor a carta-controle de sensibilidade do organismo, que também é útil na avaliação da metodologia do ensaio e na validação de todo o experimento.

\subsubsection{Ensaios de toxicidade com sedimento integral - Ceriodaphnia dubia}

A realização dos ensaios com sedimento integral utilizando Ceriodaphnia dubia seguiram os procedimentos descritos na Norma Técnica ABNT NBR 13373 (2005), com modificações propostas por Burton et al., (2002) específicas para ensaios com amostras de sedimento integral. Cinco $\mathrm{mL}$ da amostra de sedimento bruto foram introduzidos em béqueres de $40 \mathrm{~mL}$ e adicionados $20 \mathrm{~mL}$ de água de diluição. A transferência de água nas réplicas foi realizada cuidadosamente a fim de evitar a ressuspensão do sedimento (Figura 16 a e b). Após o repouso do sistema por 24h, um organismo jovem (neonato) foi adicionado a cada uma das réplicas, totalizando 10 organismos para cada ponto de amostragem. Em paralelo foi montado um controle também com 10 réplicas apenas com água de diluição. 

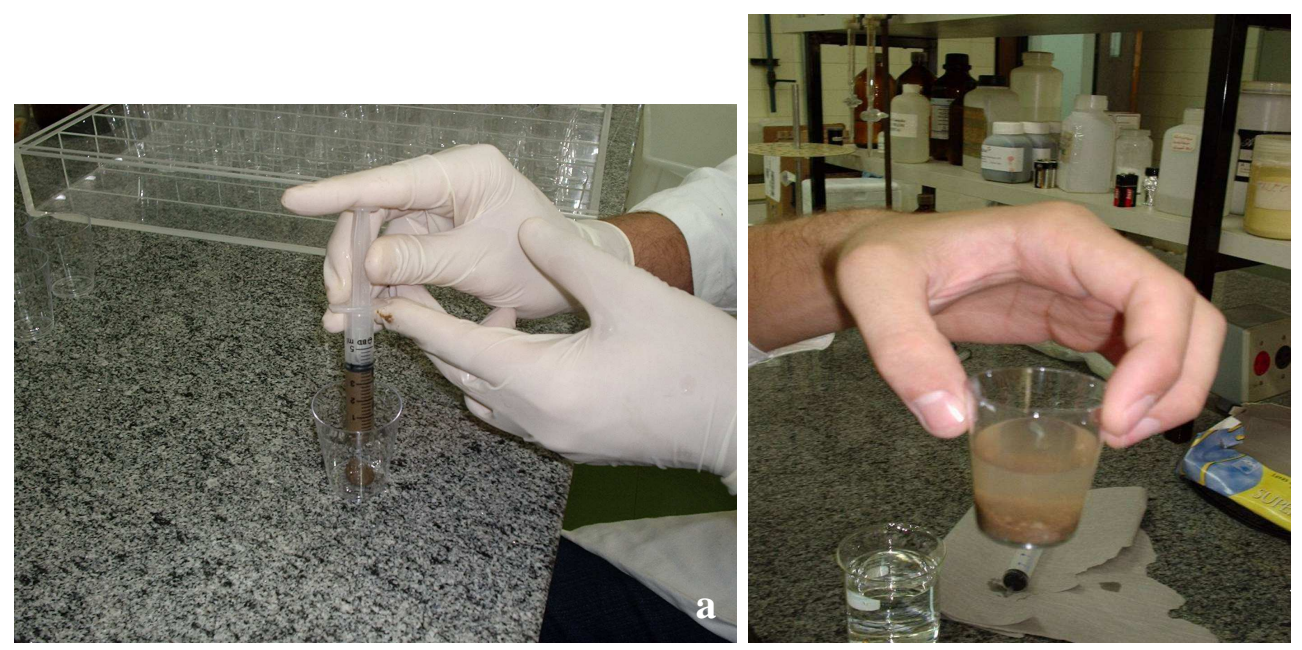

Figura 16. Preparo das réplicas para o ensaio de toxicidade com $C$. dubia.

O alimento foi fornecido diariamente e, a troca da água sobrejacente foi realizada a cada dois dias. A cada troca de água e no encerramento do ensaio (duração de sete dias), foram contados os neonatos de cada réplica. Os resultados permitiram comparar o potencial de reprodução de cada ponto, àquele obtido no controle.

\subsubsection{Ensaios de toxicidade com elutriato - Ceriodaphnia dubia}

O elutriato foi obtido pela agitação da mistura de uma parte de sedimento (aproximadamente $150 \mathrm{~mL}$ ) com quatro partes de água de diluição (600 mL), durante 30 minutos, utilizando um agitador magnético (Figura 17 a e b), de acordo com os procedimentos descritos na Norma ABNT NBR15469 (2007). Essa mistura foi submetida à decantação por duas horas e apenas o sobrenadante foi utilizado nos ensaios de toxicidade. Quando não foi obtida decantação total do material suspenso, a mistura foi centrifugada a $4.000 \mathrm{rpm}$, por cinco minutos. O sobrenadante resultante foi divido em 3 alíquotas e congelado até a realização dos ensaios.

Para a realização do ensaio de toxicidade, as amostras foram descongeladas e sua temperatura estabilizada a $25^{\circ} \mathrm{C}$. Foram adicion ados $15 \mathrm{~mL}$ de amostra e um organismo neonato em cada réplica, no total de 10. Em paralelo foi montado um controle também com 10 réplicas apenas com água de diluição. 

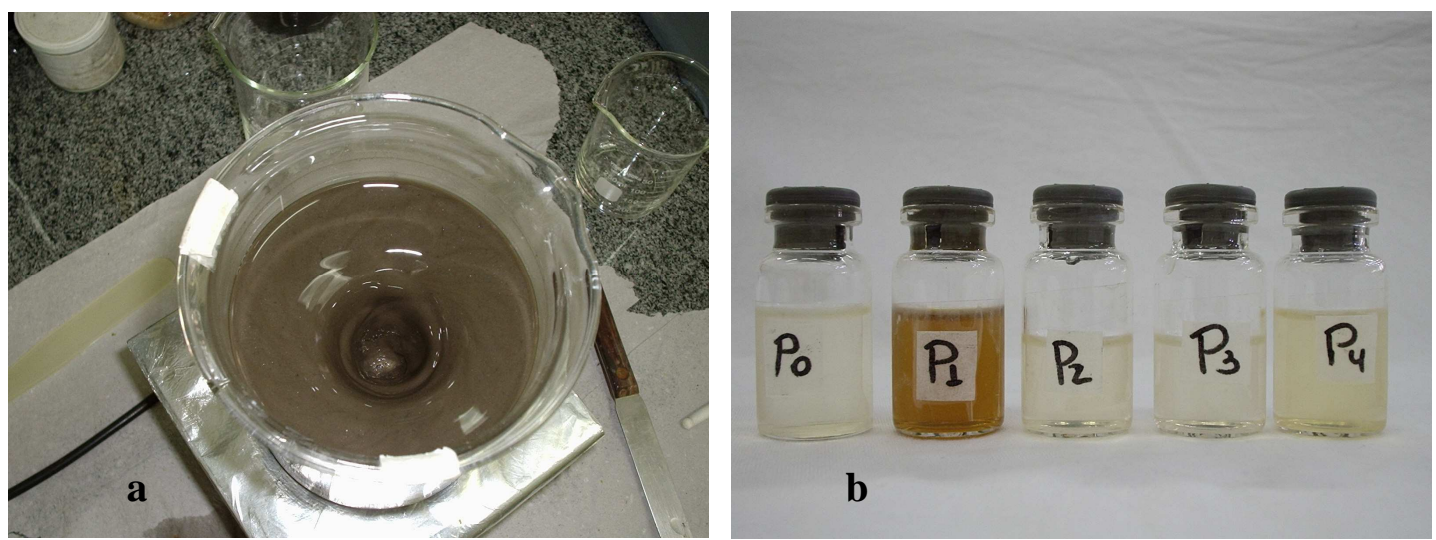

Figura 17. Preparo do elutriato das amostras de sedimento.

A duração do ensaio foi sete dias, com alimentação diária dos organismos. A troca de solução foi realizada a cada dois dias e, ao fim do ensaio, o total de neonatos de cada réplica foram contados e comparados com o número de organismos obtidos no controle.

\subsubsection{Ensaios de toxicidade com amostras de água do Rio Tietê - Ceriodaphnia dubia}

Antes do início do ensaio, as amostras foram descongeladas e estabilizadas à temperatura de $25^{\circ} \mathrm{C}$. Posteriormente, foram adicion ados $15 \mathrm{~mL}$ de amostra em cada réplica, adicionando-se um organismo neonato, totalizando 10 organismos por ponto de amostragem.

O ensaio teve duração de sete dias, com alimentação diária e troca da solução a cada dois dias. A cada troca de solução e ao fim do ensaio (sete dias), os neonatos obtidos em cada réplica foram contados. O número de neonatos obtidos em cada ponto foi comparado ao número obtido no controle.

Todos os ensaios com C.dubia foram validados quando o número médio de neonatos obtidos no controle foi igual ou superior a 15.

A sensibilidade dos organismos foi avaliada mensalmente, seguindo a metodologia descrita na Norma técnica ABNT NBR 13373 (2005), utilizando-se o cloreto de potássio $(\mathrm{KCl})$ como substância-referência. As concentrações utilizadas foram $0,75,125,250$ e $300 \mathrm{mg} / \mathrm{L}$. 
Para cada concentração de $\mathrm{KCl}$, foram preparadas 10 réplicas com $15 \mathrm{~mL}$ de solução-teste em cada uma. Posteriormente foi adicionado 1 organismoteste e foi fornecido alimento $(\mathrm{RL})$ a cada 2 dias e suspensão algácea, diariamente. Ao fim de 7 dias o ensaio foi finalizado, sendo somados os organismos neonatos obtidos em cada réplica das concentrações avaliadas. As concentrações de letalidade foram calculadas através do método de interpolação linear (USEPA, 2002) e utilizadas para compor a carta-controle de sensibilidade do organismo.

\subsubsection{Análise estatística: Teste de Hipóteses por Bioequivalência}

Os resultados dos ensaios com interface sedimento-água e elutriato realizados com Ceriodaphnia dubia e do ensaio com sedimento integral utilizando Hyalella azteca foram tratados utilizando-se o teste de hipóteses por bioequivalência (Erickson \& McDonald, 1995).

Segundo Erickson \& McDonald (1995), Shukla et al., (2000) e Buratini \& Bertoletti (2006), a utilização do teste de hipóteses por bioequivalência tem sido proposta para o tratamento dos resultados de ensaios de toxicidade visando diminuir a incidência de resultados falsos positivos, (efeitos significativos estatisticamente, porém não significativos biologicamente) e, de resultados falsos negativos (efeitos que não são detectados) decorrentes da aplicação de testes estatísticos convencionais como o teste "t", por exemplo. Para sua aplicação é necessária a definição do nível de efeito biologicamente significativo, incorporado ao cálculo pela constante de proporcionalidade "B" (Prósperi et al., 2008).

Neste estudo foram utilizadas as constantes de bioequivalência (B) calculadas por Bertoletti et al. (2007) para Ceriodaphnia dubia $(\mathrm{B}=0,79)$ e Hyalella azteca $(B=0,89)$. Os testes estatísticos foram realizados com o programa TOXSTAT, Versão 3.5 (Gulley, 1995). Após a análise estatística, as amostras foram classificadas como "tóxicas" ou "não tóxicas" em relação ao controle. 


\subsubsection{Ensaios de toxicidade em água intersticial dos sedimentos - Vibrio fischeri}

A extração da água intersticial foi realizada em uma centrífuga refrigerada (Eppendorf $\circledast$ modelo 5804R). Centrifugação por 15 minutos a 4.000 rpm.

O ensaio consistiu em expor as bactérias bioluminescentes à amostra por 15 minutos, sendo registrada a quantidade de luminescência inicial $\left(I_{0}\right)$ e aquela obtida após a exposição $\left(l_{15}\right)$, seguindo a metodologia descrita na Norma ABNT NBR154112 (2006). As concentrações utilizadas nos ensaios com água intersticial foram 0 , 10,23\%, 20,47\%, 40,95\%, 81,9\%. A maior concentração utilizada neste ensaio foi $81,9 \%$, devido ao ajuste osmótico na maior concentração da amostra. Foi utilizada solução salina $(\mathrm{NaCl}, 20 \%)$ por tratar-se de bactéria de origem marinha.

Essa bactéria foi adquirida da empresa Unwelt@, na forma congelada. $O$ equipamento utilizado foi Toxicity Analyser M500, Microbics $\AA^{(F i g u r a ~ 18) . ~}$

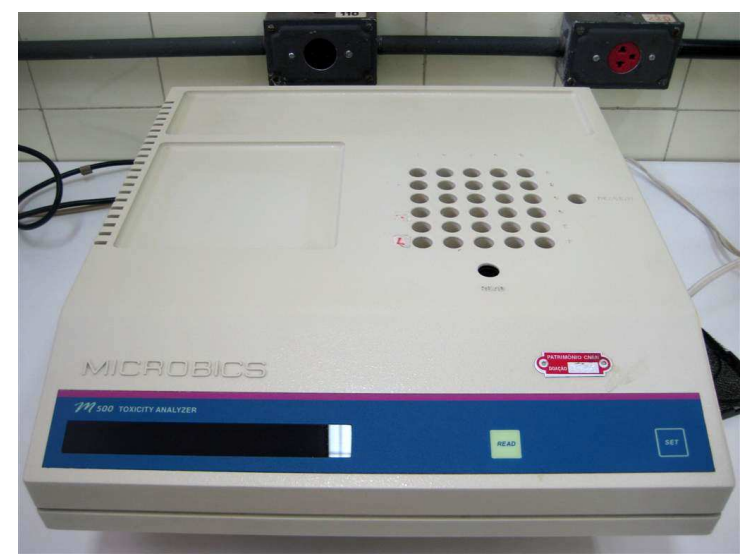

Figura 18. Equipamento utilizado no ensaio com a bactéria luminescente $V$. fischeri

Para validação dos ensaios realizados com as amostras de água intersticial, foi avaliada a sensibilidade dos organismos-teste utilizando-se o fenol como substância referência. O ensaio seguiu a metodologia descrita na Norma Técnica ABNT 15411-2 (2006). Os ensaios foram realizados na mesma data dos ensaios com amostras da água intersticial e seus resultados foram utilizados para compor a carta controle de sensibilidade, segundo a Norma de referência utilizada. 
Os resultados obtidos com amostras de água intersticial para $V$. fischeri foram expressos por $\mathrm{CE}(\mathrm{I})$ 50;15min, representando a concentração que reduziu $50 \%$ da luminescência produzida pela bactéria, durante uma exposição de 15 minutos, a 15ㄷ. A partir de dados brutos foi gerada uma curva de regressão linear com valores de gama (relação entre luz perdida e luz remanescente) e concentrações da diluição serial, utilizando-se o programa estatístico específico da Microbics®.

\subsection{Quantificação de contaminantes orgânicos e inorgânicos em amostras de sedimento}

$\mathrm{Na}$ Tabela 4 estão apresentadas as diferentes metodologias e equipamentos utilizados para essas análises. A maioria delas foi realizada em outros laboratórios.

O laboratório ECOLABOR Comercial e Consultoria e Análises Ltda que possui certificação ISO/IEC 17025 e ISO 9001 realizou a caracterização química dos possíveis contaminantes nos sedimentos buscando atender os requisitos da Resolução CONAMA 344/2004.

Para as análises dos componentes orgânicos foi utilizada cromatografia gasosa com espectrometria de massa, enquanto que os seis metais (cádmio, cobre, cromo, níquel, chumbo e zinco) e o arsênio foram quantificados com espectrometria de emissão óptica, sendo previamente realizado um ataque ácido forte nas amostras de sedimento, seguido por aquecimento em microondas.

A fim de melhorar a quantificação dos valores de metais, elementos-traço e terras-raras, foram realizadas análises por meio de ativação neutrônica (AAN). Segundo Orvine et al., (2000) e Marqués et al., (2000), essa metodologia apresenta como vantagens em relação à espectrometria de emissão óptica, alta sensibilidade, elevada precisão, além de dispensar a dissolução das amostras e não ser afetada por interferentes. Permite também a determinação simultânea de um grande número de elementos.

Alguns autores já utilizaram a análise por ativação neutrônica para quantificar metais em amostras de sedimentos, Pellegati et al., (2001) quantificou os metais e terras-raras presentes em amostras de sedimento da Baía de Sepitiba, Rio de 
Janeiro; Fávaro et al., quantificaram terras-raras e elementos traço no reservatório de Rio Grande Santos a fim de verificar a influência antropogênica na contaminação do reservatório Santos et al., (2007) quantificaram terras-raras em amostras de sedimento da Baía do Almirantado, Antárctica.

Embora a análise por ativação neutrônica apresente maior sensibilidade em relação à espectrometria, as concentrações de metais obtidas por meio de AAN não devem ser comparadas com os valores estabelecidos pela Resolução CONAMA 344, que sugere como metodologia o ICP-OES (Espectrometria de Emissão Óptica).

Para determinação total de mercúrio, foi aplicada a técnica de Absorção atômica com geração de vapor frio (CV AAS). Estas análises foram realizadas pelo Laboratório de Análises por Ativação Neutrônica (LAN) do Centro do Reator de Pesquisas no IPEN (CRPq - IPEN /CNEN-SP).

Preparo dos sedimentos para as análises de metais e elementos terrasraras por AAN: as amostras de sedimento foram previamente descongeladas e, posteriormente secas a $45^{\circ} \mathrm{C}$ em estufa ventilada, até atingirem peso constante. $\mathrm{Em}$ seguida, os sedimentos foram peneirados em peneira com malha de $2 \mathrm{~mm}$. A fração $<2 \mathrm{~mm}$ foi moída em um almofariz de ágata e novamente peneirada, (malha de 200 mesh) sendo esta fração utilizada nas análises. Apenas a fração $<2 \mathrm{~mm}$ foi analisada visando diminuir o efeito diluidor das frações mais grossas do sedimento (areia), normalmente com concentrações mais baixas de metais pesados e distribuídas randomicamente (Nascimento, 2003).

Após o preparo das amostras de sedimentos, estas foram enviadas ao LAAN, onde foram irradiadas no Reator IEA-R1. Em seguida, foram realizados os espectros (raios gama) com picos identificados e a partir dos quais foram calculadas as concentrações dos contaminantes da amostra pela comparação entre picos obtidos com materiais de referência.

\subsection{Determinação da amônia não ionizada}

A análise de nitrogênio amoniacal foi realizada pelo TECAM Laboratórios Ltda, que possui certificação ISO/IEC 17025 além de BPL (Boas Praticas de Laboratório). 
Em $25 \mathrm{~mL}$ de amostra de água intersticial, obtida por centrifugação do sedimento durante 15 minutos a $4.000 \mathrm{rpm}$. Para a análise foram adicionados o reagente Ammonia Salicylate Reagent Powder Pillows e o Ammonia Cyanurate Reagent Powder Pillows, da marca Hach. O mesmo procedimento foi feito no controle branco, com água deionizada. Posteriormente foi realizada a leitura da absorbância em Espectrofotômetro Hach DR/2000, utilizando-se o comprimento de onda de 655nm.

Os valores de amônia não ionizada foram obtidos por cálculo a partir dos valores de nitrogênio amoniacal, $\mathrm{pH}$, salinidade e temperatura de cada amostra, conforme descrito por Bower \& Bidwell (1978). 
Tabela 4. Metodologias e equipamentos utilizados nas análises realizadas em outros laboratórios.

\begin{tabular}{|c|c|c|c|c|}
\hline Parâmetros & Técnica & Equipamentos & Métodos & Laboratório \\
\hline $\begin{array}{c}\text { Metais pesados, } \\
\text { elementos traço e terras } \\
\text { raras }\end{array}$ & $\begin{array}{l}\text { Análise por ativação } \\
\text { neutrônica (AAN) } \\
\text { Absorção atômica com } \\
\text { geração de vapor frio } \\
\text { (CV AAS) }\end{array}$ & $\begin{array}{c}\text { Espectrômetro gama com } \\
\text { detector de germânio } \\
\text { hiperpuro Canberra®e } \\
\text { eletrônica associada } \\
\text { FIMS (Flow Injection } \\
\text { Mercury System) Perkin } \\
\text { Elmer }\end{array}$ & Ativação Neutrônica & $\begin{array}{c}\text { Laboratório de Análise } \\
\text { por Ativação Nêutronica } \\
\text { (LAN - CRPq - } \\
\text { IPEN /CNEN-SP) }\end{array}$ \\
\hline $\begin{array}{c}\text { Amônia não-ionizável, } \\
\text { nitrogênio amoniacal e } \\
\text { pH }\end{array}$ & Espectrofotometria & $\begin{array}{c}\text { Espectrofotômetro Hach } \\
\text { DR/2000 }\end{array}$ & $\begin{array}{c}\text { Standart Methods for } \\
\text { the Examination of } \\
\text { Water and } \\
\text { Wastewater, } 21 \text { st ed. }\end{array}$ & TECAM \\
\hline
\end{tabular}




\subsection{Análises Multivariadas}

Os dados de toxicidade e da contaminação ambiental (parâmetros orgânicos e inorgânicos) das coletas 2 e 3 foram integrados pela análise multivariada de fatores, utilizando a análise de componentes principais ( $P C A)$, o que permite explorar a distribuição das variáveis. Os dados utilizados nesta análise incluem ensaios de toxicidade (ensaios com sedimento integral e elutriato utillizando $C$. dubia, ensaio com sedimento integral em $H$. azteca e ensaio com água intersticial com a bactéria V. fischeri) e 9 parâmetros químicos ( $\mathrm{As}, \mathrm{Cd}, \mathrm{Cu}, \mathrm{Cr}, \mathrm{Hg}, \mathrm{Ni}, \mathrm{Pb}, \mathrm{Zn}$ e somatória de HPA's).

A análise dos fatores foi realizada na matriz de correlação, onde as variáveis foram padronizadas e tratadas com igual importância. Todas as análises foram realizadas utilizando as opções $P C A$ e "multivariate exploratory technics", seguindo a configuração básica do software STATISTICA, versão 8 (Stat Soft, Inc.,2006).

Os resultados dos ensaios de toxicidade deste trabalho são qualitativos uma vez que não foi utilizada diluição. Para utilização destes dados na matriz das análises multivariadas, foram atribuídos valores numéricos aos efeitos obtidos em cada ensaio da seguinte maneira: nos ensaios de toxicidade crônica (C. dubia), o número de neonatos obtidos em cada ponto foi transformado em porcentagem de reprodução em relação ao controle. O passo seguinte foi dividir 100 pelo valor obtido e o resultado da divisão foi utilizado na matriz de correlação.

No caso dos ensaios de toxicidade aguda $(H$. azteca e $V$. fischer $)$, o mesmo procedimento foi realizado, porém o valor utilizado como divisor foi a porcentagem de sobrevivência em relação ao controle (H. azteca) e a CE (I) 50 ( $V$. fischeri). 


\section{RESULTADOS}

Neste trabalho foram analisadas amostras de sedimentos e suas fases aquosas, provenientes do reservatório de Ponte Nova (Salesópolis, SP) e da calha do Rio Tietê nos municípios de Biritiba-mirim, Mogi das Cruzes e Suzano, SP, quanto à toxicidade. Durante as campanhas 3 e 4 foram coletadas amostras de água do rio a fim de avaliar a toxicidade deste compartimento. Nos sedimentos foram realizadas análises químicas para quantificação de contaminantes orgânicos, elementos-traço e terras raras (coletas 2 e 3 ) e amônia (coleta 3 ).

\subsection{Resultados dos Ensaios de Toxicidade}

Os resultados dos ensaios de toxicidade foram tratados qualitativamente usando as constantes de bioequivalência: $B=0,89$ para $H$. azteca e $B=0,79$ para Ceriodaphnia dubia.

Os resultados dos ensaios de toxicidade com $H$. azteca em amostras de sedimento integral provenientes do ponto P0 foram organizados na figura 19 e representam a porcentagem de sobrevivência deste anfípoda durante a exposição às amostras do sedimento. Foram consideradas tóxicas (efeito agudo) as amostras onde a mortalidade obtida foi estatisticamente diferente do controle e encontram-se assinalados $\left(^{*}\right)$. 


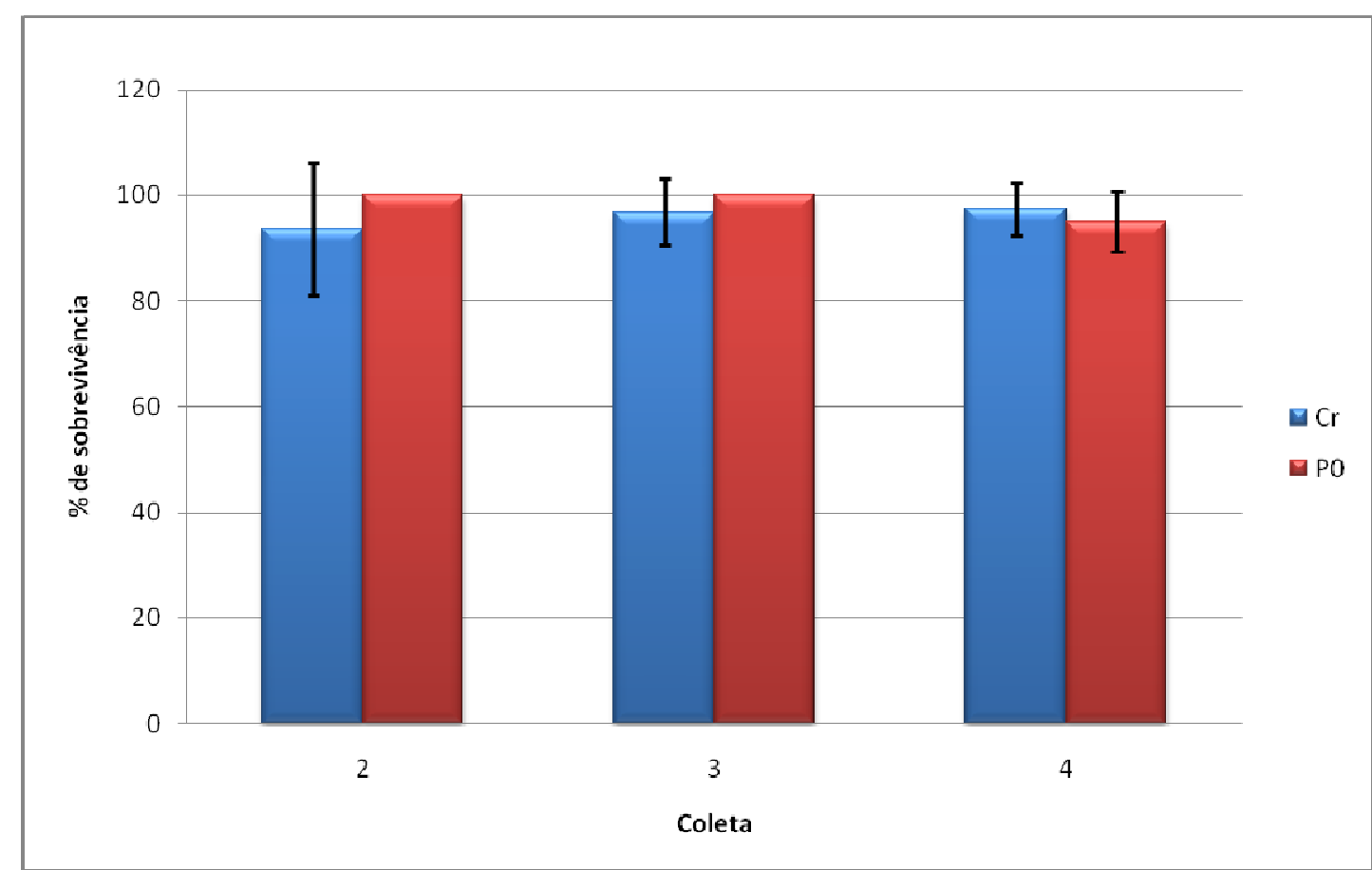

19. Porcentagem de sobrevivência de $H$. azteca durante exposição ao sedimento integral - PO.

As médias de neonatos obtidas durante a exposição de C.dubia à amostras de sedimento integral, e elutriato provenientes do ponto P0 durante as 4 coletas, foram organizadas na Figura 20. Os pontos onde foi encontrada diferença significativa com o controle (mortalidade ou reprodução) encontram-se destacados ( ${ }^{*}$ ). 


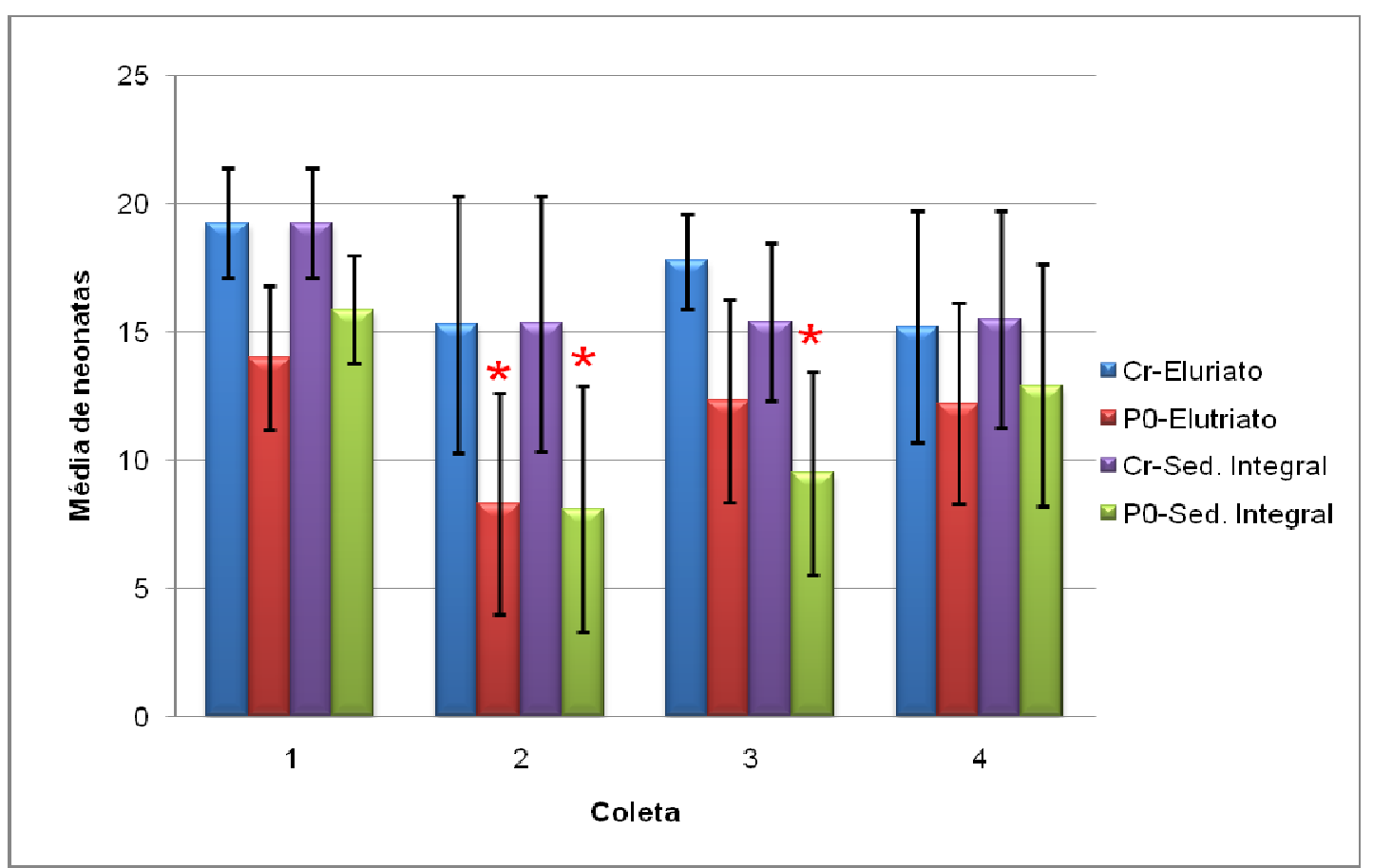

Figura 20. Média de neonatos de $C$. dubia obtidos durante a exposição à amostras de sedimento integral e elutriato - P0.

A seguir, nas Figuras 21 e 22 se encontram a porcentagem de sobrevivência de $H$. azteca (sedimento integral) e a média de neonatos obtidos nos ensaios com $C$. dubia (sedimento integral e elutriato) quando expostos às amostras provenientes do ponto $\mathrm{P} 1 \mathrm{e}$, da mesma forma, os pontos que apresentaram diferença significativa em relação ao controle (mortalidade ou reprodução) encontram-se destacados $\left(^{*}\right)$. 


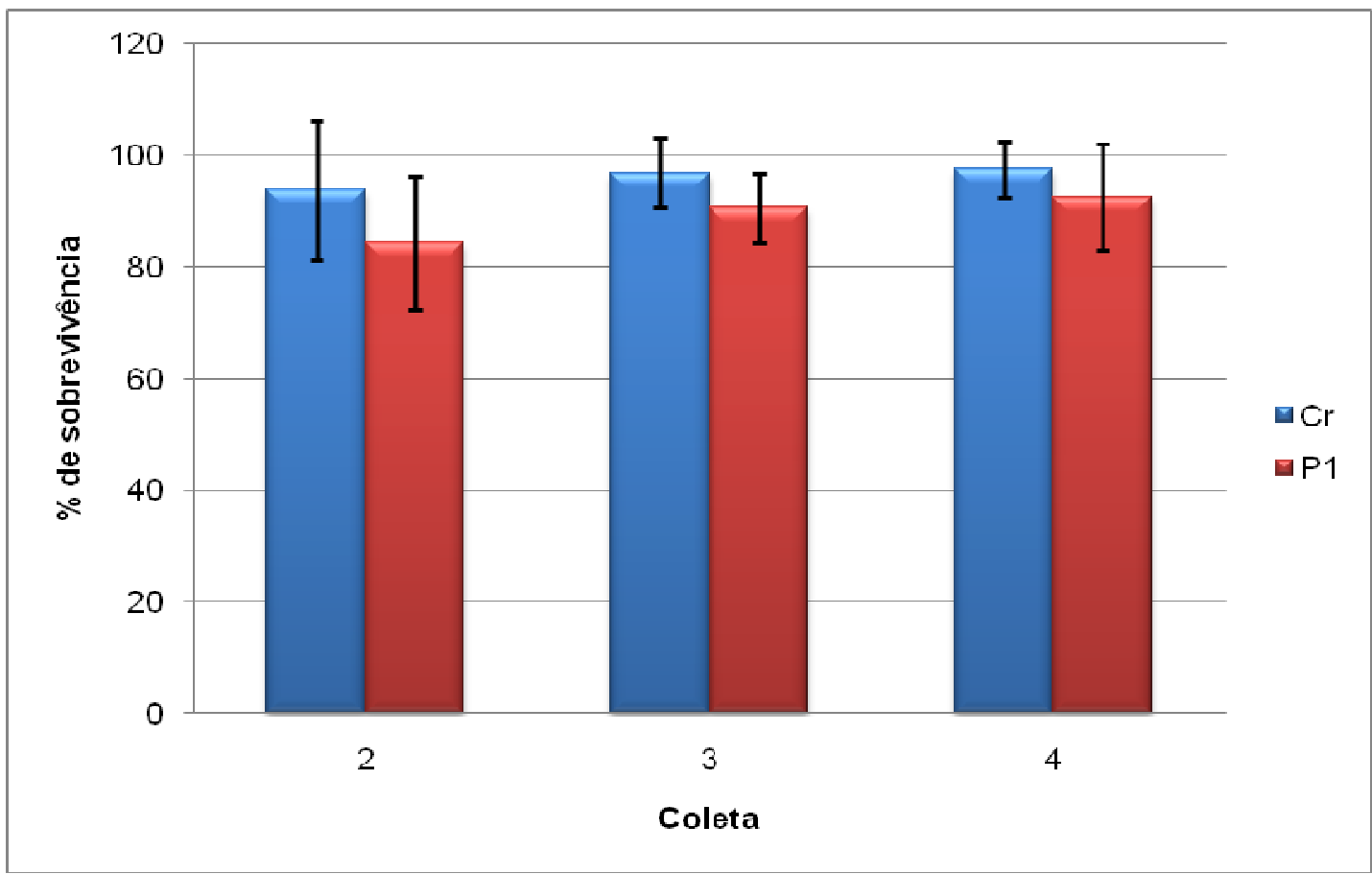

Figura 21. Porcentagem de sobrevivência de $H$. azteca durante exposição ao sedimento integral - P1.

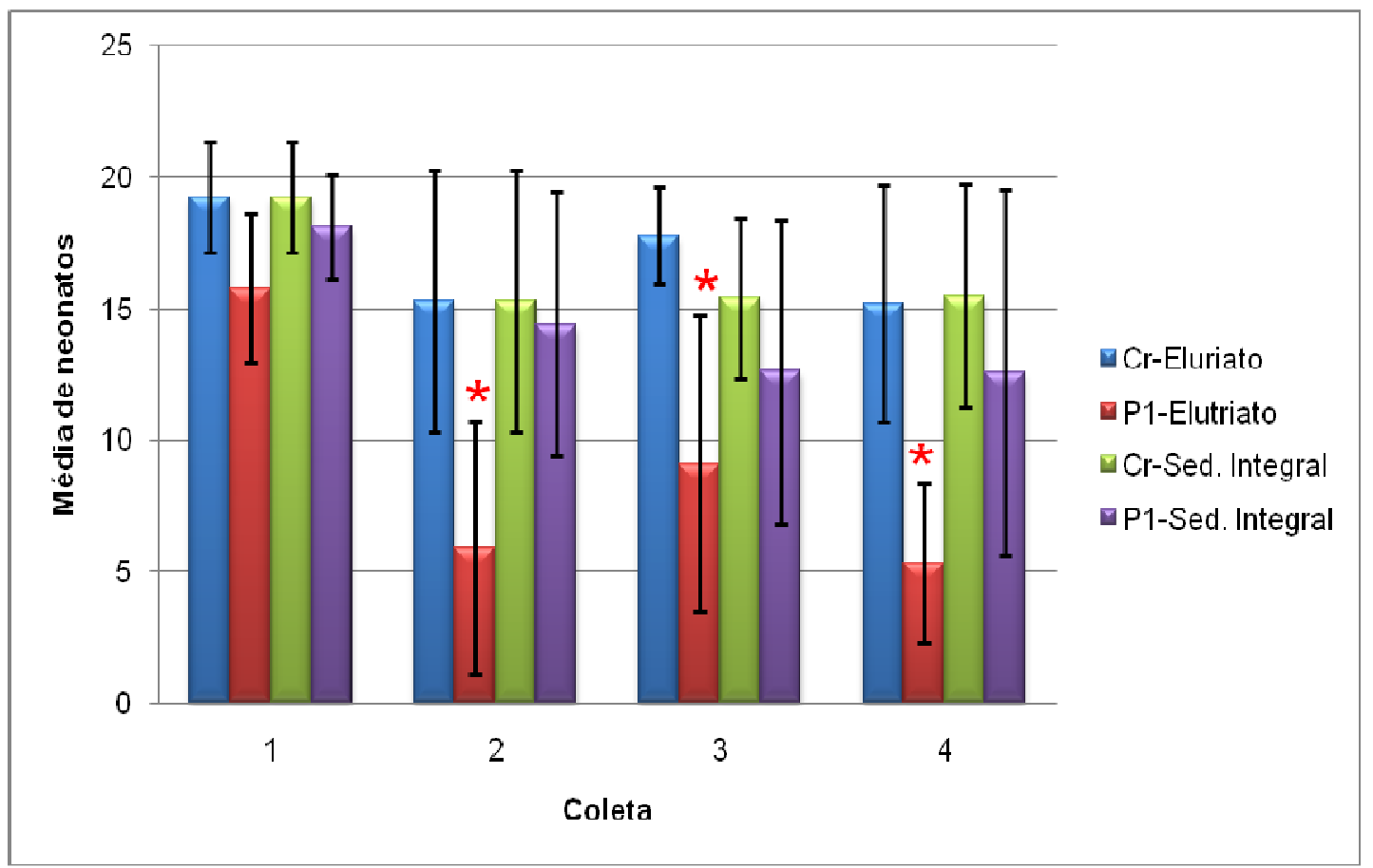

Figura 22. Média de neonatos de $C$. dubia obtidos durante a exposição à amostras de sedimento integral e elutriato - P1. 
As Figuras 23 e 24 mostram a porcentagem de sobrevivência de $H$. azteca (sedimento integral) e a média de neonatos obtidos nos ensaios com $C$. dubia (sedimento integral e elutriato) quando expostos às amostras provenientes do ponto P2, nas Figuras 25 e 26 os resultados obtidos durante a exposição dos mesmos organismos às amostras do ponto P3, e, por fim, nas Figuras 27 e 28 quando expostos às amostras do ponto P4. Da mesma forma, os pontos que apresentaram diferença significativa em relação ao controle (mortalidade ou reprodução) encontram-se destacados $\left(^{*}\right)$.

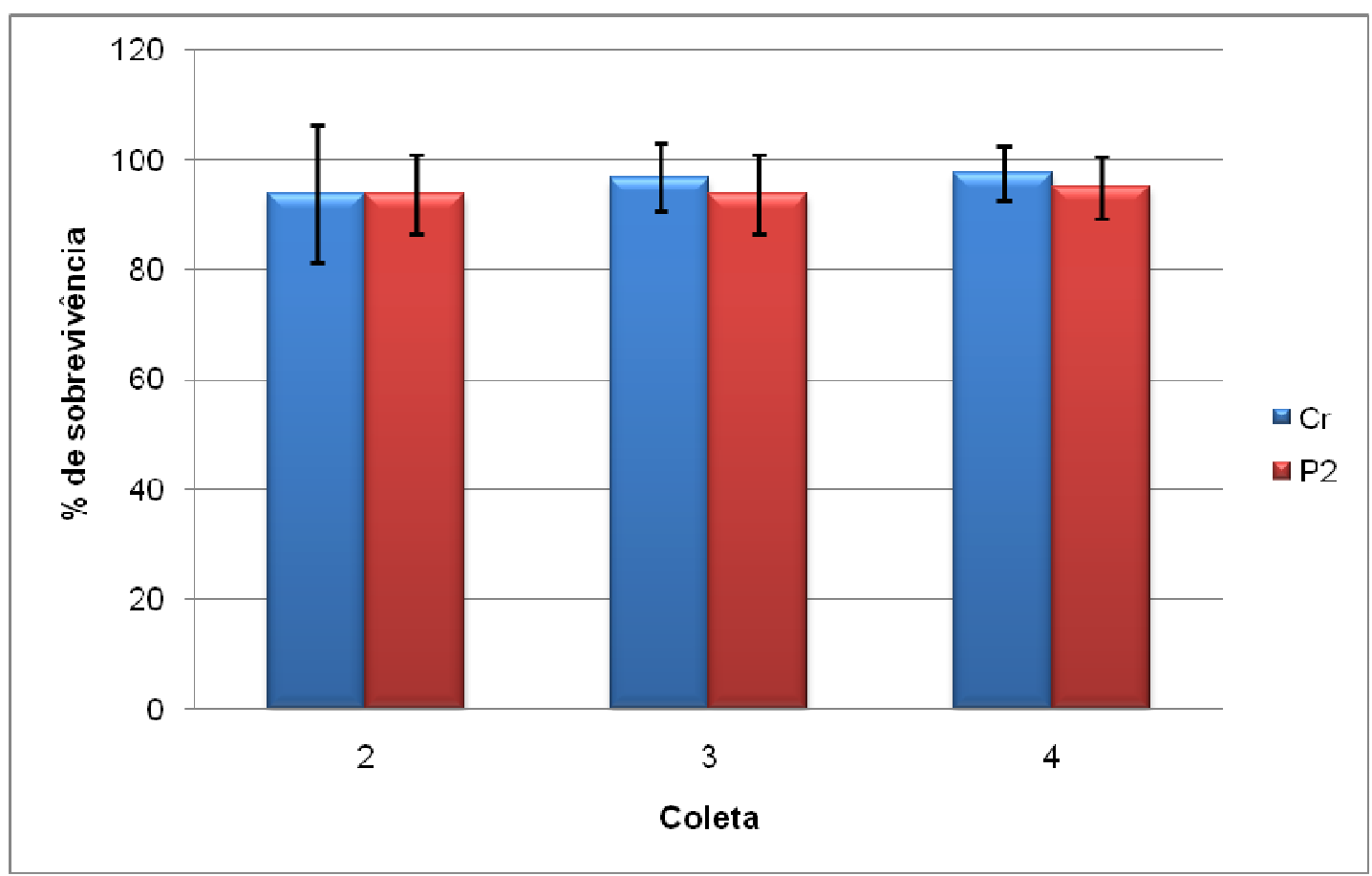

Figura 23. Porcentagem de sobrevivência de $H$. azteca durante exposição ao sedimento integral - P2. 


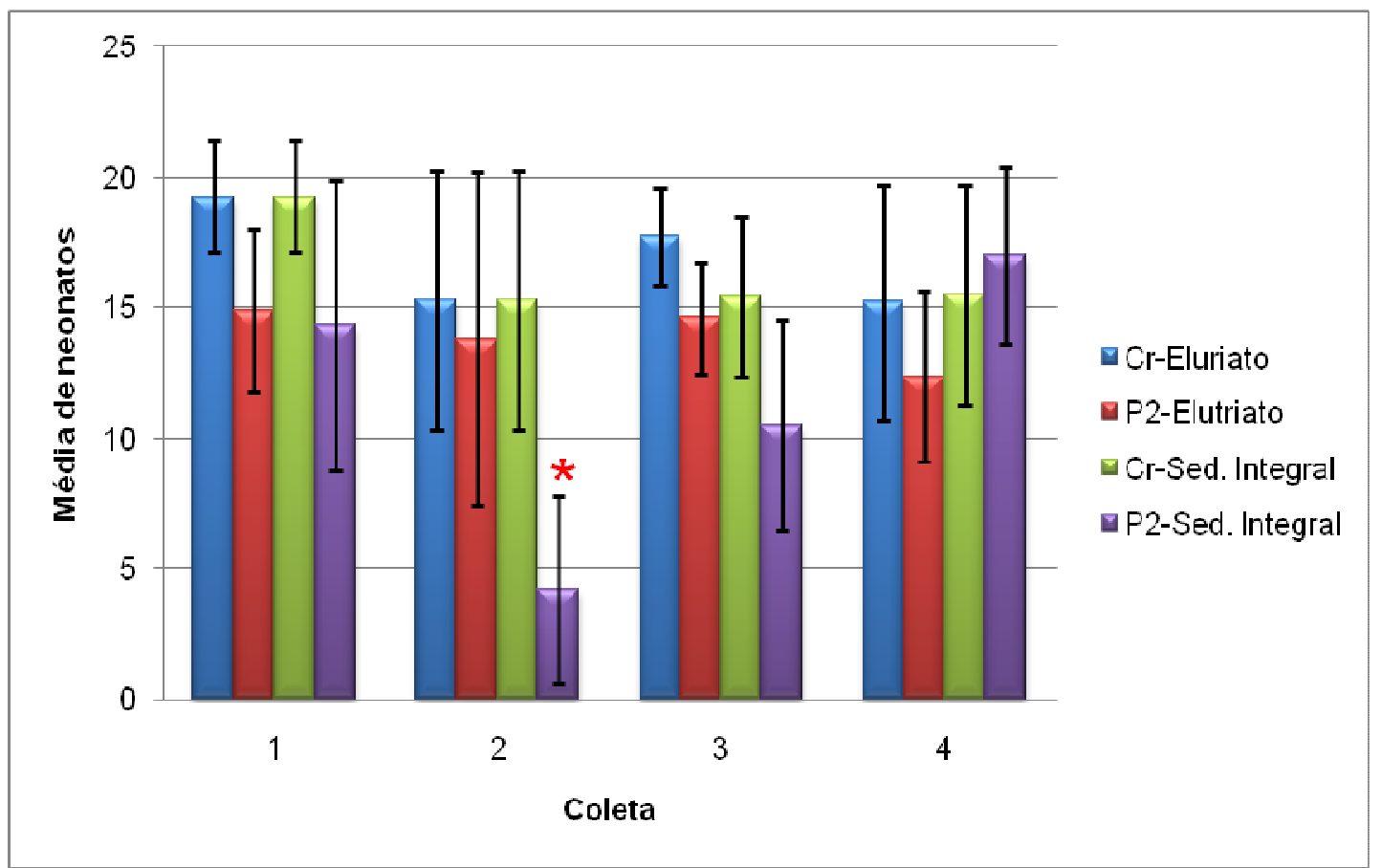

Figura 24. Média de neonatos de $C$. dubia obtidos durante a exposição à amostras de sedimento integral e elutriato - P2.

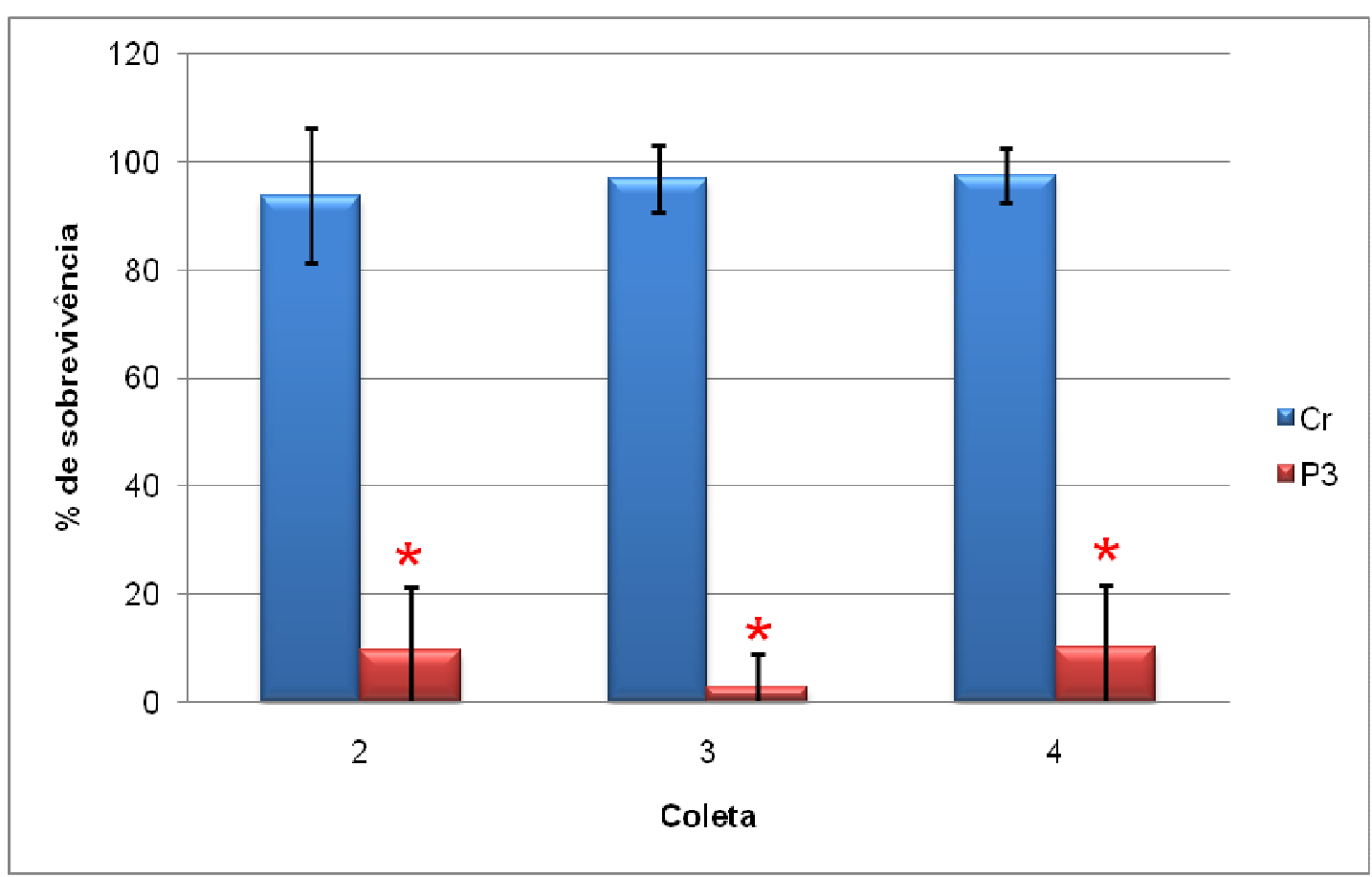

Figura 25. Porcentagem de sobrevivência de $H$. azteca durante exposição ao sedimento integral - P3. 


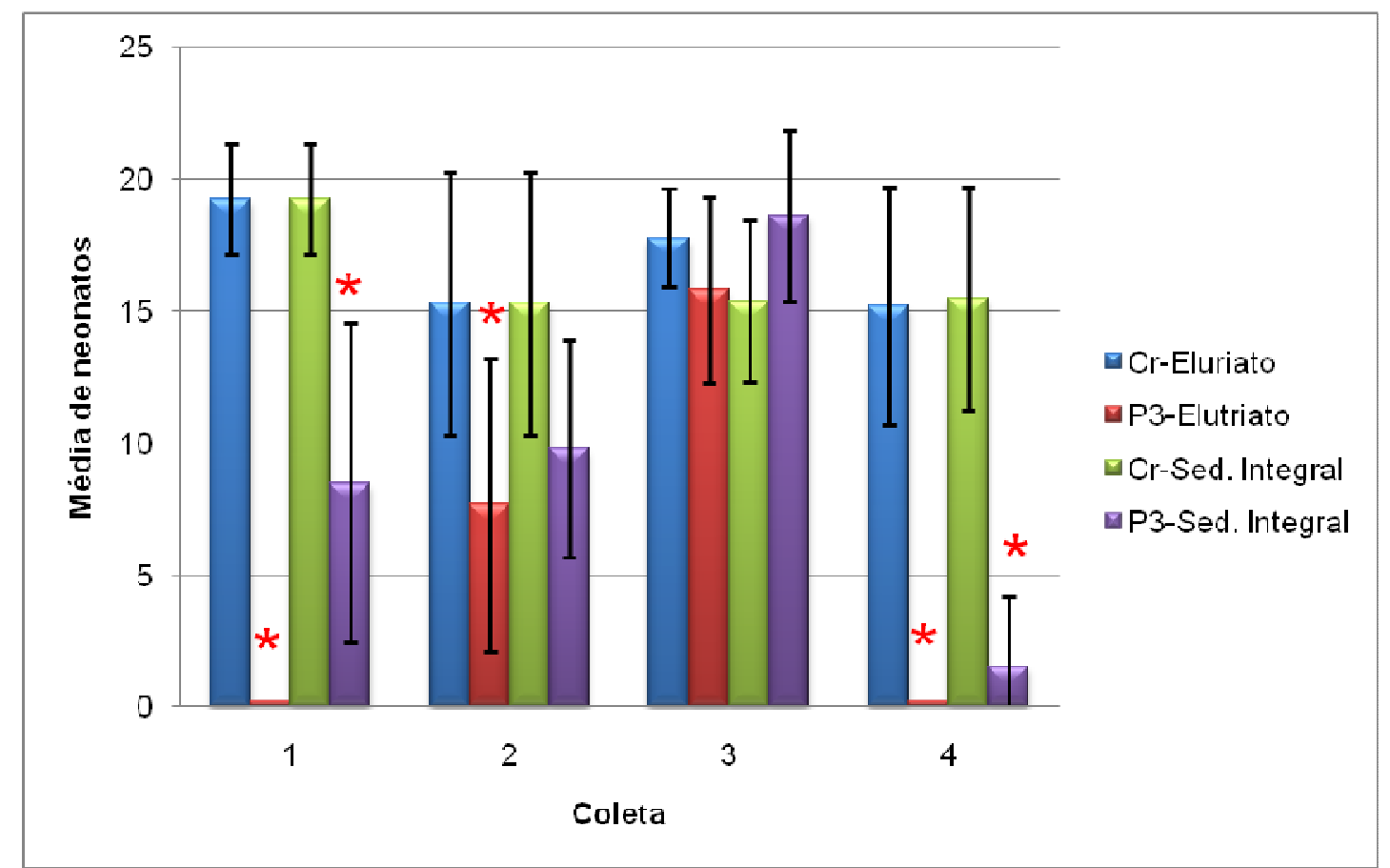

Figura 26. Média de neonatos de $C$. dubia obtidos durante a exposição à amostras de sedimento integral e elutriato - P3.

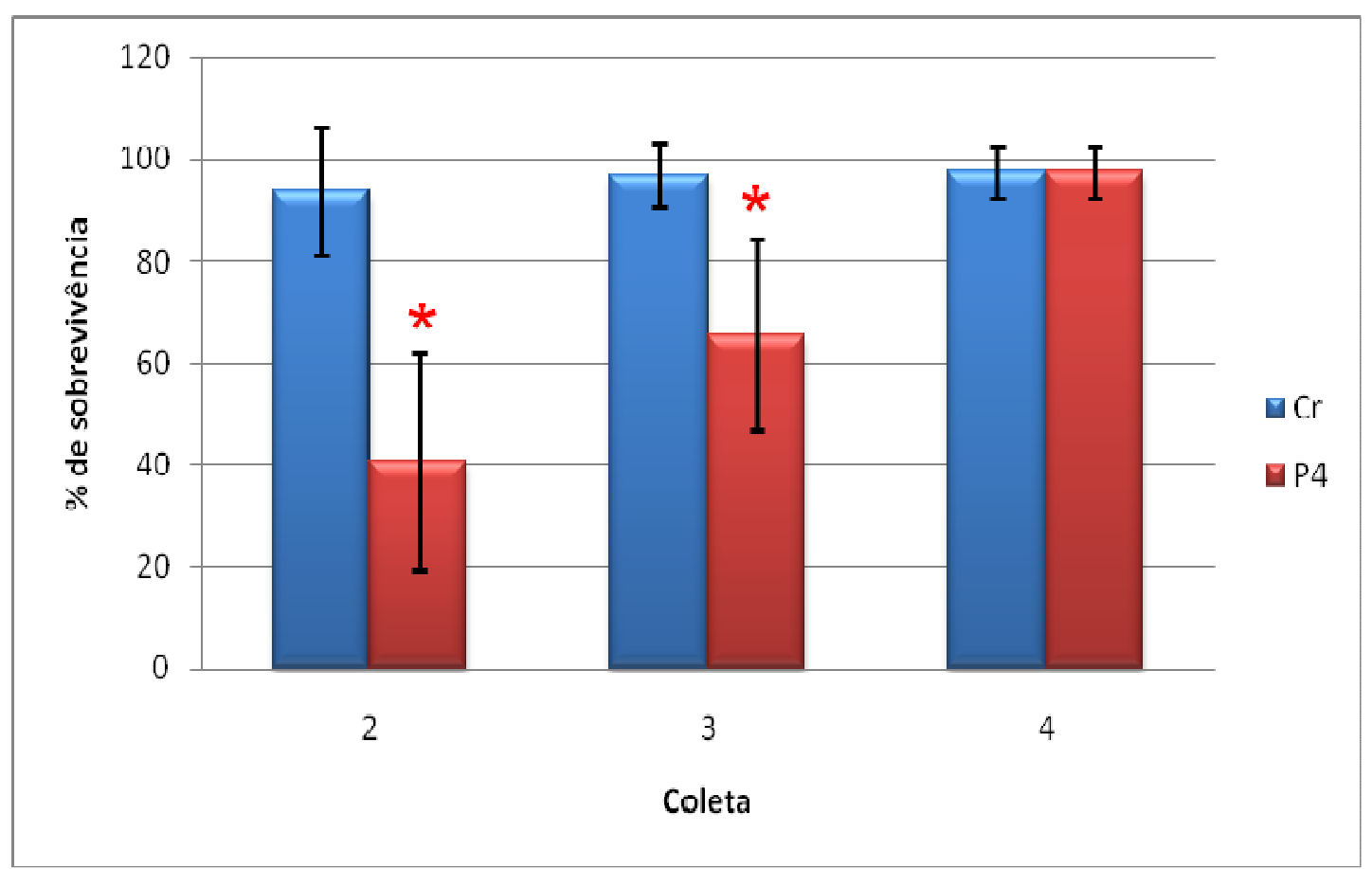

Figura 27. Porcentagem de sobrevivência de $H$. azteca durante exposição ao sedimento integral $-\mathrm{P} 4$. 


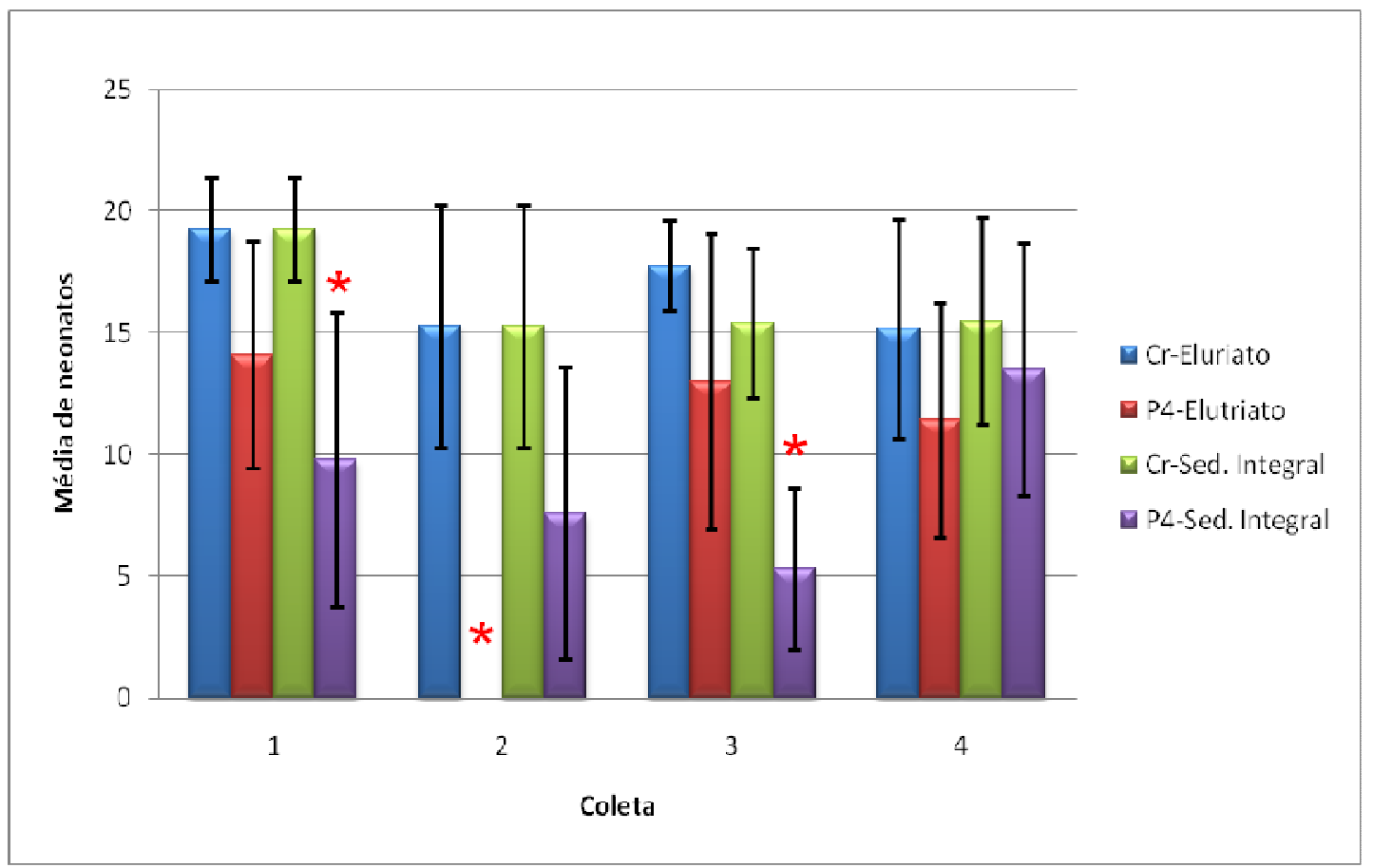

Figura 28. Média de neonatos de $C$. dubia obtidos durante a exposição à amostras de sedimento integral e elutriato - P4.

As amostras de água intersticial proveniente dos pontos P0, P1, P2, P3 e P4 foram submetidas a ensaio de toxicidade aguda para Vibrio fischeri. A água intersticial foi submetida somente a este ensaio devido à dificuldade de obtenção de maior volume de amostra.

A maior concentração permitida neste ensaio foi de $81,9 \%$, devido ao ajuste osmótico realizado para correção de salinidade.

$\mathrm{Na}$ Tabela 5 foram organizados os dados dos ensaios com água intersticial utilizando a bactéria luminescente Vibrio fischeri. 
Tabela 5. Resultados obtidos nos ensaios com água intersticial utilizando $V$. fischeri CE50.

\begin{tabular}{|c|c|c|c|c|c|}
\hline \multicolumn{6}{|c|}{ CE50 (\%, v/v, $15 \mathrm{~min})$} \\
\hline Coleta & PO & P1 & P2 & P3 & P4 \\
\hline 1 & $>81,90$ & $\begin{array}{c}37,35 \\
(20,67-53,80)\end{array}$ & $>81,90$ & $\begin{array}{c}\mathbf{2 1 , 4 1} \\
(15,12-30,32)\end{array}$ & $>81,90$ \\
\hline 2 & $>81,90$ & $\begin{array}{c}\mathbf{2 2 , 6 0} \\
(16,05-31,84)\end{array}$ & $>81,90$ & $\begin{array}{c}16,25 \\
(7,74-34,08)\end{array}$ & $\begin{array}{c}\mathbf{2 5 , 4 6} \\
(21,61-29,99)\end{array}$ \\
\hline 3 & $>81,90$ & $\begin{array}{c}5,96 \\
(5,62-6,31)\end{array}$ & $>81,90$ & $\begin{array}{c}\mathbf{2 2 , 7 3} \\
(22,08-23,41)\end{array}$ & $\begin{array}{c}\mathbf{2 6 , 7 4} \\
(17,34-41,26)\end{array}$ \\
\hline 4 & $>81,90$ & $\begin{array}{c}11,93 \\
(3,82-37,26)\end{array}$ & $>81,90$ & $>81,90$ & $>81,90$ \\
\hline
\end{tabular}

Nas coletas 3 e 4 foram realizados, também, ensaios com amostras de elutriato utilizando $V$. fischeri. A seguir, a Tabela 6 apresenta os resultados obtidos neste ensaio.

Tabela 6. Resultados obtidos na exposição de $V$. fischeri ao elutriato.

\begin{tabular}{|c|c|c|c|c|c|}
\hline \multicolumn{6}{|c|}{ CE50 (\%, v/v, $15 \mathrm{~min})$} \\
\hline Coleta & PO & P1 & P2 & P3 & P4 \\
\hline 1 & $\mathrm{nr}$ & $\mathrm{nr}$ & $\mathrm{nr}$ & $\mathrm{nr}$ & $\mathrm{nr}$ \\
\hline 2 & $\mathrm{nr}$ & $\mathrm{nr}$ & $\mathrm{nr}$ & $\mathrm{nr}$ & $\mathrm{nr}$ \\
\hline 3 & $>81,90$ & $\begin{array}{c}6,47 \\
(4,99-8,39)\end{array}$ & $>81,90$ & $\begin{array}{c}13,61 \\
(11,42-16,21)\end{array}$ & $\begin{array}{c}13,61 \\
(12,90-14,29)\end{array}$ \\
\hline 4 & $>81,90$ & $\begin{array}{c}27,93 \\
(15,75-49,53)\end{array}$ & $>81,90$ & $>81,90$ & $\begin{array}{c}28,98 \\
(17,68-47,50)\end{array}$ \\
\hline
\end{tabular}

Nas mesmas coletas (coletas 3 e 4 ) foram realizados ensaios com amostras de água do Rio Tietê. Os resultados encontram-se organizados na Figura 22. 


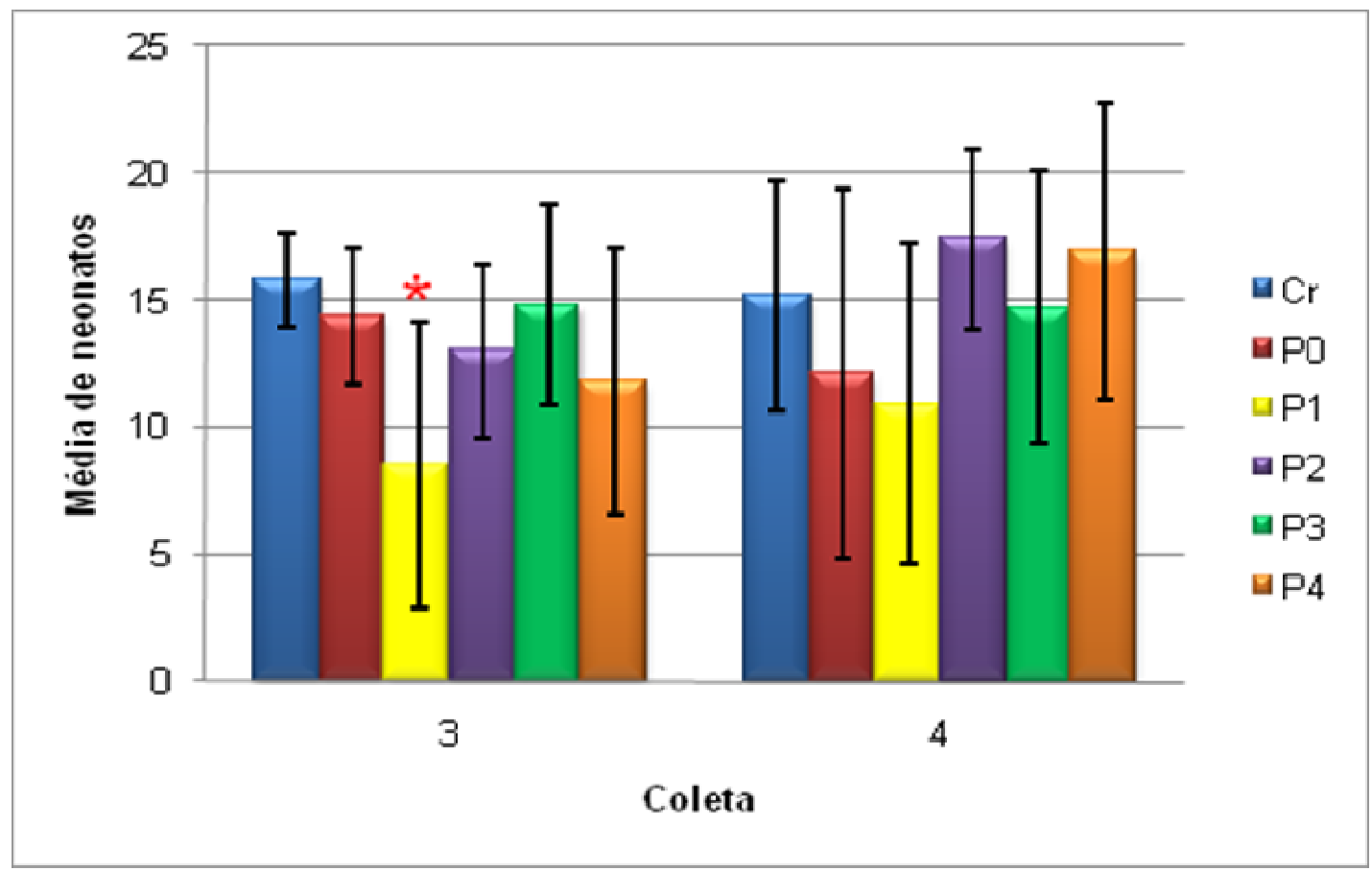

Figura 29 Média de neonatos de $C$. dubia obtidos durante a exposição à água do Rio Tietê.

Os dados brutos dos ensaios de toxicidade constam do Anexo I.

Os resultados dos ensaios após o tratamento estatístico foram organizados na Tabela 7 e classificados segundo o efeito observado (ensaios com Ceriodaphnia dubia e Hyalella azteca) e, de acordo com Bullich (1992) (ensaios com Vibrio fischeri) onde as amostras com $\mathrm{CE}(\mathrm{I}) 50<25,00 \%$ foram consideradas "muito tóxicas"; entre $25 \%$ e $50 \%$, "tóxicas"; entre $51 \%$ e $75 \%$, "moderadamente tóxicas"; > 75\% "levemente tóxicas". 
Tabela 7. Classificação dos resultado dos ensaios de toxicidade após tratamento estatístico

\begin{tabular}{ccccccc}
\hline & Coleta & P0 & P1 & P2 & P3 & P4 \\
\hline & 1 & NR & NR & NR & NR & NR \\
Sedimento Integral - & 2 & NT & NT & NT & TA & TA \\
Hyalella azteca & 3 & NT & NT & NT & TA & TA \\
& 4 & NT & NT & NT & TA & NT \\
\hline & 1 & NT & NT & NT & TC & TC \\
Sedimento Integral - & 2 & $T C$ & NT & TC & NT & TC \\
Ceriodaphnia dubia & 3 & $T C$ & NT & NT & NT & TC \\
& 4 & NT & NT & NT & ITA & NT \\
\hline & 1 & NT & NT & NT & TA & NT \\
Elutriato - & 2 & TC & TC & NT & TC & TA \\
Ceriodaphnia dubia & 3 & NT & TC & NT & NT & NT \\
& 4 & NT & TC & NT & TA & NT \\
\hline & 1 & IT & $T$ & IT & MT & IT \\
Água Intersticial - & 2 & IT & MT & IT & MT & MT \\
Vibrio fischeri & 3 & IT & MT & IT & MT & T \\
& 4 & IT & MT & IT & NT & NT \\
\hline Elutriato - Vibrio & 3 & IT & MT & IT & MT & MT \\
fischeri & 4 & IT & $T$ & IT & NT & T \\
\hline Água do Rio Tietê - & 3 & NT & TC & NT & NT & NT \\
Ceriodaphnia dubia & 4 & NT & NT & NT & NT & NT
\end{tabular}

NR - Não Realizada; NT - Não Tóxico; TC - Toxicidade Crônica; ITA - Indícios de Toxicidade Aguda; TA - Toxicidade Aguda; T - Tóxica; MT - Muito tóxica.

\subsection{Resultados obtidos na quantificação dos contaminantes orgânicos e inorgânicos}

Os contaminantes orgânicos (HPA's) e inorgânicos (metais e arsênio) contidos nas amostras de sedimento provenientes das coletas 2 e 3 foram quantificados. Os resultados foram comparados aos valores estabelecidos na Resolução CONAMA $344 / 04$. 
Utilizando-se Análise por Ativação Neutrônica, foram quantificados 24 metais e o arsênio. Os valores de todos os metais quantificados por esta técnica constam do Anexo II.

Nas Tabelas 8, 9 e 10 foram organizados os valores de contaminantes orgânicos, metais potencialmente biodisponíveis (devido à extração ácida), e metais totais (quantificados por meio de AAN), respectivamente, encontrados nos sedimentos nas coletas 2 e 3 . Os valores destacados referem-se àqueles em que a concentração ultrapassou o Nível 1 ou o Nível 2, propostos pelo CONAMA 344 ou ainda os Valores de Referência Regionais (VRR) propostos por Nascimento (2003), apresentados na Tabela 10. 
Tabela 8. Contaminantes orgânicos quantificados nas amostras de sedimentos nas coletas 2 e 3 ( $\mu \mathrm{g} / \mathrm{kg})$.

\begin{tabular}{|c|c|c|c|c|c|c|c|c|c|c|c|c|}
\hline \multirow[b]{2}{*}{ Parâmetros } & \multirow[b]{2}{*}{ Nível 1} & \multirow[b]{2}{*}{ Nível 2} & \multicolumn{2}{|c|}{ PO } & \multicolumn{2}{|c|}{ P1 } & \multicolumn{2}{|c|}{$\mathbf{P 2}$} & \multicolumn{2}{|c|}{ P3 } & \multicolumn{2}{|c|}{$\mathbf{P 4}$} \\
\hline & & & Coleta 2 & Coleta 3 & Coleta 2 & Coleta 3 & Coleta 2 & Coleta 3 & Coleta 2 & Coleta 3 & Coleta 2 & Coleta 3 \\
\hline Acenaftileno & 5,87 & 128 & nd & nd & nd & nd & nd & 1,72 & nd & nd & nd & nd \\
\hline Criseno & 57,1 & 862 & nd & nd & nd & nd & 19,6 & nd & nd & nd & nd & nd \\
\hline Fenantreno & 41,9 & 515 & nd & nd & nd & nd & nd & 7667 & nd & 1744 & nd & nd \\
\hline Fluoranteno & 111 & 2355 & 16 & nd & 320 & 60810 & nd & 39957 & nd & nd & nd & nd \\
\hline Naftaleno & 34,6 & 391 & nd & 32,1 & nd & nd & nd & 98,4 & nd & 75,9 & nd & 35,7 \\
\hline Pireno & 53 & 375 & 21,3 & nd & 376 & 53870 & 69,6 & 32790 & nd & nd & nd & nd \\
\hline$\Sigma$ de PAH's & 1000 & & 37,8 & 32,1 & 696 & 114680 & 89,1 & 80514 & nd & 1820 & nd & 35,7 \\
\hline
\end{tabular}

nd - não detectado.

Tabela 9. Metais quantificados em amostras de sedimentos nas coletas 2 e 3 ( $\mathrm{mg} / \mathrm{kg})$.

\begin{tabular}{cccccccccccccc}
\hline & & \multicolumn{1}{c}{} & \multicolumn{4}{c}{ P0 } & \multicolumn{2}{c}{ P1 } & \multicolumn{2}{c}{ P2 } & \multicolumn{2}{c}{ P3 } \\
\hline Parâmetros & Nível 1 & Nível 2 & VRR $^{\star}$ & Coleta 2 & Coleta 3 & Coleta 2 & Coleta 3 & Coleta 2 & Coleta 3 & Coleta 2 & Coleta 3 & Coleta 2 & Coleta 3 \\
\hline Cádmio & 0,6 & 3,5 & 0,24 & & & & 0,08 & & 0,04 & $\mathbf{0 , 3}$ & 0,05 & 0,6 & $\mathbf{0 , 4 8}$ \\
Cobre & 35,7 & 197 & 18 & 2 & 4,65 & & 0,657 & 0,5 & 0,73 & 89,3 & 11,2 & 83,2 & 65,4 \\
Cromo & 37,3 & 90 & 30 & 8 & 10,8 & 8,1 & 4,59 & 3,2 & 4,06 & 52,2 & $\mathbf{3 4 , 6}$ & 52,9 & 48,8 \\
Mercúrio & 0,17 & 0,486 & 0,16 & 0,061 & 0,128 & 0,076 & 0,102 & $<10 \mathrm{ppb}$ & 0,123 & $\mathbf{0 , 4 4 8}$ & $\mathbf{0 , 4 1 1}$ & $\mathbf{0 , 5 8 3}$ & $\mathbf{0 , 6 5 2}$ \\
Níquel & 18 & 35,9 & 20 & 0,7 & 1,15 & 2,1 & 1,1 & 0,5 & 0,974 & 14,8 & 8,58 & 29 & 17,9 \\
Chumbo & 35 & 91,3 & 61 & 3,8 & 7,68 & 9 & 5,15 & 1,7 & 3,39 & 46,9 & 8,13 & 57,5 & 33,6 \\
Zinco & 123 & 315 & 82 & 11 & 9,87 & 27 & 9,31 & 4,6 & 7,74 & 390 & 77,7 & 590 & 248 \\
\hline
\end{tabular}

nd - não detectado. Valores em negrito - acima dos Valores de Referência Regionais* (Nascimento, 2003).

\begin{tabular}{|c|c|c|c|c|}
\hline$<\mathrm{TEL}$ & $\begin{array}{c}\mathrm{TEL}+ \\
50 \%\end{array}$ & $\begin{array}{c}\mathrm{TEL}+ \\
51 \%\end{array}$ & $>\mathrm{PEL}$ & $\begin{array}{c}\mathrm{PEL}+ \\
50 \%\end{array}$ \\
\hline ótima & boa & regular & ruim & péssima \\
\hline
\end{tabular}


Tabela 10. Metais totais quantificados nos sedimentos nas amostras das coletas 2 e 3 (mg/kg).

\begin{tabular}{ccccccccccc}
\hline \multirow{2}{*}{ Parâmetro } & \multicolumn{2}{c}{ P0 } & \multicolumn{2}{c}{ P1 } & \multicolumn{2}{c}{ P2 } & \multicolumn{2}{c}{ P3 } & P4 \\
\cline { 2 - 10 } & Coleta 2 & Coleta 3 & Coleta 2 & Coleta 3 & Coleta 2 & Coleta 3 & Coleta 2 & Coleta 3 & Coleta 2 & Coleta 3 \\
\hline Arsênio & nd & 10,00 & 2,30 & 2,80 & nd & 3,60 & 13,20 & 8,10 & 19,70 & 34,20 \\
Cromo & 31,20 & 38,60 & 19,90 & 21,40 & 14,20 & 31,40 & 94,60 & 142,1 & 122,1 & 110,3 \\
Zinco & 33,00 & 36,00 & 55,00 & 39,00 & 16,00 & 50,00 & 459,0 & 285,0 & 929,0 & 386,0 \\
\hline
\end{tabular}

nd - não detectado. 
Foram denominados "metais potencialmente biodisponíveis" aqueles que foram extraídos por meio de ataque ácido, porém sem digestão total. Segundo Rensing \& Maier (2003), do ponto de vista ecotoxicológico, a fração de metais não dissolvida em ácidos concentrados, tem uma biodisponibilidade muito baixa, sendo igualmente baixo seu potencial tóxico.

\subsection{Quantificação de amônia não ionizada}

Com o objetivo de monitorar a concentração desse interferente nos ensaios de toxicidade, a quantificação de amônia foi realizada na água intersticial das amostras de sedimento da coleta 3 .

Os valores de amônia não ionizada (NI) foram calculados a partir do nitrogênio amoniacal quantificado na água intersticial dos sedimentos, $\mathrm{pH}$, salinidade e temperatura. Os resultados obtidos encontram-se na Tabela 11.

Tabela 11. Amônia não ionizada, nitrogênio amoniacal e pH obtidos nas amostras de água intersticial da coleta 3.

\begin{tabular}{ccccccc}
\hline Parâmetro & Unidade & P0 & P1 & P2 & P3 & P4 \\
\hline Amônia (NI) & $\mathrm{mg} / \mathrm{L}$ & 0,05 & 0,23 & 0,02 & 0,09 & 0,14 \\
$\mathbf{N}_{\text {amoniacal }}$ & $\mathrm{mg} / \mathrm{L}$ & 2,25 & 53,75 & 4,50 & 10,50 & 14,50 \\
pH & - & 6,57 & 6,88 & 6,81 & 7,17 & 7,24 \\
Salinidade & $\% \circ$ & 0 & 0 & 0 & 0 & 0 \\
Temperatura & ${ }^{0} \mathrm{C}$ & 25,0 & 25,0 & 25,0 & 25,0 & 25,0 \\
\hline
\end{tabular}

\subsection{Análises multivariadas}

Os resultados da análise de fatores aplicado às amostras de sedimento provenientes da coleta 2, encontram-se na Tabela 12. Os valores destacados em negrito são aqueles onde foi observada correlação. 
Tabela 12. Resultados das análises de fatores da coleta 2.

\begin{tabular}{|c|c|c|}
\hline Variáveis & Fator 1 & Fator 2 \\
\hline Cádmio & 0.980824 & -0.025124 \\
\hline Chumbo & 0.988649 & 0.144365 \\
\hline Cobre & 0.965905 & 0.091231 \\
\hline Cromo & 0.975211 & 0.137624 \\
\hline Mercúrio & 0.988698 & 0.082135 \\
\hline Níquel & 0.976290 & 0.019491 \\
\hline Zinco & 0.996557 & 0.043179 \\
\hline$\Sigma$ de HPA's & -0.521522 & 0.742178 \\
\hline Sedimento integral (C. dubia) & -0.136776 & -0.895068 \\
\hline Elutriato (C. dubia) & 0.768802 & -0.024076 \\
\hline Sedimento integral $(H$. azteca $)$ & 0.623692 & 0.234688 \\
\hline Água intersticial ( $V$. fischerı) & 0.551137 & 0.805258 \\
\hline Expl. Var & 8.321737 & 2.113799 \\
\hline Prp. Totl & 0.693478 & 0.176150 \\
\hline
\end{tabular}

A seguir, pode-se observar nas Figuras 30 (a; b) e 31 (a; b) e 32, a pontuação estimada de cada fator analisado em cada ponto, durante a coleta $2 \mathrm{e}$, na Tabela 13, a porcentagem de variação dos dados explicada pelo fatores 1 e 2 e o total (destacado).
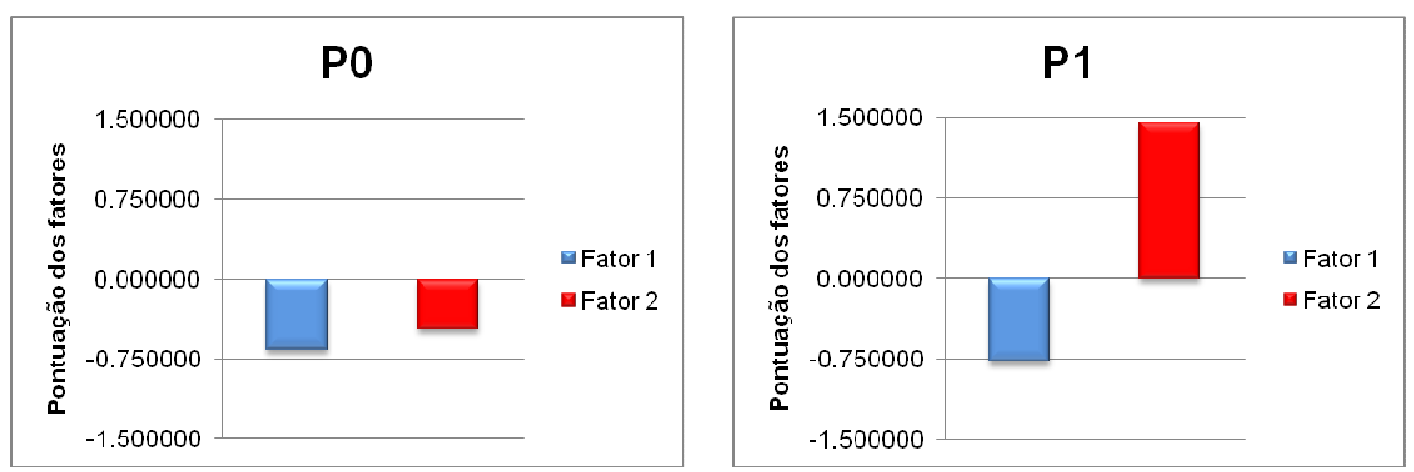

Figura 30 a e b. pontuação estimada para os fatores 1 e 2 nos pontos P0 e P1. 

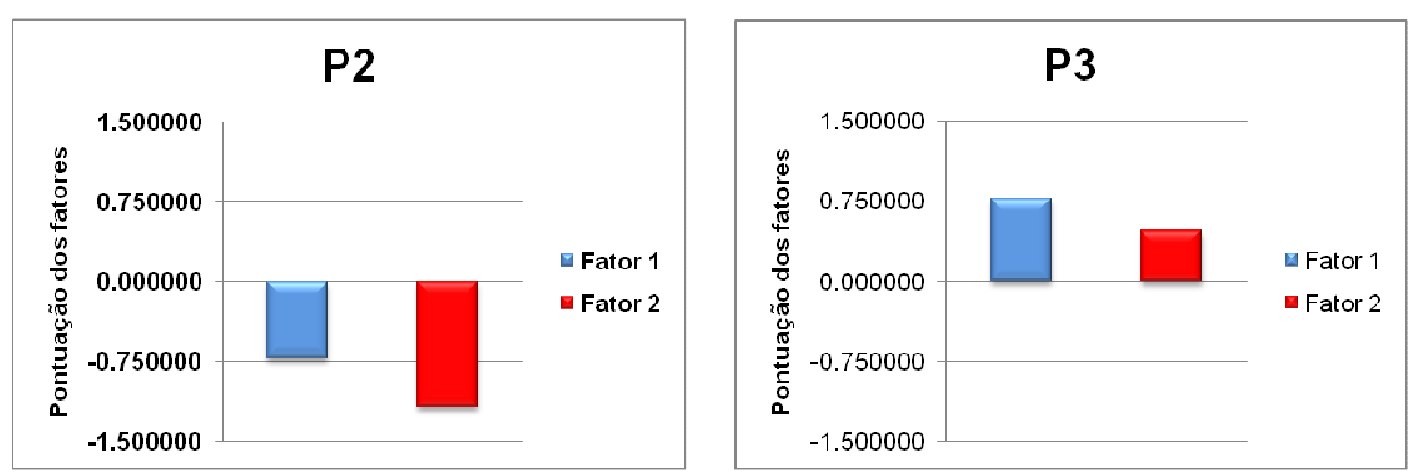

Figura 31 a e b. Pontuação estimada para os fatores 1 e 2 nos pontos P2 e P3.

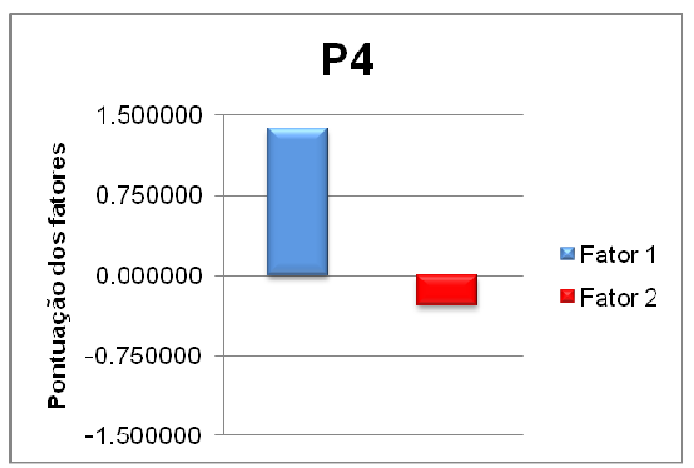

Figura 32. Pontuação estimada para os fatores 1 e 2 no ponto P4.

Tabela 13. Variação dos dados de cada fator analisado na coleta 2.

\begin{tabular}{lcccc}
\hline & Peso & $\begin{array}{c}\text { \% total da } \\
\text { variância }\end{array}$ & $\begin{array}{c}\text { Peso } \\
\text { cumulativo }\end{array}$ & \% Cumulativa \\
\hline Fator 1 & 8.420868 & 70.17390 & 8.42087 & 70.17390 \\
Fator 2 & 2.014667 & 16.78889 & 10.43554 & $\mathbf{8 6 . 9 6 2 8 0}$ \\
\hline
\end{tabular}

Os resultados da análise de fatores aplicado às amostras de sedimento provenientes da coleta 3 , encontram-se na Tabela 14. Os valores destacados são aqueles onde foi observada correlação. 
Tabela 14. Resultados das análises de fatores da coleta 3.

\begin{tabular}{ccc}
\hline Variáveis & Fator $\mathbf{1}$ & Fator 2 \\
\hline Cádmio & $\mathbf{0 . 9 6 8 2 4 8}$ & 0.163405 \\
Chumbo & $\mathbf{0 . 9 9 9 0 6 6}$ & -0.011264 \\
Cobre & $\mathbf{0 . 9 9 8 8 0 4}$ & 0.048515 \\
Cromo & $\mathbf{0 . 8 4 8 5 1 0}$ & $\mathbf{- 0 . 5 0 9 7 0 7}$ \\
Mercúrio & $\mathbf{0 . 8 9 6 0 1 7}$ & $\mathbf{- 0 . 3 9 9 7 7 6}$ \\
Níquel & $\mathbf{0 . 9 3 6 3 0 9}$ & -0.290834 \\
Zinco & $\mathbf{0 . 9 7 9 9 5 8}$ & -0.138040 \\
I de HPA's & $\mathbf{- 0 . 4 5 9 2 5 3}$ & $\mathbf{0 . 6 6 9 9 0 4}$ \\
Sed. Integral C. dubia & $\mathbf{0 . 7 6 0 9 2 4}$ & $\mathbf{0 . 5 7 8 6 4 6}$ \\
Elutriato C. dubia & 0.013799 & $\mathbf{0 . 9 9 4 6 3 1}$ \\
Sed. Integral H. azteca & -0.202133 & $\mathbf{- 0 . 9 1 1 8 8 1}$ \\
Á. Intersticial V. fischeri & -0.348296 & $\mathbf{0 . 5 1 5 2 3 2}$ \\
\hline Expl. Var & 7.245332 & 3.422328 \\
Prp. Totl & 0.603778 & 0.285194 \\
\hline
\end{tabular}

A seguir, pode-se observar nas Figuras 33 ( $a$; b) e 34 (a; b) a pontuação estimada de cada fator analisado em cada ponto, durante a coleta $3 \mathrm{e}$, na Tabela 15, a porcentagem de variação dos dados explicada pelo fatores 1 e 2 e o total (destacado).
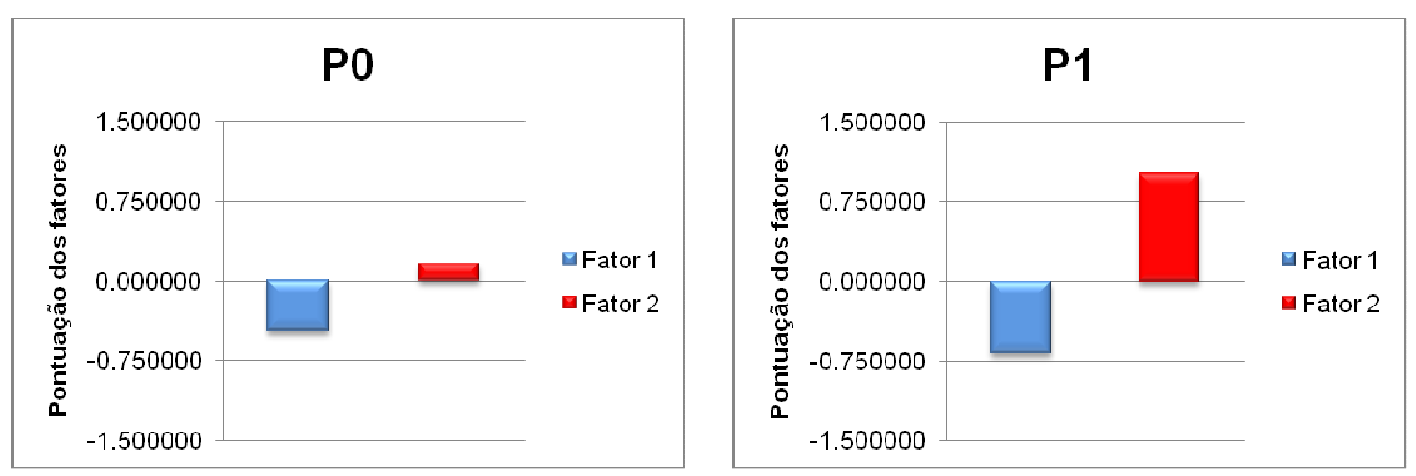

Figura 33 a e b. Pontuação estimada para os fatores 1 e 2 nos pontos P0 e P1. 

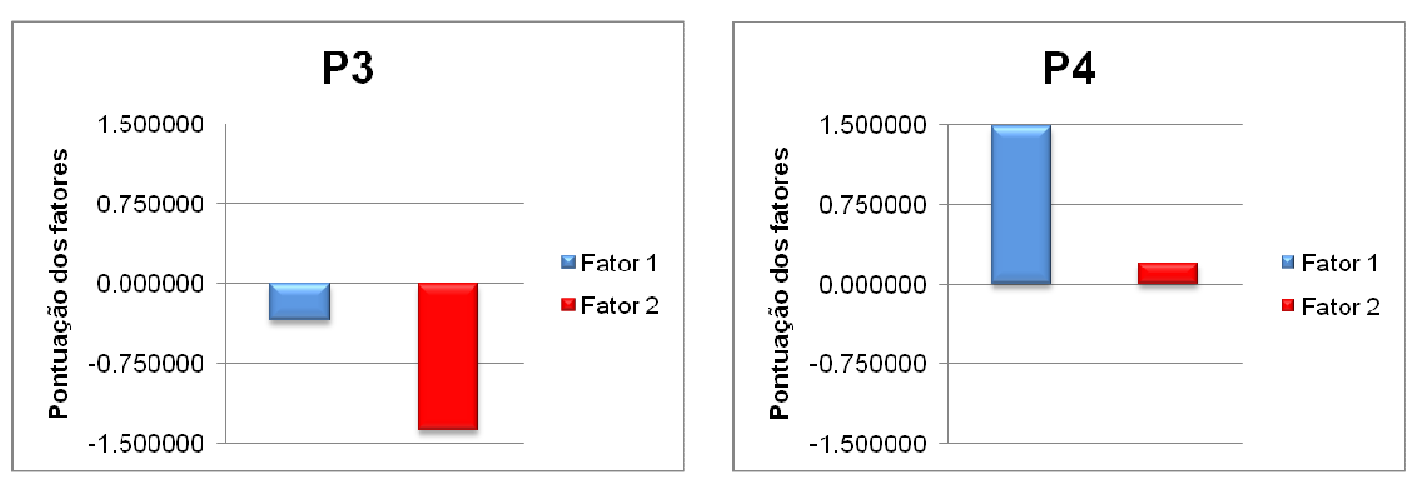

Figura 34 a e b. Pontuação estimada para os fatores 1 e 2 nos pontos P3 e P4.

Tabela 15. Variação dos dados de cada fator analisado na coleta 3.

\begin{tabular}{lcccc}
\hline & Peso & $\begin{array}{c}\text { \% total da } \\
\text { variância }\end{array}$ & $\begin{array}{c}\text { Peso } \\
\text { cumulativo }\end{array}$ & \% Cumulativa \\
\hline Fator 1 & 7.426459 & 61.88716 & 7.42646 & 61.88716 \\
Fator 2 & 3.241201 & 27.01001 & 10.66766 & $\mathbf{8 8 . 8 9 7 1 7}$ \\
\hline
\end{tabular}




\section{DISCUSSÃO}

\subsection{A Presença de metais no ambiente e riscos associados}

Segundo Rodgher et al., (2005), metais são elementos extremamente importantes nos ecossistemas aquáticos, pois são essenciais em pequenas concentrações. Porém quando em altas concentrações, apresentam elevada toxicidade podendo ainda bioacumular e biomagnificar nas cadeias tróficas, apresentando riscos para os predadores de topo da cadeia alimentar, incluindo o homem.

Neste trabalho os valores de metais obtidos foram comparados aos níveis estabelecidos pela CONAMA 344 e aos Valores de Referência Regionais para sedimentos límnicos (VRR) estabelecidos por Nascimento (2003).

Arsênio: embora o metalóide arsênio não tenha sido detectado através de ICPOES em nenhum dos pontos avaliados (Tabela 8), quando foi quantificado por meio de análise por ativação neutrônica (ANN) nas mesmas amostras (Tabela 8), esse elemento foi encontrado no ponto P0 (amostra proveniente da coleta 3 ) e nos pontos P3 e P4 (amostras provenientes das coletas 2 e 3).

Cádmio e cobre: a partir da Tabela 9, pode-se observar que as concentrações de cádmio potencialmente biodisponíveis dos pontos P3 (coleta 2) e P4 (coletas 2 e 3) estiveram acima do valor de referência regional, estabelecidos por Nascimento (2003), evidenciando sinais de contaminação.

Os pontos P3 e P4 também foram os que apresentaram maiores concentrações de cobre (Tabela 9). O ponto P3 apresentou concentração acima do nível 1 e do valor de referência regional (VRR), enquanto que na amostra P3 (coleta 2) apresentou concentrações acima do nível 1 e também do VRR nas amostras das coletas 2 e 3. No trabalho realizado por Gusmão (2004) este metal mostrou-se mais tóxico do que o cromo aos cladóceros.

Cromo: as concentrações de cromo dos pontos P3 (coleta 2) e P4 (coletas 2 e 3) apresentaram-se acima do Nível 1 estabelecido pelo CONAMA na resolução 344 e do valor de referência regional (VRR) (Nascimento, 2003), (Tabela 9) indicando 
uma possível contaminação ambiental também oriunda principalmente de fontes industriais.

A concentração total de cromo nos mesmos pontos (Tabela 9), apresentaramse acima do nível 2, onde já são esperados efeitos à biota aquática e, dos valores de referencia regionais (VRR). No ponto P0 a concentração total de cromo ultrapassou o nível 1 e o VRR. Apesar de apresentar toxicidade geralmente baixa quando comparado a outros metais, o cromo possui alta capacidade de bioacumulação ao longo da cadeia trófica (Gusmão, 2004)

Mercúrio: nas coletas 2 e 3, o mercúrio foi quantificado por meio de CV-AAS, sendo detectado em todos os pontos amostrados (Tabela 9), porém os pontos P3 e P4 foram aqueles que apresentaram concentrações de mercúrio acima do nível 1 do CONAMA nas duas coletas em que esse metal foi quantificado. O ponto P3 apresentou concentrações muito próximas no nível 2 e, o ponto P4 concentrações acima do nível 2 nas coletas 2 e 3.

Níquel e zinco: Como pode-se observar na Tabela 9, apenas no ponto P4 as concentrações potencialmente biodisponíveis de níquel ultrapassaram o nível 1 estabelecido pelo CONAMA nas duas coletas em que esse metal foi quantificado.

Com referência ao zinco, concentrações importantes foram observadas nos pontos P3 e P4, sendo que na coleta 3, a concentração desse metal no P3 esteve acima do nível 1 do CONAMA e, na coleta 2, a concentração ultrapassou o nível 2. No ponto P4, nas duas coletas em que foi quantificado, o zinco esteve presente em concentrações acima do nível 2.

Com relação às concentrações totais de zinco (Tabela 9), os dois pontos (P3 e P4) também foram aqueles que apresentaram as maiores concentrações desse metal.

Chumbo: os pontos P3 e P4 foram os únicos que apresentaram concentrações de chumbo potencialmente biodisponíveis acima do nível 1 (CONAMA 344), ou seja, em uma concentração onde ocasionalmente espera-se efeitos aos organismos aquáticos, Entretanto, estes valores estão abaixo valor de referência regional de sedimentos fluviais do Rio Tietê (Nascimento, 2003) como mostra a Tabela 9. 


\subsection{Hidrocarbonetos policíclicos aromáticos (HPA’S)}

Assim como os metais, os hidrocarbonetos são poluentes merecedores de atenção quando se avalia a qualidade dos sedimentos, pois possuem elevado potencial tóxico e cancerígeno (Meire et al., 2007).

Como demonstrado na Tabela 8, os pontos onde foram encontradas as maiores concentrações de HPA's foram P1 e P2. No ponto P2, principalmente na coleta 3 , foram encontradas elevadas concentrações de fenantreno, fluoranteno e pireno, chegando a valores até 15 vezes mais elevados do que aqueles estabelecidos pelo nível 2 da resolução CONAMA 344.

O ponto $\mathrm{P} 1$ apresentou, na coleta 3 concentrações de fenantreno e pireno mais de quinze vezes acima das estabelecidas pelo nível 2. Na coleta 3, o ponto P3 apresentou concentração de fenantreno 3 vezes superior àquela estabelecida pelo nível 2 (Tabela 8).

\subsection{Amônia}

Segundo Moore et al., (1997) e Carr et al., (2001), a presença de altas concentrações de amônia não-ionizada pode interferir de sobremaneira nos resultados de testes de toxicidade com água intersticial. Abessa (2002), enfatiza que a presença desse interferente pode produzir resultados falsos positivos (efeito negativo devido ao interferente e não aos contaminantes) devendo esta, ser avaliada e considerada na interpretação dos resultados.

O Conselho Nacional do Meio Ambiente (CONAMA) na resolução 20 de 1986 estabelece um limite de $0,02 \mathrm{mg} / \mathrm{L}$ de amônia não ionizada para a proteção da vida aquática (CONAMA, 1986) em rios de classe 1 e 2. Atualmente o CONAMA 357 de 2005, expressa o valor em Amônia total (mais especificamente como nitrogênio amoniacal total) em função do $\mathrm{pH}$ (CONAMA, 2005).

O conhecimento da concentração de amônia não ionizada nas amostras e a sensibilidade do organismo-teste a essa substância são essenciais para a avaliação dos resultados dos testes de toxicidade com sedimento e suas frações, uma vez que 
o efeito tóxico observado pode ser devido à presença de concentrações que são diretamente tóxicas para o organismo teste (CARR et al., 2001).

De acordo com Schiff et al., (1992), para a bactéria $V$. fisheri a concentração de amônia não ionizada responsável por causar diminuição da luminescência em 50\% das bactérias expostas é de cerca de 1,49 mg/L.

Andersen \& Beckley (1994), avaliaram diferentes concentrações de amônia não ionizada encontrando a concentração média de $1,18 \mathrm{mg} / \mathrm{L}$ como aquela capaz de causar mortalidade a organismos de C. dubia em um período de 48 horas. Cowgill \& Milazzo também avaliaram a concentração da amônia capaz de causar efeitos aos organismos em 48 horas, chegando a uma CE50\% de 1,00 mg/L.

Em um trabalho recente na região do Alto Tietê, Araújo et al., (2006b) realizaram a caracterização dos sedimentos do Barragem do Rasgão com o objetivo de identificar quais contaminantes foram responsáveis pelos efeitos observados nos ensaios de toxicidade (TIE - Toxicity Identification Evaluation). Os autores concluíram que nos ensaios com Ceriodaphnia dubia elevadas concentrações de amônia foram as maiores responsáveis pela toxicidade.

Pode-se observar na Tabela 11 que os maiores valores de amônia não ionizada foram obtidos nos pontos P1 e P4, provavelmente relacionados à maior concentração de matéria orgânica associada ao sedimento, entretanto, os valores de amônia não ionizada encontrados em todos os pontos avaliados neste trabalho estiveram abaixo do limiar de efeitos para as espécies utilizadas nos ensaios com elutriato ( $C$. dubia) e água intersticial ( $V$. fischeri), não sendo este um fator interferente no resultado dos ensaios de toxicidade.

\subsection{Toxicidade}

Neste trabalho quando os resultados dos ensaios de toxicidade foram tratados estatisticamente utilizando os testes "F" e "t", foram obtidas 30 ocorrências de toxicidade (aguda e crônica), enquanto que para o tratamento com o teste "t" por bioequivalência foram obtidas 21 ocorrências, sendo possível observar que essa 
ferramenta estatística diminuiu a freqüência de toxicidade. Esses resultados sugerem cautela na utilização do teste "t" por bioequivalência, pois embora considere um fator biológico para cada organismo, tornando menor a ocorrência de falsos positivos e seja atualmente recomendada pela agência reguladora do estado de São Paulo (CETESB).

Com relação aos ensaios de toxicidade e fases estudadas, as amostras de água intersticial apresentaram elevada toxicidade para a bactéria $V$. fischeri. Embora não seja a principal rota de exposição para os organismos planctônicos e epibentônicos, a avaliação da água intersticial constitui uma etapa efetiva em programas de avaliação ambiental como um relevante indicador da toxicidade do sedimento, sendo muito importante principalmente quando combinada com outras rotas de exposição (Chapman \& Wang, 2001).

O ensaio com amostras de sedimento integral utilizando $H$. azteca apresentaram resultados mais condizentes com a realidade dos pontos amostrados em relação aos ensaios com $C$. dubia. Amostras provenientes de pontos visivelmente degradados, à jusante de áreas industrializadas (P3 e P4), foram mais tóxicos ao organismo $H$. azteca do que à $C$. dubia, exposta principalmente à interface sedimento-água, justificando a escolha do organismo $H$. azteca pela CETESB, bem como por muitos autores no Brasil e no exterior, na avaliação da toxicidade dos sedimentos.

Porém, o estudo da contaminação dos sedimentos utilizando organismos planctônicos como C. dubia também são bastante significativos, pois segundo Meletti et al., (2003), muitos contaminantes presentes nos sedimentos podem se difundir para a coluna d'água pela constante atividade dos organismos bentônicos e também após eventos como chuvas e ventos intensos, dragagens e turbulência causada por embarcações. Por esse motivo ensaios com elutriato dos sedimentos foram realizados utilizando $C$. dubia a fim de simular a ressuspensão dos sedimentos (principalmente devido a atividades de dragagens e aporte de água pluvial) possibilitando avaliar os efeitos de uma possível re-biodisponibilização dos contaminantes para a coluna d’água. 


\section{Ponto P0}

O reservatório de Ponte Nova (Ponto P0) foi escolhido como ponto referência devido à sua proximidade da nascente do Rio Tietê e, principalmente, por suas águas serem utilizadas para abastecimento público.

Os sedimentos desse ponto apresentaram uma coloração alaranjada, presença de vegetação e resíduos de galhos e folhas, e ausência de odor em todas as coletas realizadas.

Dentre os ensaios de toxicidade realizados com amostras de sedimento no reservatório Ponte Nova, foi observada apenas toxicidade crônica no ensaio com sedimento integral ( $C$. dubia) durante as coletas 2 e 3, e no ensaio com elutriato na coleta 2. Todavia se fôr excluída umas das réplicas dos dados brutos obtidos na coleta 3, o ensaio passa a ser classificado como "não tóxico".

Quando os resultados das análises químicas e dos ensaios de toxicidade da coleta 2 foram integrados por meio das análises multivariadas, a toxicidade encontrada nos ensaios com amostras de elutriato e sedimento integral (C. dubia) não foram correlacionados com nenhum dos contaminantes detectados (Figura 30a), sendo assim, o efeito observado pode ter sido causado por outro fator não elucidado neste trabalho. Porém, a toxicidade observada no ensaio com sedimento integral ( $C$. dubia) com a amostra proveniente da coleta 3 mostrou forte correlação com as concentrações de cromo, mercúrio (que apresentou concentrações em níveis onde são esperados efeitos à biota) e HPA's (Figura 33a).

Embora em pequenas concentrações (Tabela 9), os metais presentes no ponto P0 podem ter causado os efeitos observados na coleta 2, pois segundo Silvério (2003), mesmo quando presentes em baixas concentrações pode haver um efeito aditivo entre os metais, resultando em toxicidade.

Apesar da toxicidade observada nas amostras de sedimento, as amostras de água analisadas (coletas 3 e 4) não apresentaram toxicidade crônica para $C$. dubia (Tabela 7). 


\section{Ponto P1}

À jusante do reservatório de Ponte Nova, o Ponto P1 está localizado no Rio Tietê, abaixo da ponte em um trecho da estrada entre Salesópolis e Biritiba-Mirim, próximo da Empresa VCN de mineração de areia (Figura 6). Durante todas as coletas realizadas neste ponto, foi possível observar muita matéria orgânica nos sedimentos, que se apresentaram sempre com coloração escura e granulometria bastante fina.

Os ensaios com amostras de sedimento integral utilizando os organismos $H$. azteca e $C$. dubia não apresentaram toxicidade aguda ou crônica, porém os ensaios com a elutriato das coletas 2, 3 e 4 apresentaram toxicidade crônica (Tabela 7). A água intersticial apresentou elevada toxicidade à Vibrio fischeri em todas as coletas realizadas conforme a Tabela 7 .

Nas análises multivariadas, a toxicidade desse ponto nos ensaios com elutriato e água intersticial, esteve fortemente correlacionada com a presença de HPA's nas coletas 2 e 3 (Figuras 30b e 33b), possivelmente devido às elevadas concentrações de fluoranteno e pireno encontradas nesse ponto, principalmente na coleta 3 (Tabela 8).

Estes dois compostos apresentam solubilidade relativamente baixa $0,26 \mathrm{mg} / \mathrm{L}^{-1}$ (pireno) e 0,132 mg/L (fluoranteno) (Meire et al., 2007). Embora não tenha sido realizada a quantificação destes compostos na água intersticial e elutriato, segundo Eom et al., (2007) concentrações da ordem de $\mu \mathrm{g} / \mathrm{L}$ destes dois compostos já são capazes de causar efeitos à $C$. dubia e $V$. fischeri.

A concentração de amônia não-ionizada na água intersticial do ponto $P 1$ foi a maior encontrada entre os pontos amostrados (Tabela 11), porém abaixo dos limiares de efeito para os organismos utilizados neste trabalho, não contribuindo de forma direta na toxicidade.

Durante a realização deste trabalho, o ponto P1 apresentou toxicidade crônica na amostra de água da coleta 3 (setembro de 2008), conforme apresentado na Tabela 7. 
O ponto onde foram realizadas as coletas de sedimentos é muito próximo ao ponto de amostragem "TIET02050" onde a CETESB coleta amostras de água para análises físico-químicas e biológicas, sendo os resultados utilizados para compor o Relatório de Qualidade de Águas Interiores.

Amostras de água deste ponto tiveram inúmeras variáveis analisadas na composição do Índice de Qualidade da Água (IQA) como Coliformes fecais, pH, DBO, nitrogênio total, fósforo total, temperatura, turbidez, resíduo total e oxigênio dissolvido a fim de avaliar a qualidade das águas, tendo como principal objetivo a sua utilização para o abastecimento público. Já o Índice de Proteção da Vida Aquática (IVA) leva em consideração a presença e concentração de contaminantes químicos tóxicos, seu efeito sobre os organismos aquáticos (toxicidade), além do pH e oxigênio dissolvido, essenciais para manutenção da vida.

Segundo o relatório referente ao ano de 2008, a água deste ponto apresentou classificação do IQA "BOA" sendo que no mês de setembro, a classificação foi "ÓTIMA". Foi verificada toxicidade crônica em ensaios com C. dubia nos meses de julho e setembro, corroborando com o resultado obtido neste trabalho. O IVA obteve a classificação "REGULAR" neste local (CETESB, 2009).

Esse ponto foi classificado como ambiente mesotrófico, com baixas concentrações de fósforo e metais na água, além da concentração de oxigênio dissolvido em torno de 5,0 mg/L nos últimos anos (CETESB, 2009).

\section{Ponto P2}

O ponto P2 localiza-se na calha do Rio Tietê, após sua passagem pela área urbana do município de Biritiba-Mirim, ao lado da ponte sobre o rio, na estrada do Rio Acima (Figura 7), próximo ao ponto de captação da Sabesp. Os sedimentos do ponto P2 apresentaram a maior granulometria entre os pontos amostrados neste trabalho. Em todas as coletas não apresentaram matéria orgânica aparente e, muitas vezes foi observada a presença de pequenos bivalves nas amostras de sedimento. 
Nos meses entre as coletas 2 e 3, ocorreu a pavimentação da estrada do Rio Acima, esse fato pode explicar as concentrações extremamente elevadas de HPA's observadas na amostra proveniente da coleta 3 (Tabela 8), uma vez que a estrada passa muito próxima do rio.

O ponto 2 foi o que apresentou melhor qualidade com relação à toxicidade (uma ocorrência), durante todas as coletas realizadas neste trabalho, apenas 0 ensaio com sedimento integral utilizando a amostra de proveniente da coleta 2 apresentou toxicidade crônica, porém esse efeito não foi correlacionado a nenhum dos contaminantes encontrados nesse ponto, conforme Figura 31a.

As amostras de água deste ponto avaliadas com C. dubia não apresentaram toxicidade crônica (Tabela 7).

O ponto P2 fica próximo ao ponto de coleta da CETESB "TIET02090". Segundo o Relatório da Qualidade das Águas Interiores (CETESB, 2009), a água deste ponto apresentou classificação "BOA" para o Índice de qualidade da água (IQA) e regular para índice de proteção da vida aquática (IVA).

Embora tenham sido observadas concentrações altas de fósforo em alguns momentos, o ambiente foi classificado como "mesotrófico", os metais e o fósforo estiveram em concentrações baixas ao longo dos últimos anos e, a concentração de oxigênio dissolvido em torno de 5,5 mg/L (CETESB, 2008; 2009).

\section{Ponto P3}

O ponto P3 (Figura 8) localiza-se na calha do Rio Tietê sob ponte da avenida Valentina Borenstein, próximo ao parque Leon Feffer no município de Mogi das Cruzes. Nesse ponto, o rio já atravessou a cidade de Mogi das Cruzes, recebendo diversos efluentes industriais e domésticos.

Durante todas as coletas, os sedimentos deste ponto apresentaram um forte odor de hidrocarbonetos (óleo) além de muitos materiais sintéticos (plástico, isopor, nylon, etc.), coloração escura e granulometria muito fina. Foram observadas também a presença de um efluente na margem esquerda do rio e constantemente, a 
presença de aves aquáticas no local e pegadas de capivara na margem direita do rio.

Com relação aos ensaios de toxicidade, o ponto P3 foi o que apresentou os piores resultados (12 ocorrências) uma vez que, em todas as coletas onde foi realizado ensaio com amostras de sedimento integral utilizando $H$. azteca foi encontrada toxicidade aguda, com níveis de sobrevivência muito próximos a zero (Figura 25).

Embora não tenha sido observada toxicidade crônica para $C$. dubia nos sedimentos das coletas 2 e 3, a amostra da coleta 1 apresentou toxicidade crônica e, a amostra da coleta 4, indícios de toxicidade aguda, pois apresentou mortalidade superior a $60 \%$ dos organismos expostos (Tabela 8 do Anexo I).

O elutriato do ponto P3 apresentou toxicidade aguda para $C$. dubia nas coletas 1 e 4 sendo observada mortalidade de todos os organismos expostos após um período de 48 horas (Tabelas 8 e 11 do anexo I) e, toxicidade crônica na coleta 2 . Na coleta 3 não foi observada toxicidade crônica para $C$. dubia, porém quando foi realizado ensaio com a bactéria $V$. fischeri (Tabela 6) essa amostra apresentou elevada toxicidade (CE50=13,61\%).

A água intersticial do ponto P3 apresentou elevada toxicidade nas coletas 1, 2 e 3 (Tabela 5).

Por meio das análises multivariadas, a toxicidade da amostra proveniente da coleta 2 foi fortemente correlacionada com a presença dos metais cádmio, chumbo, cobre, cromo, mercúrio, níquel e zinco, muitas vezes encontrados em concentrações onde ocasionalmente ocorrem efeitos à biota.

Embora não tenha sido observada a presença de hidrocarbonetos, conforme a Tabela 8, o ponto P3 apresentou correlação com o fator 2 (HPA's) na coleta 2 (Figura 31b), muito provavelmente devido ao fato de apresentar elevada toxicidade nas amostras de água intersticial ( $V$. fischeri) e toxicidade crônica no ensaio com sedimento integral ( $C$. dubia), sendo que estes ensaios foram correlacionado com as concentrações de HPA's. 
Na coleta 3, a toxicidade do ensaio com sedimento integral ( $H$. azteca) e água intersticial ( $V$. fischeri) não foi correlacionada com nenhum dos contaminantes encontrados nesse ponto (Figura 34a), podendo ter sido causada por outro fator não elucidado neste estudo.

Embora as amostras de sedimentos e suas fases aquosas tenha apresentado elevada toxicidade, as amostras de água do Rio Tietê das coletas 3 e 4 não apresentaram toxicidade crônica para C. dubia (Tabela 7).

\section{Ponto P4}

O ponto P4 localiza-se na calha do Rio Tietê após sua passagem pela ETE Suzano, próximo à avenida Miguel Badra no município de Suzano. Nesse ponto, o rio já atravessou as cidades de Mogi das Cruzes e Suzano, recebendo toda carga de efluentes industriais e domésticos destas cidades, além do efluente da ETE.

Os sedimentos desse ponto apresentaram coloração escura, com a presença além de materiais sintéticos (plásticos, nylon e isopor) e forte odor de matéria orgânica.

Os sedimentos do ponto P4 apresentaram toxicidade aguda à Hyalella azteca nas coletas 2 e 3 (Tabela 7). Quando os sedimentos foram avaliados utilizando 0 organismo Ceriodaphnia dubia, foi observada toxicidade crônica nas coletas 1, 2 e 3 (Tabela 7).

O elutriato desse ponto apresentou toxicidade aguda para C. dubia na coleta 2, sendo observada mortalidade de todos os organismos expostos após um período de 48 horas (Tabela 9 do anexo I). Quando avaliadas utilizando-se a bactéria Vibrio fischeri as amostras provenientes das coletas 3 e 4 também apresentaram elevada toxicidade conforme Tabela 5.

A água intersticial desse ponto apresentou toxicidade aguda para $V$. fischeri nas coletas 2 e 3 (Tabela 5).

Com relação às análises multivariadas, conforme pode-se observar nas Figuras 32 e 34b, a toxicidade observada nas coletas 2 e 3 esteve fortemente correlacionada às concentrações dos metais cádmio, chumbo, cobre, cromo, mercúrio, níquel e 
zinco pois estes metais apresentaram níveis onde são esperados efeitos à organismos aquáticos (CONAMA 344, 2004).

O ponto P4 coincide com o ponto de amostragem da CETESB "TIET03120". Segundo o relatório de Qualidade de Águas Interiores de 2009, neste ponto o rio Tietê começa a sofrer impactos expressivos do lançamento de esgotos domésticos e industriais, o que resultou na classificação "PÉSSIMO" do IQA e IVA. Este relatório mostrou também uma significativa redução do oxigênio dissolvido nas águas, com uma concentração média de 0,5 mg/L nos últimos anos (CETESB, 2009).

Devido a esse aporte de efluentes a concentração de metais e de fósforo e nitrogênio amoniacal sempre estiveram altos, sendo este ponto classificado como um ambiente "Hipereutrófico" (CETESB, 20009). Porém a concentração de amônia não-ionizada na água intersticial proveniente do sedimento da coleta 3 também esteve abaixo do limiar de efeito para os organismos-teste utilizados neste trabalho.

Embora neste trabalho tenham sido realizadas coletas em épocas distintas do ano visando abranger períodos chuvosos e secos (verão e inverno) não foi possível estabelecer uma relação entre a quantidade de chuvas e a toxicidade apresentada nos pontos avaliados.

Alguns dos poucos trabalhos realizados na região do Alto Tietê se preocuparam mais em determinar contaminantes e efeitos nos reservatórios do que na calha do rio.

Rodgher et al., (2005) avaliaram a qualidade dos reservatórios ao longo do Rio Tietê e concluíram que os reservatórios que fazem parte das bacias do Médio e Baixo Tietê, encontram-se bastante comprometidos, sendo que boa parte dos metais e compostos orgânicos chegam a esses reservatório principalmente trazidos pelos rios Tietê (após sua passagem pela região metropolitana de São Paulo) e Piracicaba.

Bramorsky (2004) avaliou os rios Piracicaba e Tietê em seus compartimentos de entrada no reservatório de Barra Bonita, constatando também que o maior aporte de contaminantes que chegam ao reservatório de Barra Bonita são trazidos pelo Rio Tietê, apontando este como prioritário para aplicação de medidas mitigadoras. 
Durante o período de 1999 a 2003 foi realizado um importante projeto de caracterização química, ecotoxicológica e de alterações na comunidade bentônica ao longo do Rio Tietê, chamado projeto Qualised. Entre alguns dos inúmeros trabalhos resultantes desse projeto destaca-se o de Nascimento (2003), que propôs valores de referência para concentração de metais e metalóides em sedimentos de reservatórios e rios da Bacia Hidrográfica do Tietê e, o de Silvério (2003) que visou a elaboração de valores-guia de qualidade de sedimentos para metais na mesma região de estudo.

Um trabalho recente, realizado por Rocha et al, (2009) avaliou o potencial genotóxico dos sedimentos dos reservatórios de Ponte Nova, Billings, Barra Bonita, Bariri, Promissão e Três Irmãos. Trabalho que apontou elevada genotoxicidade no reservatório Billings e, moderada genotoxicidade no reservatório de Ponte Nova; evidenciando efeitos já no primeiro reservatório do Rio Tietê, localizado à montante da Região Metropolitana de São Paulo.

Segundo Medaglia e Cunha (2009) no fim do século 19 o Rio Tietê teve suas águas destinadas para a geração de energia. Para esse fim, não houve preocupação em tratar os esgotos antes do lançamento, causando um rápido comprometimento do rio que, desde então, é visto apenas como uma obra hidráulica utilizada no controle de enchentes e como destino final de diversos efluentes industriais e domésticos.

O que chama atenção é a velocidade que ocorreu o processo de degradação do rio, em menos de 100 anos, o Tietê passou de marco da cidade de São Paulo, palco de provas de natação e remo, pescarias e lazer, a um exutório natural, recebendo toda sorte de substâncias nocivas e perdendo totalmente sua vivacidade.

Embora ações tomadas no Projeto Tietê, criado em 1992, como a construção de três estações de tratamento de esgotos (ETEs Parque Novo Mundo, ABC e São Miguel) e ampliação da ETE Barueri tenham reduzido de forma considerável a descarga de efluentes industriais e domésticos não tratados (a porcentagem que era de $83 \%$, passou a 61\%) no rio, o quadro ainda é bastante crítico (http://www2.sabesp.com.br/projetotiete). A ETE Suzano desempenha papel 
importantíssimo na região (Alto Tietê) mas por receber efluentes industriais em volumes elevados, merece muita atenção no gerenciamento e qualidade de seus efluentes.

Os resultados obtidos neste trabalho podem auxiliar em programas de gerenciamento e recuperação do Rio Tietê, pois apontam uma significativa contaminação dos sedimentos por metais pesados, principalmente nos pontos à jusante do município de Mogi das Cruzes e, HPA's nos pontos próximos ao município de Biritiba-Mirim.

Esses resultados devem ser considerados antes da realização de atividades de dragagem para rebaixar a calha do rio em programas de desassoreamento para contenção de enchentes, pois poderia haver uma re-biodisponibilização dos contaminantes para a coluna d'água, contaminando áreas menos impactadas à jusante do curso do rio.

Com relação ao rio, ainda hoje um parâmetro de vital importância para o rio e sua biota é, sem dúvida, o oxigênio dissolvido nas águas, sendo necessário haver um controle muito forte das fontes de poluição. Com o término das obras da $2^{\underline{a}}$ fase, em 2008, o índice de coleta de esgoto na região Metropolitana saltou de $80 \%$ para $84 \%$ e o de tratamento, de $62 \%$ para $70 \%$. Além disso, cerca de 400 milhões de litros de esgoto deixaram de ser despejados diariamente na bacia do Alto Tietê. Houve ainda umaforte movimentação de indústrias que preferiram mudar suas atividades para outras regiões. 


\section{CONCLUSÕES}

Da exposição dos organismos-teste ao sedimento integral resultaram que o local denominado ponto P3 foi o que causou maior mortalidade à Hyalella azteca e para Ceriodaphnia dubia os piores efeitos também foram obtidos em P3, P4 e P2 (este somente na segunda coleta - março de 2008);

Os resultados obtidos para elutriato confirmaram o P3 como o local de maior efeito para Ceriodaphnia dubia, seguidos de P4 e P1;

A toxicidade obtida em água intersticial reforçou os resultados anteriores e apontou valores de elevada toxicidade para Vibrio fischeri no ponto P1 (5,96\% e $11,93 \%$ ), nos meses de setembro de 2008 e fevereiro de 2009;

Quanto aos ensaios de toxicidade nas águas do rio, os percentuais de reprodução mais baixos foram obtidos em P0, P1 e P4, para Ceriodaphnia dubia, nas condições experimentais;

Os pontos P1 e P2 apresentaram maior contaminação por HPA's, em particular na coleta 3;

Os pontos P3 e, principalmente P4 apresentaram maior contaminação por metais pesados;

Foi possível observar um aumento na concentração de contaminantes partindo do reservatório de Ponte Nova (Salesópolis) em direção à cidade de Suzano;

Não foi possível observar uma correlação entre os períodos de coleta (verão e inverno) e a toxicidade observada;

$\mathrm{O}$ tratamento estatístico utilizando o teste t por bioequivalência diminuiu o número de ocorrências tóxicas de 30 (quando utilizados teste "F" e "t" apenas) para 21 ocorrências;

As amostras de sedimento apresentaram efeitos negativos com maior freqüência em relação às amostras de água. 
8. SUGESTÕES PARA TRABALHOS FUTUROS

Avaliações dos sedimentos quanto a efeitos ecotoxicológicos in situ, no rio, bem como de alterações na comunidade bentônica;

Estudos da capacidade de liberação dos contaminantes para a coluna d'água. 


\section{REFERÊNCIAS BIBLIOGRÁFICAS}

Abessa, D.M.S. Avaliação da qualidade de sedimentos do Sistema Estuarino de Santos, SP, Brasil. 2002. Tese (Doutorado). Instituto Oceanográfico da Universidade de São Paulo, São Paulo.

Adams, W.J.; Kimerle, R.A.; Barnett JunioR, J.W. Sediment Quality and Aquatic Life Assessment. Environmetal Science and Technology, v. 26. n. 10, p. 1865-1875, 1992.

Andersen, H. B.; Buckley, J. A. Acute toxicity of ammonia to Ceriodaphnia dubia and a procedure to improve control survival. Bulletin of Environmental Contamination and Toxicology, n. 61, p. 116-122, 1998.

Ankley, G. T.; Katko, A. \& ARthur, J. W. Identification of ammonia as an important sediment-associated toxicant in the Lower Fox River and Green Bay Wisconsin. Environmental Toxicology and Chemistry, n. 9, p. 313-322, 1990.

Araújo, R. P. A. Testes de toxicidade como instrumento na avaliação dos sedimentos de água doce do Estado de São Paulo. 2005. Tese (Doutorado). Instituto de Biociências da Universidade de São Paulo. São Paulo.

Araújo, R. P. A.; Shimizu, G. Y.; Almeida, C. A.; Rocha, O. Testes com invertebrados para avaliar a toxicidade de contaminantes associados ao sedimento de ecossistemas de água doce. In: Mozeto, A. A.; Umbuzeiro, G. A.; Jardim, W. F. (Ed.) Projeto QUALISED Métodos de coleta, análises físico-químicas e ensaios biológicos e ecotoxicológicos de sedimentos de água doce. São Carlos, SP.: Cubo,. 2006(a). cap. 1 parte 3. 111 - $1301^{\text {a }}$ edição.

Araújo, R. P. A.; Botta-Paschoal, C. M. R., Silvério, P. F.; Almeida, V. F.; Rodrigues, P. F.; Umbuzeiro, G. A.; Jardim, W. F.; Mozeto, A. A. Application of toxicity identification evaluation to sediment in a highly contamined water reservoir in southeastern Brazil. Environmental Toxicology and Chemistry, v. 25, n. 2, p. 581588, 2006(b).

Associação Brasileira de Normas Técnicas. Ecotoxicologia aquáticaPreservação e Preparo de Amostras. ABNT, 2007. (NBR15469).

Associação Brasileira de Normas Técnicas. Ecotoxicologia aquática Determinação do efeito inibitório de amostras de água sobre a emissão de luz de Vibrio fischeri (Ensaio de bactéria luminescente) Parte 2: Método utilizando bactérias desidratadas. ABNT, 2006 (NBR 15411-2).

Associação Brasileira de Normas Técnicas. Ecotoxicologia aquática - Toxicidade crônica - Método de ensaio com Ceriodaphnia spp (Crustacea, cladocera). ABNT, 2005. (NBR 13373). 
Associação Brasileira de Normas Técnicas. Ecotoxicologia aquática - Toxicidade em sedimento - Método de ensaio com Hyalella spp (Amphipoda). ABNT, 2007. (NBR 15470).

Baudo, R., Beltrami, M., Rossi, D. In situ tests to assess the potencial of aquatic sediments. Aquatic Ecosystem Health and Management, v. 2, p. 361-365, 1999.

Bertoletti, E.; Buratini, S. V.; Prospéri, V. A.; Araújo, R. P. A.; Werner, L. I. Selection of Relevant Effect Levels for Using Bioequivalence Hypothesis Testing. Journal of the Brazilian Society of Ecotoxicology. v. 2, n. 2, p 139-145. 2007.

Besser, J. M., Brumbaugh, W.G., Allert, A. L., Poulton, B.C., SchmitT, C. J., Ingersoll, C. G. Ecological impacts of lead mining on Ozark streams: Toxicity of sediment and porewater. Ecotoxicological and Environmental Safety, v. 72, p. 516-526, 2009.

Borrely, S.I. Avaliação da redução da toxicidade de efluentes tratados por irradiação com feixe de elétrons, por meio de testes de toxicidade aguda. 2001.Tese (Doutorado) - Instituto de Pesquisas Energéticas e Nucleares - USP. São Paulo.

Borrely, S.I., Tornieri, P.H., Sampa, M.H. de O. Avaliação da Toxicidade Aguda em Efluentes Industriais, Afluentes e Efluentes de Estação de Tratamento de Esgotos. In ESPINDOLA, E. L. G,; PASCHOAL, C. M. R. B.; ROCHA, O. BOHRER, M. B. C.; NETO, A. L. O. Ecotoxicologia - Perspectivas para o século XXI. Ed. Rima. São Carlos. 2002. 575p.

Bower, C.E.; Bidwell, J.P. Ionization of ammonia in seawater: effects of temperature, $\mathrm{pH}$ and salinity. Journal of the Fisheries Research Board of Canada, n. 35, p. 1012-1016, 1978.

Bramorski, J. 2004. Avaliação da qualidade de sedimentos dos rios Tietê e Piracicaba nos seus compartimentos de entrada no reservatório de Barra Bonita, SP. Dissertação (Mestrado). Universidade de São Paulo, Escola de Engenharia de São Carlos, São Carlos.

Bulich, A. A. A practical and reliable method for monitoring the toxicity of aquatic samples. Process Biochemistry, March/April, 45-47, 1982.

Buratini, S. V. \& Bertoletti, E. Análises Estatística. In: Zagatto, P. A. \& Bertoletti, E. (Editores). Ecotoxicologia Aquática: Princípios e Aplicações. São Carlos, SP. Rima, 2006. p. 221-249.

Burton, Jr., G.A. Sediment Collection and Processing: Factors affecting realism. Sediment Toxicity Assessment. Boca Raton: Lewis Publishers, Cap 10, p. 213240. 1992. 
Burton, G. A. Jr; Denton, D. L.; HO, K.; Ireland, D. S. Sediment Toxicity Testing: Issues and Methods. In: Hoffman, D. J.; Rattner, B. A.; Burton, G. A. Jr.; Cairns, J. Jr. Handbook of Ecotoxicology. Boca Raton, FL. 2002. 2 Ed. p 111 - 150.

Campagna, A.F. 2005. Toxicidade dos sedimentos da Bacia Hidrográfica do rio Monjolinho (São Carlos): ênfase nas substâncias cobre, aldrin e heptacloro. Dissertação (Mestrado). Universidade de São Paulo, São Paulo.

Canadian Council of Ministers of the Environment. "Canadian Environmental Quality Guidelines - Summary Tables". CCME 1999, updated 2002. Canadian Sediment Quality Guidelines for the protection of Aquatic Life - Summary Tables.

CADEQ - Cadastro de Emergências Químicas da CETESB <http://www.cetesb.sp.gov.br/emergencia/estatisticas/estatisticas.pdf>, Acesso em 30 de agosto de 2009.

Carr, R.S., Nipper, M.G.; Adams, W.J.; Berry, W.; Burton Jr., G.A.; Ho, K.; MacDonald, D.; Scroggins, R \& Winger, P.V. Summary of a SETAC Technical workshop porewater toxicity testing: biological, chemical and ecological considerations with a review of methods and applications, and recommendations for future areas of research, 18 a 22 março de 2000; Pensacola, FL. SETAC. Society of Enviromental Toxicology and Chemistry. 2001.

Cesar, A. 2003. Análises ecotoxicologico integrado de la contaminacion marina en los sedimentos de la costa de Murcia: el caso de Portmán, sudeste España. Tese (Doutorado). Universidad de Múrcia. Espanha.

Cesar, A.; Abessa, D. M. S.; Pereira, C. D. S.; Santos, A. R.; Fernandéz, N.; Choueri, R. B.; DelValls, A. T. A Simple Approach to Integrate the Ecotoxicological and Chemical Data for the Establishment of Environmental Risk Levels. Brazilian Archives of Biology and Technology, v. 52, n. 1, p. 233-240, 2009.

CHAPMAN, P.M.; WANG, F.; GERMANO, J.D.; BATLEY, G. Pore water testing and analysis: the good, the bad, and the ugly. Marine Pollution Bulletin, n. 44, p. 359366, 2002.

Comitê de Bacias do Alto Tietê http://www.tietecabeceiras.com.br/default.asp?sp= municipios.asp. Acesso em 15 de agosto de 2009.

Companhia de Saneamento Básico do estado de São Paulo - SABESP. 2006. Estação de Tratamento de Esgotos de Suzano, ETE SUZANO (Folheto descritivo).

Companhia de Saneamento Básico do estado de São Paulo - SABESP. Projeto Tietê. http://www2.sabesp.com.br/projetotiete/. Acesso em 28 de setembro de 2009.

Companhia Ambiental do Estado de São Paulo - CETESB. 1983 a. Avaliação da Toxicidade das Águas e Sedimentos dos Rios da Região de Cubatão. São Paulo: CETESB, Relatório Técnico. 
Companhia Ambiental do Estado de São Paulo - CETESB. 1983 b. Ensaios Biológicos com Água e Sedimentos da Represa Billings. São Paulo: CETESB, Relatório Técnico.

Companhia Ambiental do Estado de São Paulo - CETESB. Relatório de Qualidade das Águas Interiores no Estado de São Paulo. São Paulo: Relatórios/Secretaria do Meio Ambiente, 2008.

Companhia Ambiental do Estado de São Paulo - CETESB. Relatório de Qualidade das Águas Interiores no Estado de São Paulo. São Paulo: Relatórios/Secretaria do Meio Ambiente, 2009.

Connell, D. W. Introduction to Ecotoxicology. Hong-Kong: Blackwell Publishing Ltd, 1999.

Conselho Nacional do Meio Ambiente - Resolução n² 20, de 18 de junho de 1986. CONAMA, 1986.

Conselho Nacional do Meio Ambiente - Resolução no 344, de 25 de março de 2004. CONAMA, 2004.

Conselho Nacional do Meio Ambiente - Resolução n³ 57, de 17 de março de 2005. CONAMA, 2005.

Costa, J. B. de \& Espindola, E. L. G. Avaliação Ecotoxicológica da Água e Sedimento em Tributários do Reservatório de Barra Bonita (Médio Tiête Superior, $S P$ ). In: ESPINDOLA, E. L. G,; PASCHOAL, C. M. R. B.; ROCHA, O. BOHRER, M. B. C.; NETO, A. L. O. Ecotoxicologia - Perspectivas para o século XXI. Ed. Rima. São Carlos. 2002. 575p.

Cowgill, U. M. \& Milazzo, D. P. The response of three brood Ceriodaphnia test to fifteen formulations and pure compounds in common use. Archieves of Environmental Contamination and Toxicology, n. 21, p. 35-40, (1991).

Coz, A., Rodríguez-Obeso, O., Alonso-Santurde, R., Álvarez-Guerra, M., Andrés, A., Viguri, J. R., Mantzavinos, D., Kalogerakis, N. Toxicity bioassays in core sediments from the Bay of Santander, northern Spain. Environmental Research, n. 106, p. 304-312, 2008.

Cullen, W. R.; Li, X. F.; Reimer, K. J. Degradation of phenantrene and pyrene by microorganisms isolated from marine sediment and seawater. Science of the Total Environment, n. 156, p. 27-37, 1994.

DelValls, T. A.; Forja, J. M.; Gómez-Parra, A.; The use of multivariate analysis to link sediment contamination and toxicity data to estabilish sediment quality guidelines: An example in the gulf of Cádiz (Spain). Ciencias Marinas, n. 24, v. 2, p. 127-154, 1998. 
DelValls, T. A. \& Chapman, P. M. Site-specific sediment quality values for the Gulf of Cádiz (Spain) and San Francisco Bay (USA), using the sediment quality triad and multivariate analysis. Ciencias Marinas, n. 24. v. 3, p. 313-336, 1998.

DelValls, T. A.; Forja, J. M.; Gómez-Parra, A. Seasonality of contamination, toxicity and quality values in sediments from littoral ecosystems in the Gulf of Cádiz (SW Spain). Chemosphere, n. 46, p. 1033-1043, 2002.

Delistraty, D. \& Yokel, J. Chemical and ecotoxicological characterization of Columbia River sediments below the Hanford site (USA). Ecotoxicology and Environmental Safety, n. 66, p. 16-28, 2007.

Departamento de Águas e Energia Elétrica - DAAE. Reservatóriode Ponte Nova http://www.daee.sp.gov.br/cgi-bin/Carrega.exe?arq=/altotiete/index.htm Acesso em 13 de agosto de 2009.

Duarte, C. L. Aplicação do processo avançado de oxidação por feixe de elétrons na degradação de compostos orgânicos presentes em efluentes industriais. 1999. Tese (Doutorado). Instituto de Pesquisas Energéticas e Nucleares - USP, São Paulo.

Erickson, W.P \& McDonald, L. L.; Tests for bioequivalence of control media in studies of toxicity. Environmental Toxicology and Chemistry, v. 14, p. 1247-1256, 1995.

Esteves; F.A. Fundamentos da Limnologia. Rio de Janeiro, RJ. Ed. Interciências FINEP, 1988.

Fronza, L. 2006. Capacidade de liberação de hidrocarbonetos dos sedimentos de áreas contaminadas do estuário da Lagoa dos Patos - RS. Dissertação (Mestrado). Fundação Universidade Federal de Rio Grande. Rio Grande do Sul.

Governo do Estado de São Paulo; Secretária de Planejamento e Gestão. Empresa Metropolitana de Planejamento da Grande São Paulo S/A. Uso e ocupação do solo de interesse regional na Macrometrópole,.v. 1. São Paulo, EMPLASA, 1992.

Gulley, D., 1996, Toxstat 3.5, West Inc. University of Wyoming. Cheyenne, Wyoming.

Gusmão, L. F. M. de. 2004. Efeitos do Cobre e Cromo na comunidade zooplanctonica: um estudo experimental em mesocosmos. Dissertação (Mestrado). Escola de Engenharia de São Carlos - USP, São Carlos.

Hamada, N. 2008. Ensaios de toxicidade empregados na avaliação de efeitos no sistema de tratamento de esgotos e efluentes, ETE Suzano, e seu entorno, utilizando organismos aquáticos. Dissertação (Mestrado). Instituto de Pesquisas Energéticas e Nucleares - USP. São Paulo.

Hsu. P.; Matthäi. A.; Heise. S.; Ahlf, W. Sazonal variation of sediments toxicity in the river Dommel and Elbe. Environmental Polution, n. 148, p. 817-823, 2007. 
Ignácio, G. M. 2007. Avaliação da contaminação por hidrocarbonetos em água, sedimentos e ostras do complexo estuarino da baía de Paranaguá (Paraná Brasil). Dissertação (Mestrado). Fundação Universidade do Rio Grande. Rio Grande do Sul.

Lamparelli, M. L.; Costa, M. P.; Prósperi, V. A.; Bevilácqua, J. E.;Araújo, R. P. A.; Eysink, G. G. L.; Pompéia, S. 2001. Sistema Estuarino de Santos e São Vicente. Relatório Técnico CETESB. São Paulo.

Mariani. C. F. 2006. Reservatório Rio Grande: caracterização limnológica da água e biodisponibilidade de metais-traço no sedimento. Dissertação (Mestrado). Instituto de Biociências, Universidade de São Paulo. São Paulo.

Manahan, S. E. Water Pollution. In: MANAHAN, S. E. Fundamentals of Environmental Chemistry. Boca Raton, FL.: CRC Press, 2001.

Medaglia, T.; Cunha, V. Tietê um rio de várias faces. Ed. Horizonte, São Paulo, 2009

Meire, R. O.; Azeredo, A.; Torres, J. P. M. Aspectos ecotoxicológicos hidrocarbonetos policíclicos aromáticos. Oecologia Brasiliensis, v. 11, n. 2, p. 188201, 2007.

Meletti, P. C., Rocha, O.: Martinez, C. B. R. Avaliação da degradação ambiental da Bacia do rio Mogi-Guaçu por meio de testes de toxicidade com sedimentos e análises histopatológicas em peixes. In: Limnologia fluvial: um estudo no rio Mogi-Gauçu. São Carlos: Rima, 2003.

MOORE, D.W.; BRIDGES, T.S.; GRAY, B.R. \& DUKE, B.M. (1997). Risk of ammonia toxicity during sediment bioassays with the estuarine amphipod Leptocheirus plumulosus. Environmental Toxicology and Chemistry., v. 16, n. 5, p. 1020-1027.

Mozeto, A. A. \& Zagatto, P. A. Introdução de agentes químicos no ambiente. In: Zagatto, P. A. \& Bertoletti, E. (Editores). Ecotoxicologia Aquática: Princípios e Aplicações. São Carlos, SP. Rima, 2006. p. 295-320.

Namiesnik, J.; Moncheva, S.; Park, Y. S.; Ham, K. S.; Heo, B. G.; Tashma, Z.; Katrich, E.; Gorisntein, S. Concentration of bioactive compounds in mussels Mytilus galloprovincialis as an indicator of pollution. Archives of Environmental Contamination and Toxicology, n. 73, p. 938-944, 2008.

Nascimento, M. R. L. 2003. Proposição de Valores de Referência pra concentração de Metais e Metalóides em sedimentos límnicos e fluviais da Bacia Hidrográfica do rio Tietê, SP. Tese (Doutorado). Centro de Ciências Exatas e Tecnologia. Universidade Federal de São Carlos. São Carlos.

Newman, M.C.; Unger, M. A. Fundamentals of Ecotoxicology. Second Edition. Lewis Publishers, 2002. 
Nowierski, M.; Dixon, D.G.; Borgmann, U. Effects of water chemistry on the bioavailability of metals in sediments to Hyalella azteca: Implications for sediment quality guidelines. Archives of Environmental Contamination and Toxicology, $n$. 49, p. 322-332, 2005.

Padial, P. R. 2009. Qualidade, heterogeneidade especial e biodisponibilidade de metais no sedimento de um reservatório tropical urbano eutrofizado (Reservatório Guarapiranga, SP). Dissertação (Mestrado). Instituto de Biociências da Universidade de São Paulo. São Paulo.

Péry, A.R.R.; Gust, M.;Vollat, B.; Mons, R.; Ramil, M.; Fink, G.; Ternes T.; Garric, J. Fluoxetine effects assessment on the life cycle of aquatic invertebrates. Chemosphere. v. 73, p. 300-304, 2008.

Patee, O. H. \& Pain, D. J. Lead in the environment. In: Hoffman, D. J.; Rattner, B. A.; Burton, G. A. Jr.; Cairns, J. Jr. Hanbook of Ecotoxicology. Boca Raton, FL. 2002. 2 Ed. p $373-408$.

Pederzolli, E. M. 2006. Comparação de áreas submetidas a impacto pelo refino de petróleo (RS). Dissertação (Mestrado). Fundação Universidade Federal de Rio Grande. Rio Grande do Sul.

Peláez-Rodriguez, M., Peret, A.M., Matsumura-Tundisi, T. e Rocha, O. Análise da Qualidade da Água e Aplicação do Índice de Proteção da Vida Áquatica (IVA) em Duas Sub-bacias da Bacia Hidrográfica do Rio Jacaré-Guaçu. In Espindola, E. L. G,; Paschoal, C. M. R. B.; Rocha, O. Bohrer, M. B. C.; Neto, A. L. O. Ecotoxicologia Perspectivas para o século XXI. Ed. Rima. São Carlos. 2002. 575p.

Pereira, C. D. S. 2008. Biomarcadores de exposição, efeito e bioacumulação de xenobióticos em mexilhões Perna perna (Linnaeus, 1758) transplantados ao longo do litoral de São Paulo. Tese (Doutorado). Universidade de São Paulo, São Paulo.

Pereira, C. D. S.; Rotundo, M. M.; Furquim, L. G.; lannuzzi, A.; Ferraz, N. L.; Santos, A. R. Avaliação da toxicidade de águas superficiais e de fundo de uma área próxima à desembocadura do estuário de Santos. In: Anais do IV Congresso Brasileiro de Pesquisas Ambientais e Saúde. 2004, Santos, SP.

Plano da Bacia Hidrográfica do Alto Tietê - Diagnóstico Analítico da Bacia - Relatório final. Fundação de Apoio à Universidade de São Paulo, São Paulo. 2008. 482 p.

Pomati, F.; Orlandi, C.; Clerici, M.; Luciani, F.; Zucatto, E. Effects and interactions in an environmentally relevant mixture of pharmaceuticals. Toxicological Sciences. v. 102 (1), p. 129-137, 2008. 
Portela, C. M. S. 2002. Avaliação ecotoxicológica do Arroio Sapucaia, RS, com a utilização de diferentes metodologias em água superficial e sedimento. Dissertação (Mestrado). Universidade Federal do Rio Grande do Sul. Rio Grande do Sul.

Portela, C. M. S.; Arezon, A.; Raya-Rodrigues, M.T. Avaliação Ecotoxicológica do sedimento do Arrio Sapucaia, RS, Brasil, através de ensaios de toxicidade utilizando diferentes amostradores e organismos-teste. Journal of Brazilian Society of. Ecotoxicology, v. 1, n. 2 p., 119-122, 2006.

Prósperi, V. A. 2002. Comparação de métodos ecotoxicológicos na avaliação de sedimentos marinhos e estuarinos. Tese (Doutorado). Escola de Engenharia de São Carlos - USP. São Carlos.

Prosperi, V. A.; Romanelli, M. F.; Buratini, S. V.; Cachattori, D.; Sáfadi, R. S.; Tiritan, A. R. Determinação da constante de proporcionalidade utilizada no teste $t$ por bioequivalência para o ensaio com o anfípoda estuarino Leptocherus plumulosus. In: X Congresso Brasileiro de Ecotoxicologia, data!!!!, 2008,.Bento Gonçalves, RS. Livro de resumos.

Quinn, B.; Gagné, F.; Blaise, C. Evaluation of the acute, chronic and teratogenic effects of a mixture of eleven pharmaceuticals on the cnidarian Hydra attenuata. Science of the total environment. v. 407, p. 1072-1079, 2009.

Rand, G. M, Wells, P. G., \& McCarty, L. S., 1995, Introduction to Aquatic Toxicology, pp. 3-66. In: G.M. RAND (ed), Fundamentals of aquatic toxicology: effects, environmental fate, and risk assessment, Taylor \& Francis, Washington, 1995.

Reible, D. D.; Popov, V.; Valsaraj, K. T.; Thibodeux, L. J.; Dikshit, M.; Todaro, M. A. Fleeger, J. W. Contaminants fluxes from sediment due to tubificid oligochaete bioturbation. Water Research, n. 30, p. 704-714, 1996.

Rensing, C. \& Maier R. M. Issues underlying use of biosensors to measure metal bioavailability. Ecotoxicology and Environmental Safety, n. 56, p. 140-147, 2003.

Riba, I.; DelValls, T.A.; Forja, J. M.; Gómez-Parra, A.; Evaluating the heavy metal contamination in sediments from the Guadalquivir estuary after the Aznalcóllar mining spill (SW Spain): A multivariate analysis approach. Environmental Monitoring and Assessment, n. 77 191-207, 2002.

Riba, I.; García-LUQUEA, E.; Blascob, J.; DelValls, T. A.; Bioavailability of heavy metals bound to estuarine sediments as a function of $\mathrm{pH}$ and salinity values. Chemical Speciation and Bioavailability, v. 15, n. 4, p. 101-114, 2003.

Rocha, J. C.; Rosa, A.H.; Cardoso, A. A. Introdução à química ambiental. Editora Bookman 2 Ed., Porto Alegre, 2009. 
Rocha, P. S.; Luvizotto, G. L.; Kosmehl, T.Böttcher, M.; Storch, V.; Braunbeck, T.; Hollert, H. Sediment genotoxicity in the Tietê river (São Paulo, Brazil): In vitro comet assay versus in situ micronucleus assay. Ecotoxicology and Environmental Safety. Article in press, 2009.

Rodgher, S., Espíndola, E. L. G., Rocha, O., Fracácio, R.,Pereira, R. H. G., Rodrigues, M. H. S. Limnological and Ecotoxicological studies in the cascade of reservoirs in the Tietê river (São Paulo, Brazil). Brazilian Journal of Biology, v. 65, n. 4. p. 697-710, 2005.

Romanelli, M. F. 2004. Avaliação da toxicidade aguda e crônica dos surfactantes DSS e LAS submetidos à irradiação com feixes de elétrons. Dissertação (Mestrado). Instituto de Pesquisas Energéticas e Nucleares - USP. São Paulo.

Rosado, R. M. 1998. Uma abordagem integrativa da qualidade dos sedimentos de fundo da Baia de Ipanema, Porto Alegre, RS. Dissertação (Mestrado). Universidade Federal do Rio grande do Sul, Rio Grande do Sul.

Sanchez, P. S. \& Sato, M. I. Z. Microbiologia Aquática: Metodologia e Aplicações. Apostila do curso Diagnóstico de Ecossistemas aquáticos. São Paulo: Faculdade de Saúde Pública - USP, 2002.

SchifF, K. C.; Reish, D. J.; Anderson, J. W.; Bay, S. M. A comparative evaluation of produced water toxicity. In: RAY, J.P.; ENGELHARDT, F.R. Eds. Produced water: Technological Environmental Issues and Solutions Plenum Press, New York, 1992. p.199-207.

Shukla, R.; Wang, Q.; Fulk, F.; Deng, C.; Denton, D. Bioequivalence approach for whole effluent toxicity testing. Environmental Toxicology and Chemistry, v. 1, n.1. p. 169-174, 2000.

Silva, G. S.; Jardim, W. F. Aplicação do método da carga máxima total diária (CMTD) para a amônia no Rio Atibaia, região de Campinas/Paulínia - SP. Engenharia Sanitária Ambiental, v. 12, n. 2, 2007.

Silvério, P. F. 2003. Bases técnico-científicas para a derivação de valores-guias de qualidade de sedimentos para metais: experimentos de campo e laboratório. Tese (Doutorado). Escola de Engenharia de São Carlos - USP.

Silvério, P. F.; Fonseca, A. L.; Botta-Paschoal, C. M. R.; Mozeto, A. A. Release, bioavailability and toxicity of metals in lacustrine sediments: A case study of reservoirs and lakes in Southeast Brazil. Aquatic Ecossystem Health and Management, v. 8, p. 313-322, 2005. 
Tallarico. L. F. 2009. Avaliação dos efeitos tóxicos e mutagênicos de amostras ambientais do rio Tietê na região de Suzano em Biomphalaria glabrata (SAY, 1818). Tese (Doutorado). Instituto de Pesquisas Energéticas e Nucleares - USP. São Paulo.

United States Environmental Protection Agency - USEPA. Quality criteria for water. U.S. Environmental Protection Agency, Washington, DC. EPA 440/5-86-001. 1986.

United States Environmental Protection Agency - USEPA. Update of Ambient Water Quality Criteria for Ammonia. U.S. Environmental Protection Agency, Washington, DC. EPA-822-R-99-014. 1999.

United States Environmental Protection Agency - USEPA. Short-term methods for estimating the chronic toxicity of effluents and receiving waters to freshwater organisms. 4.ed. U.S. Environmental Protection Agency, Washington, DC. EPA821-R-02-013. 2002.

Viganò, L. Assessment of the toxicity of River Po sediements with Ceriodaphnia dubia. Aquatic Toxicology, n. 47, p. 191-202, 2000.

Viganò, L., Arilo, A., Buffagni, A., Camusso, M., Ciannarella, R., Crossa, G., Falugi, C., Galassi, S., Guzzela, L., Lopez, A., Mingazzini, M., Pagnotta, R., Patrolecco, L., Tartari, G., Valsecchi, S. Quality assessment of bed sediments of the Po River (Italy). Water Research, n. 37, p. 501-518, 2003.

Waltraud, L.; Wolfgang, A.; Evidence from whole sediment, porewater and elutriate testing in toxicity assessment of contamined sediments. Ecotoxicology and Environmental Safety, n. 36, p. 140-147, 1996.

Wang, F. LEUNG, A.O. W.; Wu, S. C.; Yang, M. S.; Wong, M. H. Chemical and ecotoxicological analyses of sediments and elutriates of contaminated rivers due to e-waste recycling activities using a diverse battery of bioassays. Environmental Pollution, n. 157, p. 2082-2090, 2009.

Weiner, J. G.; Krabbenhoft, D. P.; Heinz, G. H.; Scheuhammer, A. M.Ecotoxicology of Mercury. In: HOFFMAN, D. J.; RATTNER, B. A.; BURTON, G. A. Jr.; CAIRNS, J. Jr. Hanbook of Ecotoxicology. Boca Raton, FL. 2002. 2 Ed. p $409-464$.

Wright, D. A. \& Welbourn, P. Environmental Toxicology. New York, NY.: Cambridge University Press, 2002.

Yan, W.; Chi, J.; Wang, Z.; Huang, W.; Zhang, G. Spatial and temporal distribution of polycyclic aromatic hydrocarbons (PAHs) in sediments from Daya Bay, south China. Environmental Pollution, n. 157, p. 1823-1830, 2009. 
Zamboni, A. J. 1993. Avaliação da qualidade de água e sedimentos do Canal de São Sebastião através de testes de toxicidade com Lytechinus variegatus (Echinodermata: Echinoidea). Dissertação (Mestrado). Escola de Engenharia de São Carlos - USP. São Carlos.

Zagatto, P.A.; Bertolettl, E.; Gherardi-Goldstein, E.G.; Souza, H. Avaliação de Toxicidade em Sistema de Tratamento Biológico de Efluentes Líquidos. Revista da SABESP, n. 166, 1992.

Zagatto. P. A. Avaliação de risco e do potencial de Periculosidade ambiental de agentes químicos para o ambiente aquático. In: Zagatto, P. A. \& Bertoletti, E. (Editores). Ecotoxicologia Aquática: Princípios e Aplicações. São Carlos, SP. Rima, 2006. p. 383-385.

Zhang, W.; Feng, H.; Chang, J.; Qu, J.; Xie, H.; YU, L. Heavy metal contamination in surface of Yangtze River intertidal zone: An assessment from diferents indexes. Environmental Pollution, n 157, p. 1533-1543, 2009. 


\section{ANEXO I}

Tabela 1. Dados brutos dos ensaios realizados com amostras de sedimento integral (Coleta 2) utilizando Hyalella azteca.

\begin{tabular}{cccccc}
\hline & $\mathrm{R} 1$ & $\mathrm{R} 2$ & $\mathrm{R} 3$ & $\mathrm{R} 4$ & Total \\
\hline $\mathrm{Cr}$ & 8 & 8 & 6 & 8 & 30 \\
$\mathrm{P} 0$ & 8 & 8 & 8 & 8 & 32 \\
$\mathrm{P} 1$ & 6 & 8 & 6 & 7 & 27 \\
$\mathrm{P} 2$ & 7 & 8 & 8 & 7 & 30 \\
$\mathrm{P} 3$ & 0 & 1 & 0 & 2 & 3 \\
$\mathrm{P} 4$ & 1 & 4 & 5 & 3 & 13 \\
\hline \multicolumn{7}{c}{} \\
\hline
\end{tabular}

Tabela 2, Dados brutos dos ensaios realizados com amostras de sedimento integral (Coleta 3) utilizando Hyalella azteca.

\begin{tabular}{cccccc}
\hline & $\mathrm{R} 1$ & $\mathrm{R} 2$ & $\mathrm{R} 3$ & $\mathrm{R} 4$ & Total \\
\hline $\mathrm{Cr}$ & 8 & 8 & 7 & 8 & 31 \\
$\mathrm{P} 0$ & 8 & 8 & 8 & 8 & 32 \\
$\mathrm{P} 1$ & 8 & 7 & 6 & 8 & 29 \\
$\mathrm{P} 2$ & 7 & 7 & 8 & 8 & 30 \\
$\mathrm{P} 3$ & 0 & 0 & 0 & 1 & 1 \\
\hline P4 & 6 & 4 & 4 & 7 & 21 \\
\hline \multicolumn{7}{c}{} \\
\hline
\end{tabular}

Tabela 3, Dados brutos dos ensaios realizados com amostras de sedimento integral (Coleta 3) utilizando Hyalella azteca.

\begin{tabular}{cccccc}
\hline & $\mathrm{R} 1$ & $\mathrm{R} 2$ & $\mathrm{R} 3$ & $\mathrm{R} 4$ & Total \\
\hline $\mathrm{Cr}$ & 10 & 10 & 10 & 9 & 39 \\
$\mathrm{P} 0$ & 9 & 10 & 9 & 10 & 38 \\
$\mathrm{P} 1$ & 10 & 10 & 8 & 10 & 38 \\
$\mathrm{P} 2$ & 10 & 10 & 9 & 9 & 38 \\
$\mathrm{P} 3$ & 0 & 2 & 2 & 0 & 4 \\
P4 & 9 & 10 & 10 & 10 & 39 \\
\hline \multicolumn{7}{c}{} \\
\hline
\end{tabular}


Tabela 4, Dados brutos dos ensaios realizados com amostras de sedimento integral (Coleta 1) utilizando Ceriodaphnia dubia.

\begin{tabular}{|c|c|c|c|c|c|c|c|c|c|c|c|c|}
\hline \multicolumn{13}{|c|}{ Inicio do ensaio: 03/10/2008, Fim do ensaio: 10/10/2007 } \\
\hline & Data & R1 & R2 & R3 & R4 & R5 & R6 & R7 & R8 & $\mathrm{R} 9$ & $\mathrm{R} 10$ & Média \\
\hline \multirow{4}{*}{ Controle } & 05/10/2007 & 0 & 0 & 0 & 0 & 0 & 0 & 0 & 0 & 0 & 0 & \\
\hline & 08/10/2007 & 0 & 10 & 12 & 10 & 8 & 2 & 12 & 0 & 10 & 9 & \\
\hline & $10 / 10 / 2007$ & 0 & 9 & 9 & 11 & 8 & 15 & 10 & 0 & 10 & 9 & \\
\hline & Total: & - & 19 & 21 & 21 & 16 & 17 & 22 & - & 20 & 18 & 19,25 \\
\hline \multirow{5}{*}{ P0 } & Data & R1 & $\mathrm{R} 2$ & R3 & R4 & R5 & R6 & R7 & $\mathrm{R} 8$ & R9 & $\mathrm{R} 10$ & Média \\
\hline & 05/10/2007 & 0 & 0 & 0 & 0 & 0 & 0 & 0 & 0 & 0 & 0 & \\
\hline & 08/10/2007 & 12 & 8 & 9 & 11 & 8 & 7 & 9 & 10 & 8 & 9 & \\
\hline & $10 / 10 / 2007$ & 8 & 7 & 9 & 6 & 6 & 7 & 4 & 6 & 8 & 8 & \\
\hline & Total: & 20 & 15 & 18 & 17 & 14 & 14 & 13 & 16 & 16 & 17 & 16 \\
\hline \multirow{5}{*}{ P1 } & Data & R1 & $\mathrm{R} 2$ & R3 & R4 & R5 & R6 & R7 & R8 & R9 & R10 & Média \\
\hline & 05/10/2007 & 0 & 0 & 0 & 0 & 0 & 0 & 0 & 0 & 0 & 0 & \\
\hline & 08/10/2007 & 3 & 12 & 4 & 10 & 12 & 0 & 11 & 8 & 0 & 10 & \\
\hline & $10 / 10 / 2007$ & 13 & 8 & 14 & 7 & 9 & 0 & 5 & 9 & 0 & 10 & \\
\hline & Total: & 16 & 20 & 18 & 17 & 21 & - & 16 & 17 & - & 20 & 18,13 \\
\hline \multirow{5}{*}{ P2 } & Data & $\mathrm{R} 1$ & $\mathrm{R} 2$ & R3 & R4 & R5 & R6 & R7 & $\mathrm{R} 8$ & R9 & $\mathrm{R} 10$ & Média \\
\hline & 05/10/2007 & 0 & $X$ & 0 & 0 & 0 & 0 & 0 & 0 & 0 & 0 & \\
\hline & 08/10/2007 & 7 & $X$ & 9 & 9 & 0 & 11 & 9 & 10 & 10 & 8 & \\
\hline & $10 / 10 / 2007$ & 8 & $X$ & 5 & 6 & 0 & 7 & 8 & 8 & 7 & 7 & \\
\hline & Total: & 15 & 0 & 14 & 15 & - & 18 & 17 & 18 & 17 & 15 & 14,33 \\
\hline \multirow{5}{*}{ P3 } & Data & $\mathrm{R} 1$ & $\mathrm{R} 2$ & R3 & $\mathrm{R} 4$ & R5 & R6 & R7 & R8 & $\mathrm{R} 9$ & $\mathrm{R} 10$ & Média \\
\hline & 05/10/2007 & 0 & 0 & 0 & $\mathrm{X}$ & 0 & 0 & 0 & 0 & 0 & 0 & \\
\hline & 08/10/2007 & 6 & 4 & 8 & $X$ & 0 & 4 & 5 & $X$ & 5 & 4 & \\
\hline & $10 / 10 / 2007$ & 6 & 7 & 8 & $x$ & $X$ & 8 & 6 & $X$ & 8 & 6 & \\
\hline & Total: & 12 & 11 & 16 & 0 & 0 & 12 & 11 & 0 & 13 & 10 & 8,5 \\
\hline & Data & $\mathrm{R} 1$ & $\mathrm{R} 2$ & R3 & $\mathrm{R} 4$ & R5 & $\mathrm{R} 6$ & R7 & R8 & R9 & $\mathrm{R} 10$ & Média \\
\hline \multirow{4}{*}{ P4 } & 05/10/2007 & 0 & 0 & 0 & 0 & 0 & 0 & $X$ & 0 & $X$ & 0 & \\
\hline & 08/10/2007 & 10 & 8 & 7 & 8 & 6 & 6 & $X$ & 4 & $X$ & 10 & \\
\hline & 10/10/2007 & 6 & 8 & 5 & 6 & 4 & 6 & $X$ & 1 & $X$ & 3 & \\
\hline & Total & 16 & 16 & 12 & 14 & 10 & 12 & 0 & 5 & 0 & 13 & 9,8 \\
\hline
\end{tabular}


Tabela 5, Dados brutos dos ensaios realizados com amostras de sedimento integral (Coleta 2) utilizando Ceriodaphnia dubia.

\begin{tabular}{|c|c|c|c|c|c|c|c|c|c|c|c|c|}
\hline \multicolumn{13}{|c|}{ Inicio do ensaio: 04/04/2008, Fim do ensaio: 11/04/2008 } \\
\hline & Data & $\mathrm{R} 1$ & $\mathrm{R} 2$ & R3 & R4 & R5 & R6 & $\mathrm{R} 7$ & R8 & R9 & R10 & Média \\
\hline \multirow{4}{*}{ Controle } & $07 / 04 / 2008$ & 0 & 0 & 0 & 0 & 0 & 0 & 0 & 0 & 0 & 0 & \\
\hline & 09/04/2008 & 12 & 0 & 9 & 4 & 4 & 10 & 11 & 6 & 8 & 10 & \\
\hline & $11 / 04 / 2008$ & 17 & 7 & 8 & 9 & 9 & 9 & 8 & 5 & 6 & 5 & \\
\hline & Total: & 25 & 7 & 17 & 13 & 13 & 19 & 19 & 11 & 14 & 15 & 15,3 \\
\hline \multirow{5}{*}{ P0 } & Data & $\mathrm{R} 1$ & $\mathrm{R} 2$ & R3 & R4 & R5 & R6 & R7 & R8 & R9 & R10 & Média \\
\hline & $07 / 04 / 2008$ & $X$ & 4 & 4 & 1 & 0 & 2 & 0 & 0 & 0 & 0 & \\
\hline & 09/04/2008 & $x$ & 4 & 1 & 3 & 3 & 0 & 1 & 2 & 3 & 5 & \\
\hline & $11 / 04 / 2008$ & $X$ & 11 & 3 & 5 & 5 & 9 & 4 & 5 & 3 & 3 & \\
\hline & Total: & 0 & 19 & 8 & 9 & 8 & 11 & 5 & 7 & 6 & 8 & 8,1 \\
\hline \multirow{5}{*}{ P1 } & Data & $\mathrm{R} 1$ & $\mathrm{R} 2$ & R3 & R4 & R5 & $\mathrm{R} 6$ & $\mathrm{R} 7$ & R8 & R9 & $\mathrm{R} 10$ & Média \\
\hline & $07 / 04 / 2008$ & 0 & 0 & 0 & 0 & 0 & 0 & 0 & 0 & 0 & 0 & \\
\hline & 09/04/2008 & 7 & 8 & 7 & 3 & $4 / X$ & 8 & 8 & 9 & 8 & 8 & \\
\hline & $4 / 11 / 2008$ & 7 & 8 & 7 & 4 & $x$ & 8 & 11 & 9 & 10 & 10 & \\
\hline & Total: & 14 & 16 & 14 & 7 & 4 & 16 & 19 & 18 & 18 & 18 & 14,4 \\
\hline \multirow{5}{*}{ P2 } & Data & $\mathrm{R} 1$ & $\mathrm{R} 2$ & R3 & R4 & R5 & R6 & $\mathrm{R} 7$ & R8 & R9 & R10 & Média \\
\hline & $07 / 04 / 2008$ & 0 & 3 & 0 & 0 & 0 & 0 & 0 & 0 & 0 & 0 & \\
\hline & 09/04/2008 & 0 & 1 & $x$ & 1 & 5 & $3 / X$ & $2 / X$ & 4 & $2 / X$ & 0 & \\
\hline & $11 / 04 / 2008$ & 0 & 3 & $x$ & 4 & 6 & $X$ & $X$ & 4 & $x$ & 8 & \\
\hline & Total: & 0 & 7 & 0 & 5 & 11 & 3 & 2 & 8 & 2 & 8 & 4,6 \\
\hline \multirow{5}{*}{ P3 } & Data & $\mathrm{R} 1$ & $\mathrm{R} 2$ & R3 & $\mathrm{R} 4$ & R5 & R6 & $\mathrm{R} 7$ & R8 & R9 & R10 & Média \\
\hline & $07 / 04 / 2008$ & 0 & 0 & 0 & 0 & 0 & 0 & 0 & $X$ & 0 & 0 & \\
\hline & 09/04/2008 & 3 & 5 & 3 & 4 & 6 & 7 & 6 & $x$ & 4 & 2 & \\
\hline & $11 / 04 / 2008$ & 5 & 6 & 10 & 8 & 6 & 7 & 6 & $x$ & 4 & 7 & \\
\hline & Total: & 8 & 11 & 13 & 12 & 12 & 14 & 12 & 0 & 8 & 9 & 9,9 \\
\hline \multirow{5}{*}{ P4 } & Data & $\mathrm{R} 1$ & $\mathrm{R} 2$ & R3 & R4 & R5 & R6 & R7 & R8 & R9 & R10 & Média \\
\hline & $07 / 04 / 2008$ & 0 & 0 & 0 & 0 & 0 & 0 & 0 & 0 & 0 & 0 & \\
\hline & 09/04/2008 & 4 & 4 & 6 & 0 & 0 & 0 & 3 & $\mathrm{X}$ & 6 & 3 & \\
\hline & $11 / 04 / 2008$ & 1 & 6 & 10 & 0 & 12 & 2 & 8 & $x$ & 9 & 5 & \\
\hline & Total: & 5 & 10 & 16 & 0 & 12 & 2 & 11 & 0 & 15 & 8 & 7,9 \\
\hline
\end{tabular}


Tabela 6, Dados brutos dos ensaios realizados com amostras de sedimento integral (Coleta 3) utilizando Ceriodaphnia dubia.

\begin{tabular}{|c|c|c|c|c|c|c|c|c|c|c|c|c|}
\hline & Inicio do & nsai & $: 08$ & $10 / 2$ & 08,1 & $\mathrm{~m} \mathrm{~d}$ & ens & io: 1 & $6 / 10$ & 2008 & & \\
\hline & Data & $\mathrm{R} 1$ & $\mathrm{R} 2$ & R3 & R4 & R5 & R6 & R7 & R8 & R9 & $\mathrm{R} 10$ & Média \\
\hline \multirow{4}{*}{ Controle } & $10 / 10 / 2008$ & 0 & 0 & 0 & 0 & 0 & 0 & 0 & 0 & 0 & 0 & \\
\hline & $13 / 10 / 2008$ & 4 & 5 & 3 & 6 & 6 & 4 & 4 & 1 & 3 & 6 & \\
\hline & $16 / 10 / 2008$ & 13 & 11 & 10 & 15 & 13 & 11 & 12 & 10 & 10 & 7 & \\
\hline & Total: & 17 & 16 & 13 & 21 & 19 & 15 & 16 & 11 & 13 & 13 & 15,4 \\
\hline \multirow{5}{*}{ P0 } & Data & $\mathrm{R} 1$ & $\mathrm{R} 2$ & R3 & $\mathrm{R} 4$ & R5 & R6 & R7 & $\mathrm{R} 8$ & $\mathrm{R} 9$ & R10 & Média \\
\hline & $10 / 10 / 2008$ & 0 & 0 & $X$ & 0 & 0 & 0 & 0 & 0 & 0 & 0 & \\
\hline & $13 / 10 / 2008$ & 0 & 2 & $X$ & 1 & 3 & 4 & 6 & 4 & 3 & 7 & \\
\hline & $16 / 10 / 2008$ & 6 & 9 & $X$ & 7 & 8 & 7 & 8 & 8 & 8 & 4 & \\
\hline & Total: & 6 & 11 & 0 & 8 & 11 & 11 & 14 & 12 & 11 & 11 & 9,5 \\
\hline \multirow{5}{*}{ P1 } & Data & $\mathrm{R} 1$ & $\mathrm{R} 2$ & R3 & R4 & R5 & R6 & R7 & R8 & R9 & R10 & Média \\
\hline & $10 / 10 / 2008$ & 0 & 0 & 0 & 0 & 0 & 0 & 0 & 0 & 0 & 0 & \\
\hline & $13 / 10 / 2008$ & 10 & 2 & 3 & 4 & 3 & 4 & 2 & 1 & 8 & $x$ & \\
\hline & $16 / 10 / 2008$ & 13 & 10 & 8 & 11 & 12 & 12 & 9 & 9 & 5 & $x$ & \\
\hline & Total: & 23 & 12 & 11 & 15 & 15 & 16 & 11 & 10 & 13 & 0 & 12,6 \\
\hline \multirow{5}{*}{ P2 } & Data & $\mathrm{R} 1$ & $\mathrm{R} 2$ & R3 & $\mathrm{R} 4$ & R5 & R6 & $\mathrm{R} 7$ & $\mathrm{R} 8$ & R9 & $\mathrm{R} 10$ & Média \\
\hline & 10/10/2008 & 0 & 0 & 0 & 0 & 0 & 0 & 0 & 0 & 0 & 0 & \\
\hline & 13/10/2008 & 2 & 7 & 4 & 6 & 2 & 1 & 8 & 1 & 8 & 2 & \\
\hline & $16 / 10 / 2008$ & 7 & 8 & 6 & 8 & $4 / X$ & 4 & 1 & 8 & 10 & 8 & \\
\hline & Total: & 9 & 15 & 10 & 14 & 6 & 5 & 9 & 9 & 18 & 10 & 10,5 \\
\hline \multirow{5}{*}{ P3 } & Data & $\mathrm{R} 1$ & $\mathrm{R} 2$ & R3 & $\mathrm{R} 4$ & R5 & R6 & R7 & $\mathrm{R} 8$ & R9 & R10 & Média \\
\hline & $10 / 10 / 2008$ & 0 & 0 & 0 & 0 & 0 & 0 & 0 & 0 & 0 & 0 & \\
\hline & $13 / 10 / 2008$ & 4 & 4 & 10 & 1 & 2 & 3 & 9 & 4 & 2 & 4 & \\
\hline & $16 / 10 / 2008$ & 16 & 16 & 12 & 12 & 15 & 15 & 13 & 18 & 12 & 14 & \\
\hline & Total: & 20 & 20 & 22 & 13 & 17 & 18 & 22 & 22 & 14 & 18 & 18,6 \\
\hline & Data & $\mathrm{R} 1$ & $\mathrm{R} 2$ & R3 & $\mathrm{R} 4$ & $\mathrm{R} 5$ & $\mathrm{R} 6$ & R7 & $\mathrm{R} 8$ & $\mathrm{R} 9$ & $\mathrm{R} 10$ & Média \\
\hline \multirow{4}{*}{ P4 } & $10 / 10 / 2008$ & 0 & 0 & 0 & 0 & 0 & 0 & 0 & 0 & 0 & 0 & \\
\hline & $13 / 10 / 2008$ & 2 & 1 & 2 & 2 & $4 / X$ & 3 & 4 & 2 & 3 & 3 & \\
\hline & $16 / 10 / 2008$ & 4 & 0 & $4 / X$ & $2 / X$ & $x$ & 9 & $2 / X$ & $x$ & $6 / X$ & 0 & \\
\hline & Total: & 6 & 1 & 6 & 4 & 4 & 12 & 6 & 2 & 9 & 3 & 5,3 \\
\hline
\end{tabular}


Tabela 7, Dados brutos dos ensaios realizados com amostras de sedimento integral (Coleta 4) utilizando Ceriodaphnia dubia.

\begin{tabular}{|c|c|c|c|c|c|c|c|c|c|c|c|c|}
\hline \multicolumn{13}{|c|}{ Inicio do ensaio: 12/02/2009, Fim do ensaio: 19/02/2009 } \\
\hline & Data & $\mathrm{R} 1$ & $\mathrm{R} 2$ & R3 & R4 & R5 & $\mathrm{R} 6$ & R7 & $\mathrm{R} 8$ & R9 & $\mathrm{R} 10$ & Média \\
\hline \multirow{4}{*}{ Controle } & $14 / 02 / 2009$ & 0 & 0 & 0 & 0 & 0 & 0 & 0 & 0 & 0 & 0 & \\
\hline & $16 / 02 / 2009$ & 3 & 4 & 3 & 4 & 4 & 2 & 4 & 5 & 2 & 4 & \\
\hline & $19 / 02 / 2009$ & 16 & 13 & 10 & 13 & 15 & 13 & 14 & 0 & 12 & 14 & \\
\hline & Total: & 19 & 17 & 13 & 17 & 19 & 15 & 18 & 5 & 14 & 18 & 15,5 \\
\hline \multirow{5}{*}{ P0 } & Data & $\mathrm{R} 1$ & $\mathrm{R} 2$ & R3 & R4 & R5 & R6 & R7 & $\mathrm{R} 8$ & R9 & R10 & Média \\
\hline & $14 / 02 / 2009$ & 0 & 0 & 0 & 0 & 0 & 0 & 0 & 0 & 0 & 0 & \\
\hline & $16 / 02 / 2009$ & $4 / X$ & 4 & 4 & 4 & 3 & 4 & 4 & 5 & 4 & 1 & \\
\hline & $19 / 02 / 2009$ & $X$ & 7 & 7 & 4 & 15 & 13 & 14 & 6 & 13 & 13 & \\
\hline & Total: & 4 & 11 & 11 & 8 & 18 & 17 & 18 & 11 & 17 & 14 & 12,9 \\
\hline Ponto & Data & $\mathrm{R} 1$ & R2 & R3 & R4 & R5 & R6 & R7 & $\mathrm{R} 8$ & R9 & R10 & Média \\
\hline \multirow{4}{*}{ P1 } & $14 / 02 / 2009$ & 0 & 0 & 0 & $X$ & 0 & 0 & 0 & 0 & 0 & 0 & \\
\hline & $16 / 02 / 2009$ & 0 & 4 & 1 & $X$ & 4 & 3 & 4 & 4 & 3 & 3 & \\
\hline & $19 / 02 / 2009$ & 0 & 15 & 4 & $X$ & 4 & 16 & 11 & 13 & 16 & 8 & \\
\hline & Total: & 0 & 19 & 5 & 0 & 8 & 19 & 15 & 17 & 19 & 11 & 11,3 \\
\hline \multirow{5}{*}{ P2 } & Data & R1 & $\mathrm{R} 2$ & R3 & R4 & R5 & R6 & R7 & $\mathrm{R} 8$ & R9 & R10 & Média \\
\hline & $14 / 02 / 2009$ & 0 & 0 & 0 & 0 & 0 & 0 & 0 & 0 & 0 & 0 & \\
\hline & $16 / 02 / 2009$ & 6 & 4 & 4 & 4 & 4 & 3 & 9 & 3 & 4 & 4 & \\
\hline & $19 / 02 / 2009$ & 7 & 14 & 12 & 16 & 15 & 16 & 9 & 7 & 12 & 17 & \\
\hline & Total: & 13 & 18 & 16 & 20 & 19 & 19 & 18 & 10 & 16 & 21 & 17 \\
\hline \multirow{5}{*}{ P3 } & Data & $\mathrm{R} 1$ & $\mathrm{R} 2$ & R3 & $\mathrm{R} 4$ & R5 & R6 & $\mathrm{R} 7$ & $\mathrm{R} 8$ & R9 & $\mathrm{R} 10$ & Média \\
\hline & $14 / 02 / 2009$ & $x$ & $X$ & 0 & 0 & 0 & 0 & 0 & $X$ & $\mathrm{X}$ & $x$ & \\
\hline & $16 / 02 / 2009$ & $X$ & $X$ & 0 & 0 & 3 & 0 & 0 & $X$ & $X$ & $X$ & \\
\hline & $19 / 02 / 2009$ & $X$ & $x$ & 0 & 7 & 2 & 0 & 5 & $X$ & $X$ & $x$ & \\
\hline & Total: & 0 & 0 & 0 & 7 & 5 & 0 & 5 & 0 & 0 & 0 & 1,7 \\
\hline & Data & $\mathrm{R} 1$ & $\mathrm{R} 2$ & R3 & R4 & R5 & R6 & $\mathrm{R} 7$ & $\mathrm{R} 8$ & R9 & R10 & Média \\
\hline \multirow{4}{*}{ P4 } & $14 / 02 / 2009$ & 0 & 0 & 0 & 0 & 0 & 0 & 0 & 0 & 0 & 0 & \\
\hline & $16 / 02 / 2009$ & 11 & 4 & 6 & 7 & 4 & 6 & 5 & 5 & 4 & 4 & \\
\hline & $19 / 02 / 2009$ & 6 & 10 & 3 & 12 & 15 & 8 & 6 & 0 & $4 / X$ & 16 & \\
\hline & Toté & 17 & 14 & 9 & 19 & 19 & 14 & 11 & 5 & 8 & 20 & 13,6 \\
\hline
\end{tabular}


Tabela 8, Dados brutos dos ensaios realizados com amostras de elutriato (Coleta 1) utilizando Ceriodaphnia dubia.

\begin{tabular}{|c|c|c|c|c|c|c|c|c|c|c|c|c|}
\hline \multicolumn{13}{|c|}{ nsaio: $24 / 10 / 2007$, Fim do ensaio: 31/10/2007 } \\
\hline & Data & R1 & $\mathrm{R} 2$ & R3 & R4 & R5 & R6 & R7 & R8 & R9 & R10 & Média \\
\hline \multirow{4}{*}{ Controle } & 26/10/2007 & 0 & 0 & 0 & 0 & 0 & 0 & 0 & 0 & 0 & 0 & \\
\hline & 29/10/2007 & 0 & 10 & 12 & 10 & 8 & 2 & 12 & 0 & 10 & 9 & \\
\hline & $31 / 10 / 2007$ & 0 & 9 & 9 & 11 & 8 & 15 & 10 & 0 & 10 & 9 & \\
\hline & Total: & - & 19 & 21 & 21 & 16 & 17 & 22 & 0 & 20 & 18 & 19,25 \\
\hline \multirow{5}{*}{ P0 } & Data & R1 & $\mathrm{R} 2$ & R3 & R4 & R5 & $\mathrm{R} 6$ & R7 & R8 & R9 & R10 & Média \\
\hline & $26 / 10 / 2007$ & 0 & 0 & 0 & 0 & 0 & 0 & 0 & 0 & $X$ & 0 & \\
\hline & 29/10/2007 & 9 & 8 & 9 & 8 & 13 & 6 & 6 & 2 & $x$ & 13 & \\
\hline & $31 / 10 / 2007$ & 7 & 8 & 7 & 8 & 8 & 6 & 9 & 5 & $x$ & 8 & \\
\hline & Total: & 16 & 16 & 16 & 16 & 21 & 12 & 15 & 7 & 0 & 21 & 14 \\
\hline \multirow{5}{*}{ P1 } & Data & $\mathrm{R} 1$ & $\mathrm{R} 2$ & R3 & R4 & R5 & $\mathrm{R} 6$ & R7 & R8 & R9 & R10 & Média \\
\hline & 26/10/2007 & 0 & 0 & 0 & 0 & 0 & 0 & 0 & 0 & 0 & 0 & \\
\hline & 29/10/2007 & 9 & 11 & 11 & 11 & 11 & 3 & 4 & 8 & 11 & 0 & \\
\hline & $31 / 10 / 2007$ & 7 & 5 & 5 & 7 & 8 & 14 & 12 & 1 & 4 & 0 & \\
\hline & Total: & 16 & 16 & 16 & 18 & 19 & 17 & 16 & 9 & 15 & - & 15,78 \\
\hline \multirow{5}{*}{ P2 } & Data & $\mathrm{R} 1$ & $\mathrm{R} 2$ & R3 & R4 & R5 & R6 & $\mathrm{R} 7$ & R8 & R9 & R10 & Média \\
\hline & 26/10/2007 & 0 & 0 & 0 & 0 & 0 & 0 & 0 & 0 & 0 & 0 & \\
\hline & 29/10/2007 & 11 & 9 & 4 & 8 & 9 & 10 & 4 & 0 & 7 & 4 & \\
\hline & $31 / 10 / 2007$ & 8 & 6 & 6 & $9 / X$ & 7 & 7 & 12 & 0 & 7 & 6 & \\
\hline & Total: & 17 & 15 & 10 & 17 & 16 & 17 & 16 & - & 14 & 10 & 14,67 \\
\hline \multirow{5}{*}{ P3 } & Data & $\mathrm{R} 1$ & $\mathrm{R} 2$ & R3 & R4 & R5 & R6 & $\mathrm{R} 7$ & R8 & R9 & R10 & Média \\
\hline & 26/10/2007 & $x$ & $\mathrm{X}$ & $\mathrm{X}$ & $\mathrm{X}$ & $\mathrm{X}$ & $\mathrm{X}$ & $X$ & $X$ & $X$ & $\mathrm{X}$ & \\
\hline & 29/10/2007 & $x$ & $x$ & $x$ & $x$ & $x$ & $x$ & $x$ & $x$ & $x$ & $\mathrm{x}$ & \\
\hline & $31 / 10 / 2007$ & $x$ & $x$ & $X$ & $X$ & $x$ & $X$ & $X$ & $X$ & $X$ & $X$ & \\
\hline & Total: & 0 & 0 & 0 & 0 & 0 & 0 & 0 & 0 & 0 & 0 & 0 \\
\hline & Data & $\mathrm{R} 1$ & $\mathrm{R} 2$ & R3 & R4 & R5 & R6 & $\mathrm{R} 7$ & R8 & R9 & R10 & Média \\
\hline \multirow{4}{*}{ P4 } & $26 / 10 / 2007$ & 0 & 0 & 0 & 0 & 0 & 0 & 0 & 0 & 0 & 0 & \\
\hline & 29/10/2007 & 5 & 0 & 10 & 4 & 10 & 9 & $6 / X$ & 7 & 2 & 10 & \\
\hline & $31 / 10 / 2007$ & 11 & 0 & 7 & 6 & 9 & 7 & $x$ & 8 & 7 & 9 & \\
\hline & Total: & 16 & - & 17 & 10 & 19 & 16 & 6 & 15 & 9 & 19 & 14,11 \\
\hline
\end{tabular}


Tabela 9, Dados brutos dos ensaios realizados com amostras de elutriato (Coleta 2) utilizando Ceriodaphnia dubia.

\begin{tabular}{|c|c|c|c|c|c|c|c|c|c|c|c|c|}
\hline \multicolumn{13}{|c|}{ Inicio em 04/04/2008, Fim do ensaio: 11/04/2008 } \\
\hline & Data & $\mathrm{R} 1$ & R2 & R3 & R4 & R5 & R6 & R7 & R8 & R9 & R10 & Média \\
\hline \multirow{4}{*}{ Controle } & 07/04/2008 & 0 & 0 & 0 & 0 & 0 & 0 & 0 & 0 & 0 & 0 & \\
\hline & 09/04/2008 & 12 & 0 & 9 & 4 & 4 & 10 & 11 & 6 & 8 & 10 & \\
\hline & $11 / 04 / 2008$ & 17 & 7 & 8 & 9 & 9 & 9 & 8 & 5 & 6 & 5 & \\
\hline & Total: & 25 & 7 & 17 & 13 & 13 & 19 & 19 & 11 & 14 & 15 & 15,3 \\
\hline \multirow{5}{*}{ P0 } & Data & R1 & R2 & R3 & R4 & R5 & R6 & $\mathrm{R} 7$ & $\mathrm{R} 8$ & $\mathrm{R} 9$ & R10 & Média \\
\hline & 07/04/2008 & $\mathrm{X}$ & 4 & 4 & 1 & 0 & 2 & 0 & 0 & 0 & 0 & \\
\hline & 09/04/2008 & $x$ & 4 & 1 & 3 & 3 & 0 & 1 & 2 & 3 & 5 & \\
\hline & $11 / 04 / 2008$ & $x$ & 11 & 3 & 5 & 5 & 9 & 4 & 5 & 3 & 3 & \\
\hline & Total: & 0 & 19 & 8 & 9 & 8 & 11 & 5 & 7 & 6 & 8 & 8,1 \\
\hline \multirow{5}{*}{ P1 } & Data & $\mathrm{R} 1$ & $\mathrm{R} 2$ & R3 & $\mathrm{R} 4$ & R5 & R6 & $\mathrm{R} 7$ & R8 & R9 & R10 & Média \\
\hline & 07/04/2008 & 0 & 0 & 0 & 0 & 0 & 0 & 0 & 0 & 0 & 0 & \\
\hline & 09/04/2008 & 7 & 8 & 7 & 3 & $4 / X$ & 8 & 8 & 9 & 8 & 8 & \\
\hline & $11 / 04 / 2008$ & 7 & 8 & 7 & 4 & $X$ & 8 & 11 & 9 & 10 & 10 & \\
\hline & Total: & 14 & 16 & 14 & 7 & 4 & 16 & 19 & 18 & 18 & 18 & 14,4 \\
\hline \multirow{5}{*}{ P2 } & Data & R1 & $\mathrm{R} 2$ & R3 & $\mathrm{R} 4$ & R5 & $\mathrm{R} 6$ & $\mathrm{R} 7$ & R8 & R9 & R10 & Média \\
\hline & 07/04/2008 & 0 & 3 & 0 & 0 & 0 & 0 & 0 & 0 & 0 & 0 & \\
\hline & 09/04/2008 & 0 & 1 & $X$ & 1 & 5 & $3 / X$ & $2 / X$ & 0 & 0 & 0 & \\
\hline & $11 / 04 / 2008$ & 0 & 3 & $X$ & 4 & 6 & $X$ & $X$ & 4 & $2 / X$ & 8 & \\
\hline & Total: & & 7 & 0 & 5 & 11 & 3 & 2 & 4 & 2 & 8 & 4,66 \\
\hline \multirow{5}{*}{ P3 } & Data & $\mathrm{R} 1$ & $\mathrm{R} 2$ & R3 & $\mathrm{R} 4$ & R5 & $\mathrm{R} 6$ & $\mathrm{R} 7$ & $\mathrm{R} 8$ & R9 & R10 & Média \\
\hline & 07/04/2008 & 0 & 0 & 0 & 0 & 0 & 0 & - & - & - & - & \\
\hline & 09/04/2008 & 4 & 4 & 1 & 0 & $X$ & 1 & - & - & - & - & \\
\hline & $11 / 04 / 2008$ & 12 & 4 & 6 & 4 & 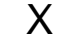 & 10 & - & - & 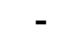 & - & \\
\hline & Total: & 16 & 8 & 7 & 4 & 0 & 11 & - & - & - & - & 7,66 \\
\hline & Data & $\mathrm{R} 1$ & $\mathrm{R} 2$ & R3 & $\mathrm{R} 4$ & R5 & $\mathrm{R} 6$ & $\mathrm{R} 7$ & $\mathrm{R} 8$ & R9 & R10 & Média \\
\hline \multirow{4}{*}{ P4 } & 07/04/2008 & 0 & 0 & 0 & 0 & 0 & 0 & - & - & - & - & \\
\hline & 09/04/2008 & $X$ & $x$ & $x$ & $x$ & $x$ & $x$ & - & - & 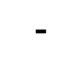 & - & \\
\hline & $11 / 04 / 2008$ & $X$ & $X$ & $X$ & X & $X$ & $X$ & 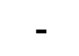 & 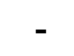 & 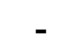 & - & \\
\hline & Total: & 0 & 0 & 0 & 0 & 0 & 0 & - & & - & 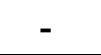 & 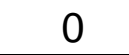 \\
\hline
\end{tabular}


Tabela 10, Dados brutos dos ensaios realizados com amostras de elutriato (Coleta 3) utilizando Ceriodaphnia dubia.

\begin{tabular}{|c|c|c|c|c|c|c|c|c|c|c|c|c|}
\hline \multicolumn{13}{|c|}{ nsaio: $15 / 10 / 2008$, Fim do ensaio: $23 / 10 / 2008$} \\
\hline & Data & $\mathrm{R} 1$ & $\mathrm{R} 2$ & R3 & R4 & R5 & R6 & R7 & $\mathrm{R} 8$ & R9 & $\mathrm{R} 10$ & Média \\
\hline \multirow{4}{*}{ Controle } & $17 / 10 / 2008$ & 0 & 0 & 0 & 0 & 0 & 0 & 0 & 0 & 0 & 0 & \\
\hline & $20 / 10 / 2008$ & 2 & 3 & 6 & 2 & 2 & 0 & 5 & 4 & 2 & 7 & \\
\hline & 23/10/2008 & 15 & 11 & 12 & 13 & 11 & 0 & 11 & 13 & 12 & 11 & \\
\hline & Total: & 17 & 14 & 18 & 15 & 13 & 0 & 16 & 17 & 14 & 18 & 15,78 \\
\hline \multirow{5}{*}{ P0 } & Data & $\mathrm{R} 1$ & $\mathrm{R} 2$ & R3 & R4 & R5 & R6 & $\mathrm{R} 7$ & R8 & $\mathrm{R} 9$ & R10 & Média \\
\hline & $17 / 10 / 2008$ & 0 & 0 & 0 & 0 & 0 & 0 & 0 & 0 & 0 & 0 & \\
\hline & $20 / 10 / 2008$ & 1 & 0 & 0 & 4 & 4 & 0 & 1 & 2 & 4 & 6 & \\
\hline & 23/10/2008 & 13 & 12 & 0 & 12 & 13 & 5 & 10 & 6 & 8 & 10 & \\
\hline & Total: & 14 & 12 & - & 16 & 17 & 5 & 11 & 8 & 12 & 16 & 12,33 \\
\hline \multirow{5}{*}{ P1 } & Data & $\mathrm{R} 1$ & $\mathrm{R} 2$ & R3 & R4 & R5 & $\mathrm{R} 6$ & R7 & $\mathrm{R} 8$ & R9 & R10 & Média \\
\hline & $17 / 10 / 2008$ & 0 & 0 & 0 & 0 & 0 & 0 & 0 & 0 & 0 & 0 & \\
\hline & 20/10/2008 & 2 & $1 / X$ & 1 & 0 & 4 & 1 & 2 & 0 & 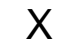 & 4 & \\
\hline & 23/10/2008 & 11 & $X$ & 8 & 8 & 11 & 12 & $6 / X$ & 7 & $X$ & 13 & \\
\hline & Total: & 13 & 1 & 9 & 8 & 15 & 13 & 8 & 7 & 0 & 17 & 9,1 \\
\hline \multirow{5}{*}{ P2 } & Data & R1 & $\mathrm{R} 2$ & R3 & R4 & R5 & R6 & R7 & $\mathrm{R} 8$ & R9 & R10 & Média \\
\hline & $17 / 10 / 2008$ & 0 & 0 & 0 & 0 & 0 & 0 & 0 & 0 & 0 & 0 & \\
\hline & 20/10/2008 & 2 & 4 & 2 & 3 & 2 & 6 & 3 & 3 & 5 & 4 & \\
\hline & 23/10/2008 & 12 & 6 & 13 & 14 & 12 & 9 & 11 & 11 & 13 & 11 & \\
\hline & Total: & 14 & 10 & 15 & 17 & 14 & 15 & 14 & 14 & 18 & 15 & 14,6 \\
\hline \multirow{5}{*}{ P3 } & Data & R1 & $\mathrm{R} 2$ & R3 & $\mathrm{R} 4$ & R5 & $\mathrm{R} 6$ & $\mathrm{R} 7$ & $\mathrm{R} 8$ & $\mathrm{R} 9$ & R10 & Média \\
\hline & 17/10/2008 & 0 & 0 & 0 & 0 & 0 & 0 & 0 & 0 & 0 & 0 & \\
\hline & 20/10/2008 & 0 & 0 & 4 & 2 & 4 & 3 & 0 & 1 & 2 & 1 & \\
\hline & 23/10/2008 & 14 & 14 & 14 & 14 & 15 & 18 & 9 & 13 & 17 & 13 & \\
\hline & Total: & 14 & 14 & 18 & 16 & 19 & 21 & 9 & 14 & 19 & 14 & 15,8 \\
\hline & Data & R1 & $\mathrm{R} 2$ & R3 & $\mathrm{R} 4$ & R5 & $\mathrm{R} 6$ & R7 & $\mathrm{R} 8$ & $\mathrm{R} 9$ & R10 & Média \\
\hline \multirow{4}{*}{ P4 } & $17 / 10 / 2008$ & 0 & 0 & 0 & 0 & 0 & 0 & 0 & 0 & 0 & 0 & \\
\hline & 20/10/2008 & 2 & $x$ & 0 & 13 & 2 & 5 & 0 & 3 & 0 & 5 & \\
\hline & 23/10/2008 & 8 & $X$ & 13 & 10 & 12 & $8 / X$ & 11 & 11 & 12 & 15 & \\
\hline & Total: & 10 & 0 & 13 & 23 & 14 & 13 & 11 & 14 & 12 & 20 & 13 \\
\hline
\end{tabular}


Tabela 11, Dados brutos dos ensaios realizados com amostras de elutriato (Coleta 4) utilizando Ceriodaphnia dubia.

\begin{tabular}{|c|c|c|c|c|c|c|c|c|c|c|c|c|}
\hline \multicolumn{13}{|c|}{ Inicio do ensaio: 27/02/2009, Fim do ensaio: 06/03/2009 } \\
\hline & Data & $\mathrm{R} 1$ & $\mathrm{R} 2$ & R3 & R4 & R5 & R6 & R7 & R8 & R9 & R10 & Média \\
\hline \multirow{4}{*}{ Controle } & $02 / 03 / 2009$ & 0 & 0 & 0 & 0 & 0 & 0 & 0 & 0 & 0 & 0 & \\
\hline & 04/03/2009 & 4 & 4 & 4 & 4 & 6 & 3 & 4 & 2 & 6 & 10 & \\
\hline & 06/03/2009 & 11 & 18 & 13 & 11 & 8 & 4 & 7 & 10 & 13 & 10 & \\
\hline & Total: & 15 & 22 & 17 & 15 & 14 & 7 & 11 & 12 & 19 & 20 & 15,2 \\
\hline \multirow{10}{*}{ P1 } & Data & $\mathrm{R} 1$ & $\mathrm{R} 2$ & R3 & R4 & R5 & R6 & R7 & R8 & $\mathrm{R} 9$ & R10 & Média \\
\hline & $02 / 03 / 2009$ & 0 & 0 & 0 & 0 & 0 & 0 & 0 & 0 & 0 & 0 & \\
\hline & 04/03/2009 & 4 & 4 & 8 & 1 & 2 & 3 & 0 & 2 & 6 & 4 & \\
\hline & 06/03/2009 & 9 & 3 & 8 & 6 & 8 & 11 & 0 & 10 & 7 & 15 & \\
\hline & Total: & 13 & 7 & 16 & 7 & 10 & 13 & - & 12 & 13 & 19 & 12,222 \\
\hline & Data & $\mathrm{R} 1$ & $\mathrm{R} 2$ & R3 & R4 & R5 & R6 & R7 & R8 & R9 & R10 & Média \\
\hline & 02/03/2009 & 0 & 0 & 0 & 0 & 0 & 0 & 0 & 0 & 0 & 0 & \\
\hline & 04/03/2009 & 2 & 0 & 1 & 3 & 1 & 2 & 0 & 0 & $X$ & 2 & \\
\hline & 06/03/2009 & 5 & $3 / X$ & 2 & $3 / X$ & 7 & 6 & 9 & 0 & $X$ & 2 & \\
\hline & Total: & 7 & 3 & 3 & 6 & 8 & 8 & 9 & - & 0 & 4 & 5,333 \\
\hline \multirow{5}{*}{ P2 } & Data & R1 & $\mathrm{R} 2$ & R3 & R4 & R5 & R6 & R7 & R8 & R9 & R10 & Média \\
\hline & 02/03/2009 & 0 & 0 & 0 & 0 & 0 & 0 & 0 & 0 & 0 & 0 & \\
\hline & 04/03/2009 & 3 & 0 & 2 & 4 & 6 & 4 & 4 & 2 & 0 & 3 & \\
\hline & 06/03/2009 & 11 & 0 & 7 & 6 & 7 & 8 & 13 & 14 & 0 & 5 & \\
\hline & Total: & 14 & - & 9 & 10 & 13 & 12 & 17 & 16 & - & 8 & 12,375 \\
\hline \multirow{5}{*}{ P3 } & Data & $\mathrm{R} 1$ & $\mathrm{R} 2$ & R3 & R4 & R5 & R6 & R7 & R8 & R9 & $\mathrm{R} 10$ & Média \\
\hline & 02/03/2009 & $X$ & $X$ & $X$ & $X$ & $X$ & $X$ & $X$ & $X$ & $X$ & $X$ & \\
\hline & 04/03/2009 & $X$ & $X$ & $X$ & $X$ & $X$ & $X$ & $X$ & $X$ & $X$ & $X$ & \\
\hline & 06/03/2009 & $X$ & $\mathrm{X}$ & $X$ & $X$ & $X$ & $X$ & $X$ & $X$ & $X$ & $X$ & \\
\hline & Total: & 0 & 0 & 0 & 0 & 0 & 0 & 0 & 0 & 0 & 0 & 0 \\
\hline & Data & $\mathrm{R} 1$ & $\mathrm{R} 2$ & R3 & R4 & R5 & R6 & R7 & $\mathrm{R} 8$ & $\mathrm{R} 9$ & R10 & Média \\
\hline \multirow{4}{*}{ P4 } & 02/03/2009 & 0 & 0 & 0 & 0 & 0 & 0 & 0 & 0 & 0 & 1 & \\
\hline & 04/03/2009 & 0 & 7 & 5 & 0 & 0 & 2 & 2 & 4 & 3 & 5 & \\
\hline & 06/03/2009 & 12 & 4 & 2 & 11 & 0 & 6 & 4 & 6 & 14 & 15 & \\
\hline & Total: & 12 & 11 & 7 & 11 & & 8 & 6 & 10 & 17 & 21 & 11,444 \\
\hline
\end{tabular}


Tabela 12, Dados brutos dos ensaios realizados com amostras de água do rio Tietê (Coleta 3) utilizando Ceriodaphnia dubia.

\begin{tabular}{|c|c|c|c|c|c|c|c|c|c|c|c|c|}
\hline \multicolumn{13}{|c|}{ Inicio do ensaio 15/10/2008, Fim do ensaio: 23/10/2008 } \\
\hline & Data & $\mathrm{R} 1$ & $\mathrm{R} 2$ & R3 & R4 & R5 & R6 & R7 & R8 & R9 & R10 & Média \\
\hline \multirow{4}{*}{ Controle } & $17 / 10 / 2008$ & 0 & 0 & 0 & 0 & 0 & 0 & 0 & 0 & 0 & 0 & \\
\hline & $20 / 10 / 2008$ & 2 & 3 & 6 & 2 & 2 & 0 & 5 & 4 & 2 & 7 & \\
\hline & $23 / 10 / 2008$ & 15 & 11 & 12 & 13 & 11 & 0 & 11 & 13 & 12 & 11 & \\
\hline & Total: & 17 & 14 & 18 & 15 & 13 & - & 16 & 17 & 14 & 18 & 15,78 \\
\hline \multirow{5}{*}{ P0 } & Data & R1 & $\mathrm{R} 2$ & R3 & R4 & R5 & R6 & R7 & $\mathrm{R} 8$ & $\mathrm{R} 9$ & R10 & Média \\
\hline & $17 / 10 / 2008$ & 0 & 0 & 0 & 0 & 0 & 0 & 0 & 0 & 0 & 0 & \\
\hline & $20 / 10 / 2008$ & 7 & 4 & 0 & 1 & 0 & 1 & 5 & 0 & 3 & 0 & \\
\hline & $23 / 10 / 2008$ & 5 & 14 & 0 & 15 & 16 & 15 & 5 & 11 & 12 & 15 & \\
\hline & Total: & 12 & 18 & - & 16 & 16 & 16 & 10 & 11 & 15 & 15 & 14,33 \\
\hline Ponto & Data & $\mathrm{R} 1$ & $\mathrm{R} 2$ & R3 & R4 & R5 & R6 & R7 & R8 & R9 & R10 & Média \\
\hline \multirow{4}{*}{ P1 } & $17 / 10 / 2008$ & $X$ & 0 & 0 & 0 & 0 & 0 & 0 & 0 & 0 & 0 & \\
\hline & 20/10/2008 & $X$ & 1 & $X$ & 0 & 3 & 3 & 0 & 2 & 1 & 2 & \\
\hline & $23 / 10 / 2008$ & $X$ & 11 & $X$ & 6 & 13 & 4 & 12 & 4 & 13 & 10 & \\
\hline & Total: & 0 & 12 & 0 & 6 & 16 & 7 & 12 & 6 & 14 & 12 & 8,5 \\
\hline \multirow{5}{*}{ P2 } & Data & $\mathrm{R} 1$ & $\mathrm{R} 2$ & R3 & R4 & R5 & R6 & R7 & $\mathrm{R} 8$ & R9 & R10 & Média \\
\hline & $17 / 10 / 2008$ & 0 & 0 & 0 & 0 & 0 & 0 & 0 & 0 & 0 & 0 & \\
\hline & 20/10/2008 & 1 & 2 & 2 & 3 & 5 & 0 & 2 & 5 & 6 & 1 & \\
\hline & $23 / 10 / 2008$ & 12 & 12 & 17 & 7 & 5 & 12 & 9 & 5 & 13 & 11 & \\
\hline & Total: & 13 & 14 & 19 & 10 & 10 & 12 & 11 & 10 & 19 & 12 & 13 \\
\hline \multirow{5}{*}{ P3 } & Data & $\mathrm{R} 1$ & $\mathrm{R} 2$ & R3 & $\mathrm{R} 4$ & R5 & R6 & R7 & R8 & $\mathrm{R} 9$ & $\mathrm{R} 10$ & Média \\
\hline & $17 / 10 / 2008$ & 0 & 0 & 0 & 0 & 0 & 0 & 0 & 0 & 0 & 0 & \\
\hline & $20 / 10 / 2008$ & 1 & 0 & 1 & 3 & 3 & 2 & 1 & 2 & 6 & 4 & \\
\hline & $23 / 10 / 2008$ & 14 & 9 & 13 & 14 & 13 & 17 & 11 & 14 & 15 & 5 & \\
\hline & Total: & 15 & 9 & 14 & 17 & 16 & 19 & 12 & 16 & 21 & 9 & 14,8 \\
\hline & Data & $\mathrm{R} 1$ & $\mathrm{R} 2$ & R3 & $\mathrm{R} 4$ & R5 & $\mathrm{R} 6$ & R7 & $\mathrm{R} 8$ & $\mathrm{R} 9$ & $\mathrm{R} 10$ & Média \\
\hline \multirow{4}{*}{ P4 } & $17 / 10 / 2008$ & 0 & 0 & 0 & 0 & 0 & 0 & 0 & 0 & 0 & 0 & \\
\hline & 20/10/2008 & 0 & 2 & 2 & 2 & 2 & 2 & 2 & 4 & 3 & 1 & \\
\hline & $23 / 10 / 2008$ & 0 & 12 & 8 & 6 & 7 & 9 & 14 & 17 & 11 & 2 & \\
\hline & Total: & - & 14 & 10 & 8 & 9 & 11 & 16 & 21 & 14 & 3 & 78 \\
\hline
\end{tabular}


Tabela 13, Dados brutos dos ensaios realizados com amostras de água do rio Tietê (Coleta 4) utilizando Ceriodaphnia dubia.

\begin{tabular}{|c|c|c|c|c|c|c|c|c|c|c|c|c|}
\hline \multicolumn{13}{|c|}{ Inicio do ensaio: 27/02/2009, Fim do ensaio: 06/03/2009 } \\
\hline & Data & $\mathrm{R} 1$ & R2 & R3 & $\mathrm{R} 4$ & R5 & R6 & R7 & $\mathrm{R} 8$ & $\mathrm{R} 9$ & R10 & Média \\
\hline \multirow{4}{*}{ Controle } & $02 / 03 / 2009$ & 0 & 0 & 0 & 0 & 0 & 0 & 0 & 0 & 0 & 0 & \\
\hline & 04/03/2009 & 4 & 4 & 4 & 4 & 6 & 3 & 4 & 2 & 6 & 10 & \\
\hline & $06 / 03 / 2009$ & 11 & 18 & 13 & 11 & 8 & 4 & 7 & 10 & 13 & 10 & \\
\hline & Total: & 15 & 22 & 17 & 15 & 14 & 7 & 11 & 12 & 19 & 20 & 15,2 \\
\hline Ponto & Data & $\mathrm{R} 1$ & $\mathrm{R} 2$ & R3 & R4 & R5 & $\mathrm{R} 6$ & R7 & $\mathrm{R} 8$ & R9 & R10 & Média \\
\hline \multirow{4}{*}{ P0 } & 02/03/2009 & 0 & 4 & $X$ & $X$ & 0 & 4 & 2 & 0 & 0 & 0 & \\
\hline & $04 / 03 / 2009$ & 5 & 4 & $X$ & $X$ & 10 & 5 & 6 & 8 & 7 & 6 & \\
\hline & 06/03/2009 & 4 & 8 & $X$ & $X$ & 9 & 11 & 7 & 8 & 7 & 4 & \\
\hline & Total: & 9 & 16 & 0 & 0 & 19 & 20 & 17 & 16 & 14 & 10 & 12,1 \\
\hline Ponto & Data & R1 & $\mathrm{R} 2$ & R3 & $\mathrm{R} 4$ & R5 & R6 & R7 & R8 & R9 & R10 & Média \\
\hline \multirow{4}{*}{ P1 } & 02/03/2009 & 0 & 0 & $X$ & 0 & 4 & 0 & 0 & 0 & 0 & 0 & \\
\hline & 04/03/2009 & 8 & 3 & $X$ & 0 & 7 & 6 & 5 & 0 & 8 & 7 & \\
\hline & 06/03/2009 & 3 & $X$ & $X$ & 0 & 5 & 9 & 6 & 0 & 5 & 11 & \\
\hline & Total: & 11 & 3 & 0 & - & 16 & 15 & 11 & & 13 & 18 & 10,875 \\
\hline Ponto & Data & R1 & R2 & R3 & R4 & R5 & R6 & $\mathrm{R} 7$ & $\mathrm{R} 8$ & $\mathrm{R} 9$ & R10 & Média \\
\hline \multirow{4}{*}{ P2 } & 02/03/2009 & 0 & 3 & 0 & 0 & 0 & 0 & 0 & 0 & 4 & 0 & \\
\hline & 04/03/2009 & 7 & 12 & 11 & 0 & 0 & 8 & 3 & 10 & 5 & 7 & \\
\hline & 06/03/2009 & 10 & 9 & 6 & 0 & 0 & 7 & 8 & 8 & 7 & 10 & \\
\hline & Total: & 17 & 24 & 17 & - & - & 15 & 11 & 18 & 16 & 17 & 16,875 \\
\hline Ponto & Data & $\mathrm{R} 1$ & $\mathrm{R} 2$ & R3 & $\mathrm{R} 4$ & R5 & R6 & R7 & $\mathrm{R} 8$ & $\mathrm{R} 9$ & R10 & Média \\
\hline \multirow{4}{*}{$\mathrm{P}$} & 02/03/2009 & 2 & 0 & 3 & 0 & 0 & 4 & $X$ & 0 & 0 & 0 & \\
\hline & $04 / 03 / 2009$ & 7 & 4 & 12 & 6 & 7 & 8 & $X$ & 8 & 9 & 6 & \\
\hline & 06/03/2009 & 9 & 10 & 3 & 10 & 8 & 8 & $X$ & 7 & 8 & 12 & \\
\hline & Total: & 18 & 14 & 18 & 16 & 15 & 16 & 0 & 15 & 17 & 18 & 14,7 \\
\hline Ponto & Data & $\mathrm{R} 1$ & $\mathrm{R} 2$ & R3 & $\mathrm{R} 4$ & R5 & $\mathrm{R} 6$ & R7 & $\mathrm{R} 8$ & R9 & $\mathrm{R} 10$ & Média \\
\hline \multirow{4}{*}{ P4 } & 02/03/2009 & 0 & 0 & 0 & 0 & 3 & 0 & 0 & 0 & 3 & 0 & \\
\hline & $04 / 03 / 2009$ & 8 & 11 & 4 & 9 & 5 & 10 & 7 & 2 & 7 & 7 & \\
\hline & 06/03/2009 & 7 & 5 & 9 & 7 & 7 & 10 & 17 & 4 & 17 & 10 & \\
\hline & Tota & 15 & 16 & 13 & 16 & 15 & 20 & 24 & 6 & 27 & 17 & 16,9 \\
\hline
\end{tabular}


Tabela 14, Dados brutos dos ensaios realizados com amostras de água intersticial dos sedimentos (Coleta 1) utilizando Vibrio fischeri.

\begin{tabular}{|c|c|c|c|c|c|c|}
\hline \multicolumn{7}{|c|}{ Extração e ensaios em 19/10/2007 } \\
\hline \multirow{4}{*}{ P0 } & Tempo & $\mathrm{Cr}$ & 10,23 & 20,47 & 40,95 & 81,9 \\
\hline & 10 & 96 & 91 & 97 & 91 & 96 \\
\hline & 115 & 197 & 196 & 193 & 167 & 107 \\
\hline & \multicolumn{6}{|c|}{ Resultado: $Y=0,8411$} \\
\hline \multirow{4}{*}{ P1 } & Tempo & $\mathrm{Cr}$ & 10,23 & 20,47 & 40,95 & 81,9 \\
\hline & 10 & 99 & 97 & 92 & 103 & 91 \\
\hline & I15 & 199 & 189 & 149 & 100 & 8 \\
\hline & \multicolumn{6}{|c|}{ Resultado: CE (I) 50\%= 33,35 $(20,67-53,80)$} \\
\hline \multirow{4}{*}{ P2 } & Tempo & $\mathrm{Cr}$ & 10,23 & 20,47 & 40,95 & 81,9 \\
\hline & 10 & 94 & 85 & 72 & 86 & 80 \\
\hline & 115 & 145 & 141 & 112 & 103 & 50 \\
\hline & \multicolumn{6}{|c|}{ Resultado: $\gamma=1,4681$} \\
\hline \multirow{4}{*}{ P3 } & Tempo & $\mathrm{Cr}$ & 10,23 & 20,47 & 40,95 & 81,9 \\
\hline & 10 & 94 & 102 & 87 & 107 & 98 \\
\hline & 115 & 141 & 122 & 80 & 33 & 6 \\
\hline & \multicolumn{6}{|c|}{ Resultado: CE (I) $50 \%=21,41(15,12-30,32)$} \\
\hline \multirow{4}{*}{ P4 } & Tempo & $\mathrm{Cr}$ & 10,23 & 20,47 & 40,95 & 81,9 \\
\hline & 10 & 91 & 91 & 94 & 75 & 82 \\
\hline & 115 & 136 & 176 & 151 & 165 & 16 \\
\hline & \multicolumn{6}{|c|}{ Resultado: $\mathrm{Y}=0,6176$} \\
\hline \multirow{4}{*}{$\begin{array}{c}\text { Fenol } \\
\text { (referência) }\end{array}$} & Tempo & $\mathrm{Cr}$ & 10,23 & 20,47 & 40,95 & 81,9 \\
\hline & 10 & 100 & 75 & 61 & 60 & 82 \\
\hline & 115 & 157 & 74 & 47 & 31 & 16 \\
\hline & \multicolumn{6}{|c|}{ Resultado: CE (I) $50 \%=18,18(14,16-23,35)$} \\
\hline
\end{tabular}


Tabela 15, Dados brutos dos ensaios realizados com amostras de água intersticial dos sedimentos (Coleta 2) utilizando Vibrio fischeri.

\begin{tabular}{|c|c|c|c|c|c|c|}
\hline \multicolumn{7}{|c|}{ Extração e ensaios em 09/04/2008 } \\
\hline \multirow{4}{*}{ P0 } & Tempo & $\mathrm{Cr}$ & 10,23 & 20,47 & 40,95 & 81,9 \\
\hline & 10 & 103 & - & - & - & 92 \\
\hline & 115 & 109 & - & - & - & 57 \\
\hline & \multicolumn{6}{|c|}{ Resultado: $\mathrm{Y}=0,7081$} \\
\hline \multirow{4}{*}{ P1 } & Tempo & $\mathrm{Cr}$ & 10,23 & 20,47 & 40,95 & 81,9 \\
\hline & 10 & 98 & 93 & 86 & 100 & 88 \\
\hline & 115 & 116 & 91 & 56 & 35 & 5 \\
\hline & \multicolumn{6}{|c|}{ Resultado: CE (I) $50 \%=22,60(16,05-31,84)$} \\
\hline \multirow{4}{*}{ P2 } & Tempo & $\mathrm{Cr}$ & 10,23 & 20,47 & 40,95 & 81,9 \\
\hline & 10 & 103 & - & - & - & 98 \\
\hline & I15 & 109 & - & - & - & 76 \\
\hline & \multicolumn{6}{|c|}{ Resultado: $\mathrm{Y}=0,3696$} \\
\hline \multirow{4}{*}{ P3 } & Tempo & $\mathrm{Cr}$ & 10,23 & 20,47 & 40,95 & 81,9 \\
\hline & 10 & 107 & 93 & 106 & 88 & 89 \\
\hline & 115 & 117 & 71 & 53 & 10 & 0 \\
\hline & \multicolumn{6}{|c|}{ Resultado: CE (I) $50 \%=16,25(7,74-29,99)$} \\
\hline \multirow{4}{*}{ P4 } & Tempo & $\mathrm{Cr}$ & 10,23 & 20,47 & 40,95 & 81,9 \\
\hline & 10 & 94 & 91 & 92 & 87 & 94 \\
\hline & I15 & 119 & 93 & 72 & 37 & 13 \\
\hline & \multicolumn{6}{|c|}{ Resultado: CE (I) $50 \%=24,46(21,61-29,99)$} \\
\hline \multirow{3}{*}{$\begin{array}{c}\text { Fenol } \\
\text { (referência) }\end{array}$} & Tempo & $\mathrm{Cr}$ & 10,23 & 20,47 & 40,95 & 81,9 \\
\hline & 10 & 94 & 91 & 93 & 91 & 90 \\
\hline & 115 & 105 & 53 & 42 & 26 & 14 \\
\hline
\end{tabular}


Tabela 16, Dados brutos dos ensaios realizados com amostras de água intersticial dos sedimentos (Coleta 3) utilizando Vibrio fischeri.

\begin{tabular}{|c|c|c|c|c|c|c|}
\hline \multicolumn{7}{|c|}{ Extração e ensaios em 05/09/2008 } \\
\hline \multirow{4}{*}{ P0 } & & $\mathrm{Cr}$ & 10,23 & 20,47 & 40,95 & 81,9 \\
\hline & 10 & 93 & - & - & - & 82 \\
\hline & 115 & 103 & - & - & - & 63 \\
\hline & \multicolumn{6}{|c|}{ Resultado: $\gamma=0,4415$} \\
\hline \multirow{4}{*}{ P1 } & 10 & $\mathrm{Cr}$ & 10,23 & 20,47 & 40,95 & 81,9 \\
\hline & 115 & 90 & 87 & 82 & 87 & 100 \\
\hline & & 109 & 60 & 28 & 10 & 4 \\
\hline & \multicolumn{6}{|c|}{ Resultado: CE (I) $50 \%=5,96(5,62-6,31)$} \\
\hline \multirow{4}{*}{ P2 } & & $\mathrm{Cr}$ & 10,23 & 20,47 & 40,95 & 81,9 \\
\hline & 10 & 90 & - & - & - & 83 \\
\hline & 115 & 99 & - & - & - & 76 \\
\hline & \multicolumn{6}{|c|}{ Resultado: $\gamma=0,2013$} \\
\hline \multirow{4}{*}{ P3 } & & $\mathrm{Cr}$ & 10,23 & 20,47 & 40,95 & 81,9 \\
\hline & 10 & 90 & 86 & 84 & 101 & 101 \\
\hline & 115 & 86 & 63 & 44 & 28 & 12 \\
\hline & \multicolumn{6}{|c|}{ Resultado: CE (I) $50 \%=22,73(22,08-23,41)$} \\
\hline \multirow{4}{*}{ P4 } & & $\mathrm{Cr}$ & 10,23 & 20,47 & 40,95 & 81,9 \\
\hline & 10 & 102 & 106 & 107 & 106 & 101 \\
\hline & 115 & 92 & 76 & 70 & 28 & 11 \\
\hline & \multicolumn{6}{|c|}{ Resultado: CE (I) 50\%= 26,74 $(17,74-41,26)$} \\
\hline \multirow{4}{*}{$\begin{array}{c}\text { Fenol } \\
\text { (referência) }\end{array}$} & & $\mathrm{Cr}$ & 10,23 & 20,47 & 40,95 & 81,9 \\
\hline & 10 & 114 & 114 & 106 & 109 & 103 \\
\hline & 115 & 101 & 97 & 82 & 65 & 44 \\
\hline & \multicolumn{6}{|c|}{ Resultado: CE (I) 50\%= 71,92 $(60,44-85,60)$} \\
\hline
\end{tabular}


Tabela 17, Dados brutos dos ensaios realizados com amostras de água intersticial dos sedimentos (Coleta 4) utilizando Vibrio fischeri.

\begin{tabular}{|c|c|c|c|c|c|c|}
\hline \multicolumn{7}{|c|}{ Extração e ensaios em 18/02/09 } \\
\hline \multirow{4}{*}{ P0 } & & $\mathrm{Cr}$ & 10,23 & 20,47 & 40,95 & 81,9 \\
\hline & 10 & 94 & - & - & - & 94 \\
\hline & 115 & 95 & - & - & - & 68 \\
\hline & \multicolumn{6}{|c|}{ Resultado: $\gamma=0,3971$} \\
\hline \multirow{4}{*}{ P1 } & & $\mathrm{Cr}$ & 10,23 & 20,47 & 40,95 & 81,9 \\
\hline & 10 & 111 & 102 & 91 & 93 & 107 \\
\hline & 115 & 101 & 55 & 24 & 5 & 1 \\
\hline & \multicolumn{6}{|c|}{ Resultado: CE (I) 50\%= 11,93 $(3,82-37,26)$} \\
\hline \multirow{4}{*}{ P2 } & & $\mathrm{Cr}$ & 10,23 & 20,47 & 40,95 & 81,9 \\
\hline & 10 & 94 & - & - & - & 88 \\
\hline & 115 & 95 & - & - & - & 69 \\
\hline & \multicolumn{6}{|c|}{ Resultado: $\gamma=0,2889$} \\
\hline \multirow{4}{*}{ P3 } & & $\mathrm{Cr}$ & 10,23 & 20,47 & 40,95 & 81,9 \\
\hline & 10 & 78 & - & - & - & 88 \\
\hline & 115 & 79 & - & - & - & 58 \\
\hline & \multicolumn{6}{|c|}{ Resultado: $\gamma=0,5367$} \\
\hline \multirow{5}{*}{ P4 } & & $\mathrm{Cr}$ & 10,23 & 20,47 & 40,95 & 81,9 \\
\hline & 10 & 78 & - & - & - & 93 \\
\hline & 115 & 79 & - & - & - & 44 \\
\hline & \multicolumn{6}{|c|}{ Resultado: $\mathrm{Y}=1,1407$} \\
\hline & & $\mathrm{Cr}$ & 10,23 & 20,47 & 40,95 & 81,9 \\
\hline \multirow{3}{*}{$\begin{array}{c}\text { Fenol } \\
\text { (referência) }\end{array}$} & 10 & 97 & 95 & 95 & 93 & 92 \\
\hline & 115 & 87 & 77 & 62 & 45 & 28 \\
\hline & \multicolumn{6}{|c|}{ Resultado: CE (I) 50\%= 47,39 $(40,11-56,01)$} \\
\hline
\end{tabular}


Tabela 18, Dados brutos dos ensaios realizados com amostras de elutriato (Coleta 3) utilizando Vibrio fischeri.

\begin{tabular}{|c|c|c|c|c|c|c|}
\hline \multicolumn{7}{|c|}{ Extração e ensaios em 05/09/08 } \\
\hline \multirow{4}{*}{ P0 } & & $\mathrm{Cr}$ & 34,55 & 46,08 & 61,42 & 81,9 \\
\hline & 10 & 107 & 98 & 110 & 92 & 105 \\
\hline & 115 & 81 & 71 & 75 & 59 & 51 \\
\hline & \multicolumn{6}{|c|}{ Resultado: CE (I) 20\%= 63,92 $(53,18-76,84)$} \\
\hline \multirow{4}{*}{ P1 } & & $\mathrm{Cr}$ & 10,23 & 20,47 & 40,95 & 81,9 \\
\hline & 10 & 94 & 101 & 95 & 105 & 86 \\
\hline & 115 & 92 & 57 & 29 & 13 & 2 \\
\hline & \multicolumn{6}{|c|}{ Resultado: CE (I) 50\%=6,47 (4,99 - 8,39) } \\
\hline \multirow{4}{*}{ P2 } & & $\mathrm{Cr}$ & 10,23 & 20,47 & 40,95 & 81,9 \\
\hline & 10 & 90 & 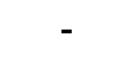 & - & - & 95 \\
\hline & 115 & 99 & - & - & - & 66 \\
\hline & \multicolumn{6}{|c|}{ Resultado: $\gamma=0,5833$} \\
\hline \multirow{4}{*}{ P3 } & & $\mathrm{Cr}$ & 10,23 & 20,47 & 40,95 & 81,9 \\
\hline & 10 & 112 & 90 & 93 & 109 & 103 \\
\hline & 115 & 97 & 64 & 48 & 37 & 12 \\
\hline & \multicolumn{6}{|c|}{ Resultado: CE (I) 50\%= 13,61 (11,42 - 16,21) } \\
\hline \multirow{4}{*}{ P4 } & & $\mathrm{Cr}$ & 10,23 & 20,47 & 40,95 & 81,9 \\
\hline & 10 & 97 & 93 & 80 & 90 & 90 \\
\hline & 115 & 81 & 48 & 22 & 10 & 3 \\
\hline & \multicolumn{6}{|c|}{ Resultado: CE (I) 50\%= 13,61 (12,97 - 14,26) } \\
\hline \multirow{5}{*}{ Fenol } & & $\mathrm{Cr}$ & 10,23 & 20,47 & 40,95 & 81,9 \\
\hline & & $\mathrm{Cr}$ & 10,23 & 20,47 & 40,95 & 81,9 \\
\hline & 10 & 114 & 114 & 106 & 109 & 103 \\
\hline & 115 & 101 & 97 & 82 & 65 & 44 \\
\hline & \multicolumn{6}{|c|}{ Resultado: CE (I) 50\%= 71,92 $(60,44-85,60)$} \\
\hline
\end{tabular}


Tabela 19, Dados brutos dos ensaios realizados com amostras de elutriato (Coleta 4) utilizando Vibrio fischeri.

\begin{tabular}{|c|c|c|c|c|c|c|}
\hline \multicolumn{7}{|c|}{ Extração e ensaios em 18/02/09 } \\
\hline \multirow{4}{*}{ P0 } & & $\mathrm{Cr}$ & 10,23 & 20,47 & 40,95 & 81,9 \\
\hline & 10 & 99 & - & - & - & 98 \\
\hline & 115 & 99 & - & - & - & 60 \\
\hline & \multicolumn{6}{|c|}{ Resultado: $\gamma=0,6333$} \\
\hline \multirow{4}{*}{ P1 } & & $\mathrm{Cr}$ & 10,23 & 20,47 & 40,95 & 81,9 \\
\hline & 10 & 93 & 90 & 69 & 87 & 91 \\
\hline & 115 & 89 & 77 & 46 & 35 & 4 \\
\hline & \multicolumn{6}{|c|}{ Resultado: CE (I) 50\%= 27,93 (15,75 - 49,53) } \\
\hline \multirow{4}{*}{ P2 } & & $\mathrm{Cr}$ & 10,23 & 20,47 & 40,95 & 81,9 \\
\hline & 10 & 99 & - & - & - & 99 \\
\hline & 115 & 99 & - & - & - & 73 \\
\hline & \multicolumn{6}{|c|}{ Resultado: $\gamma=0,3562$} \\
\hline \multirow{4}{*}{ P3 } & & $\mathrm{Cr}$ & 10,23 & 20,47 & 40,95 & 81,9 \\
\hline & 10 & 99 & - & - & - & 84 \\
\hline & 115 & 99 & - & - & - & 46 \\
\hline & \multicolumn{6}{|c|}{ Resultado: $\gamma=0,8261$} \\
\hline \multirow{4}{*}{ P4 } & & $\mathrm{Cr}$ & 10,23 & 20,47 & 40,95 & 81,9 \\
\hline & 10 & 93 & 108 & 105 & 94 & 90 \\
\hline & 115 & 95 & 95 & 77 & 42 & 7 \\
\hline & \multicolumn{6}{|c|}{ Resultado: CE (I) 50\%= 28,98 $(17,68-47,50)$} \\
\hline \multirow{4}{*}{$\begin{array}{c}\text { Fenol } \\
\text { (referência) }\end{array}$} & & $\mathrm{Cr}$ & 10,23 & 20,47 & 40,95 & 81,9 \\
\hline & 10 & 97 & 95 & 95 & 93 & 92 \\
\hline & 115 & 87 & 77 & 62 & 45 & 28 \\
\hline & \multicolumn{6}{|c|}{ Resultado: CE (I) $50 \%=47,39(40,11-56,01)$} \\
\hline
\end{tabular}




\section{ANEXO II}

Tabela 20, Elementos analisados por meio de Ativação Neutrônica - Coleta 2.

\begin{tabular}{|c|c|c|c|c|c|c|c|c|c|}
\hline Coleta 2 & As & $\mathrm{Ba}$ & $\mathrm{Br}$ & $\mathrm{Ca}(\%)$ & $\mathrm{Ce}$ & Co & $\mathrm{Cr}$ & Cs & $\mathrm{Eu}$ \\
\hline P2 & $\mathrm{n}, \mathrm{d}$ & $285,7 \pm 19,02$ & $1,40 \pm 0,17$ & $0,40 \pm 0,03$ & $221,5 \pm 9,46$ & $0,82 \pm 0,02$ & $14,15 \pm 0,63$ & $2,58 \pm 0,17$ & $0,63 \pm 0,04$ \\
\hline P4 & $19,70 \pm 0,69$ & $469,0 \pm 43,48$ & $17,86 \pm 0,51$ & $0,93 \pm 0,06$ & $114,8 \pm 3,19$ & $13,16 \pm 0,40$ & $122,1 \pm 3,52$ & $4,21 \pm 0,17$ & $0,96 \pm 0,03$ \\
\hline Coleta 2 & $\mathrm{Fe}(\%)$ & $\mathrm{Hf}$ & $\mathrm{K}(\%)$ & La & Lu & $\mathrm{Na}$ & Nd & $\mathbf{R b}$ & $\mathrm{Sb}$ \\
\hline Po & $2,77 \pm 0,01$ & $19,81 \pm 0,30$ & $\mathrm{n}, \mathrm{d}$ & $21,71 \pm 0,59$ & $0,22 \pm 0,02$ & $\mathrm{n}, \mathrm{d}$ & $6,76 \pm 1,43$ & $13,11 \pm 0,74$ & $\mathrm{n}, \mathrm{d}$ \\
\hline P3 & $4,80 \pm 0,03$ & $11,55 \pm 0,26$ & $\mathrm{n}, \mathrm{d}$ & $64,22 \pm 0,30$ & $0,46 \pm 0,04$ & $1743,5 \pm 17,89$ & $19,36 \pm 2,68$ & $60,11 \pm 4,31$ & $1,00 \pm 0,06$ \\
\hline P4 & $4,43 \pm 0,02$ & $21,09 \pm 0,37$ & $\mathrm{n}, \mathrm{d}$ & $34,70 \pm 0,83$ & $0,72 \pm 0,05$ & $2188,5 \pm 27,49$ & $23,28 \pm 3,29$ & $49,50 \pm 3,11$ & $4,76 \pm 0,29$ \\
\hline Coleta 2 & Sc & Sm & $\mathrm{Ta}$ & Tb & Th & U & $\mathrm{Yb}$ & $\mathrm{Zn}$ & \\
\hline Po & $5,04 \pm 0,10$ & $3,12 \pm 0,04$ & $2,04 \pm 0,12$ & $0,35 \pm 0,04$ & $20,20 \pm 0,73$ & $2,78 \pm 0,50$ & $1,80 \pm 0,14$ & $32,83 \pm 1,31$ & \\
\hline P1 & $5,16 \pm 0,10$ & $7,53 \pm 0,10$ & $2,05 \pm 0,15$ & $0,78 \pm 0,07$ & $23,13 \pm 0,64$ & $6,51 \pm 0,29$ & $2,36 \pm 0,10$ & $55,03 \pm 2,05$ & \\
\hline
\end{tabular}


Tabela 21, Elementos analisados por meio de Ativação Neutrônica - Coleta 3.

\begin{tabular}{cccccccccc}
\hline Coleta 3 & As & $\mathbf{B a}$ & $\mathbf{B r}$ & $\mathbf{C a}(\%)$ & $\mathbf{C e}$ & Co & Cr & Cs \\
\hline P0 & $10,02 \pm 0,19$ & $178,21 \pm 28,48$ & $9,13 \pm 0,11$ & $1,42 \pm 0,02$ & $56,40 \pm 1,58$ & $2,65 \pm 0,05$ & $38,65 \pm 1,48$ & $1,25 \pm 0,06$ & $0,63 \pm 0,02$ \\
P1 & $2,78 \pm 0,11$ & $470,16 \pm 54,75$ & $3,55 \pm 0,08$ & $0,94 \pm 0,02$ & $99,75 \pm 2,23$ & $3,97 \pm 0,07$ & $21,44 \pm 0,84$ & $3,89 \pm 0,14$ & $0,80 \pm 0,02$ \\
P2 & $3,56 \pm 0,16$ & $653,12 \pm 43,97$ & $4,19 \pm 0,10$ & $1,19 \pm 0,03$ & $171,11 \pm 5,11$ & $4,98 \pm 0,11$ & $31,39 \pm 1,14$ & $4,45 \pm 0,17$ & $1,15 \pm 0,03$ \\
P3 & $8,05 \pm 0,28$ & $447,38 \pm 32,27$ & $4,88 \pm 0,11$ & $1,06 \pm 0,02$ & $81,41 \pm 2,13$ & $8,95 \pm 0,18$ & $142,13 \pm 2,40$ & $4,27 \pm 0,17$ & $0,81 \pm 0,03$ \\
P4 & $34,23 \pm 0,89$ & $560,15 \pm 90,03$ & $7,03 \pm 0,22$ & $1,67 \pm 0,04$ & $121,87 \pm 3,11$ & $10,44 \pm 0,22$ & $110,34 \pm 5,49$ & $5,12 \pm 0,33$ & $1,12 \pm 0,04$ \\
\hline Coleta 3 & Fe(\%) & Hf & K(\%) & La & Lu & Na & Nd & Rb & Sb \\
\hline P0 & $3,85 \pm 0,02$ & $33,98 \pm 0,59$ & $0,25 \pm 0,02$ & $30,59 \pm 0,12$ & $0,36 \pm 0,02$ & $349,92 \pm 3,21$ & $7,85 \pm 1,89$ & $17,13 \pm 1,26$ & $0,46 \pm 0,03$ \\
P1 & $1,76 \pm 0,01$ & $20,78 \pm 0,35$ & $1,81 \pm 0,08$ & $40,47 \pm 0,19$ & $0,44 \pm 0,02$ & $2367,85 \pm 18,40$ & $28,95 \pm 2,40$ & $120,27 \pm 5,56$ & $0,29 \pm 0,02$ \\
P2 & $2,14 \pm 0,01$ & $54,62 \pm 1,27$ & $2,79 \pm 0,19$ & $85,39 \pm 0,46$ & $0,79 \pm 0,03$ & $3852,66 \pm 33,19$ & $67,66 \pm 5,31$ & $144,76 \pm 6,73$ & $0,25 \pm 0,02$ \\
P3 & $2,64 \pm 0,01$ & $13,78 \pm 0,23$ & $1,06 \pm 0,14$ & $43,32 \pm 0,25$ & $0,42 \pm 0,02$ & $2040,43 \pm 19,82$ & $33,51 \pm 2,79$ & $78,80 \pm 3,99$ & $1,18 \pm 0,05$ \\
P4 & $4,82 \pm 0,03$ & $24,57 \pm 0,45$ & $1,65 \pm 0,57$ & $43,22 \pm 0,20$ & $0,85 \pm 0,11$ & $1976,84 \pm 20,82$ & $33,90 \pm 3,47$ & $66,80 \pm 6,01$ & $3,84 \pm 0,55$ \\
\hline Coleta 3 & Sc & Sm & Ta & Tb & Th & U & Yb & Zn \\
\hline P0 & $7,60 \pm 0,03$ & $4,24 \pm 0,07$ & $3,22 \pm 0,33$ & $0,47 \pm 0,05$ & $30,32 \pm 0,77$ & $6,78 \pm 0,35$ & $2,32 \pm 0,09$ & $36,45 \pm 1,27$ \\
P1 & $5,30 \pm 0,02$ & $7,17 \pm 0,15$ & $2,48 \pm 0,20$ & $0,74 \pm 0,07$ & $23,95 \pm 0,85$ & $6,82 \pm 0,34$ & $2,97 \pm 0,12$ & $38,77 \pm 1,35$ \\
P2 & $6,09 \pm 0,07$ & $12,86 \pm 0,26$ & $2,93 \pm 0,23$ & $1,36 \pm 0,16$ & $44,44 \pm 1,64$ & $9,47 \pm 0,59$ & $4,91 \pm 0,19$ & $49,67 \pm 2,90$ \\
P3 & $8,51 \pm 0,10$ & $5,76 \pm 0,08$ & $2,08 \pm 0,15$ & $0,67 \pm 0,08$ & $18,40 \pm 0,67$ & $5,09 \pm 0,21$ & $2,70 \pm 0,11$ & $285,21 \pm 14,87$ \\
P4 & $20,65 \pm 0,25$ & $7,01 \pm 0,10$ & $2,51 \pm 0,22$ & $1,76 \pm 0,29$ & $26,81 \pm 1,01$ & $8,96 \pm 0,53$ & $7,27 \pm 0,42$ & $385,50 \pm 15,39$ \\
\hline
\end{tabular}

